\title{
Historia biogeográfica de las briófitas de Chile
}

\section{Biogeographical history of bryophytes in Chile}

\section{Carolina Villagrán Moraga}

Departamento de Biología, Facultad de Ciencias, Universidad de Chile

*Carolinavillagran.moraga@gmail.com

\section{RESUMEN}

Se examinan algunos rasgos biogeográficos de las briófitas asociadas a los ecosistemas subtropicaltemplados de Chile, como diversidad, concentración de la riqueza de especies, endemismo, composición biogeográfica y disyunciones. La interpretación histórico-biogeográfica de estas características considera los grandes cambios evolutivos del grupo en tres escenarios temporales distintos, de acuerdo con las evidencias geológicas, paleobotánicas y moleculares. Para un primer momento, se examinan hepáticas talosas simples y complejas de las Clases Haplomitriopsida y Marchantiopsida-Marchantiidae representadas en Chile y pertenecientes a linajes arcaicos vinculados al poblamiento pre-Cenozoico del megacontinente Pangea. Ejemplos de distintos taxa de hepáticas talosas simples de la Clase Jungermanniopsida-Pelliidae, antocerotes de la Clase Anthocerotopsida y musgos de las Clases Bryopsida y Polytrichopsida ilustran patrones de distribución paleo-austral de briófitas de la región templada de Chile, relacionados a la fragmentación del Gonwana y expansión de las Angiospermas, durante el Cretácico/Paleógeno. Un segundo escenario Neógeno considera el levantamiento final de los Andes y desarrollo de la Diagonal Árida de Sudamérica, procesos que han jugado un rol significativo en la estructura biogeográfica de la flora de Sudamérica y de Chile. En este contexto se destacan casos de hepáticas foliosas asociadas a los bosques relictos de la costa semiárida chilena, particularmente hepáticas epifilas de las dos familias más diversas de la Clase Jungermanniopsida-Jungermannidae, Lejeuneaceae y Plagiochilaceae, adaptadas a microclimas favorecidos por neblinas costeras. En un último escenario se discute el rol relevante que han jugado las repetidas glaciaciones del Pleistoceno en la expansión del elemento sub-antártico templadofrío a lo largo de Chile central-sur, y sus efectos en la concentración de la riqueza de briófitas asociada a los ecosistemas templado-lluviosos de Chile.

Palabras clave: Diagonal Árida, glaciaciones, macrofósiles/musgos, relictos, Pangea/Gondwana.

\section{ABSTRACT}

Some biogeographical features of bryophytes associated with subtropical-temperate ecosystems in Chile are examined, including diversity, concentration of species richness, endemism, biogeographical composition and disjunctions. The historical-biogeographical interpretation of these characteristics considers the major evolutionary changes of the group in three different temporal scenarios, according to geological, paleobotanical and molecular evidences. First, simple- and complex-thalloids liverworts represented in Chile are examined, belonging to the Classes Haplomitriopsida and MarchantiopsidaMarchantiidae, archaic lineages linked to the pre-Cenozoic colonization of the Pangea mega-continent. Examples of simple-thalloids liverworts of Class Jungermanniopsida-Pelliidae, hornworts of the Class Anthocerotopsida and mosses of the Classes Bryopsida and Polytrichopsida illustrate the paleo-austral distribution patterns of bryophytes from the temperate region of Chile, related to the Gondwana breakup 
and expansion of Angiosperms during the Cretaceous/Paleogene. A second scenario, considers the final uplift of the Andes and the development of the Arid Diagonal of South America during the Neogene, processes that have played a major role in the biogeographical structure of the Chilean and South American floras. In this context, leafy liverworts associated with the relict forests of the Chilean semiarid coast stand out, particularly epiphyllous liverworts of the two most diverse families of the Class Jungermanniopsida-Jungermanniidae, Lejeuneaceae and Plagiochilaceae, adapted to microclimates favored by coastal fogs. The last scenario discusses the significant role of the Pleistocene glacial cycles in the expansion of the sub-Antarctic temperate-cold element throughout central-southern Chile, and its effects on the concentration of bryophyte richness associated with Chile's temperate-rain ecosystems.

Keywords: Arid Diagonal, glaciations, macro-fossils/mosses, relicts, Pangea/Gondwana.

\section{INTRODUCCIÓN}

Entre las plantas terrestres no vasculares, las así llamadas "briófitas" en sentido amplio revisten un particular interés biogeográfico-evolutivo, tanto por su relación con el origen y evolución de los primeros linajes de plantas terrestres, como asimismo por su larga historia geológica (c. 500-350 $\mathrm{Ma}$ ) que se remonta a los inicios de la colonización vegetal de la tierra en la era Paleozoica (Graham et al. 2004; Frahm 2001; Kenrick \& Crane 1997). Se trata de un grupo complejo que, de acuerdo a las clasificaciones más recientes integra tres grandes Divisiones o Phylum: Anthocerotophyta, los antocerotes con c. 150-220 especies; Marchantiophyta, las hepáticas con c. 6000 especies; Bryophyta, los musgos con c. 10.000 especies (Crandall-Stotler et al. 2009; Frey \& Stech 2005 a, b). Numerosos estudios morfológicos y moleculares apoyan monofiletismo de musgos y hepáticas, un grupo natural sustentado por evidencias filogenéticas recientes y para el cual se ha propuesto el nombre de 'setaphyte' (cfr. Puttick et al. 2018, Renzaglia et al. 2018). Otros investigaciones han sugerido un origen monofilético para los tres grupos de briófitas (Nishiyama et al. 2004), hipótesis avalada por algunos estudios moleculares más recientes (cfr. Puttick et al. 2018).

Los ecosistemas templado-lluviosos del sur de Sudamérica, favorecidos por un clima muy lluvioso y temperaturas relativamente moderadas por la influencia oceánica, destacan por la gran diversidad de hábitats con condiciones óptimas para el desarrollo de los distintos grupos de briófitas, especialmente aquéllas asociadas a las comunidades de bosques laurifolios y tundras magallánicas. Sobre la base de catálogos recientes, se han establecido para Chile alrededor de 880 especies de musgos (Müller 2009; He 1998), 553 taxa de hepáticas y 15 de antocerotes (Hässel de Menéndez \& Rubies 2009), un total aproximado a 1448 taxa que constituye c. del 6,6\% de la riqueza global del grupo (Tabla 1), una proporción muy alta en comparación con la contribución relativa de los restantes grupos de plantas vasculares del territorio.

Los bosques templado-lluviosos perennifolios -Valdiviano, Nordpatagónico y Subantártico-, al sur de $40^{\circ} \mathrm{S}$, concentran la diversidad de especies de briófitas chilenas. La distribución latitudinal de la riqueza a lo largo de la región mediterráneotemplada de Chile continental muestra valores máximos en

TABLA 1. Riqueza de especies de los distintos grupos de plantas terrestres de la flora nativa de Chile y su contribución relativa a la riqueza de la flora global. (datos: Hässel \& Rubies 2009; He 1998; Müller 2009; Rodríguez et al. 2018; Frey \& Stech 2005 a, b; Christenhusz \& Byng 2016). / Species richness of the different groups of land plants of the native flora of Chile and their relative contribution to the richness of the global flora (data from Hässel \& Rubies 2009; He 1998; Müller 2009; Rodríguez et al. 2018; Frey \& Stech 2005 a, b; Christenhusz \& Byng 2016).

\begin{tabular}{cccc}
\hline $\begin{array}{c}\text { Grupos de plantas terrestres } \\
\text { Reino Plantae }\end{array}$ & $\begin{array}{c}\mathbf{N}^{\circ} \text { de especies nativas } \\
\text { de Chile }\end{array}$ & $\begin{array}{c}\text { \% Flora } \\
\text { global }\end{array}$ & $\mathbf{N}^{\circ}$ de especies flora global \\
\hline Angiospermas & 4.480 & 1,5 & 295.383 \\
Gimnospermas & 15 & 1,4 & 1.079 \\
Pteridófitas y afines & 160 & 1,4 & 11.850 \\
Briófitas & 1.448 & 6,6 & 21.925 \\
\hline
\end{tabular}


las regiones de Los Ríos y de Los Lagos $\left(40^{\circ}\right.$ a $\left.44^{\circ} \mathrm{S}\right)$ y en la Región de Magallanes, al sur de $49^{\circ} \mathrm{S}$, y un descenso en la Región de los Canales ( $44^{\circ}$ a $49^{\circ} \mathrm{S}$ ) (Villagrán et al. 2005). Este patrón contrasta con las Angiospermas forestales, con mayor nivel de endemismo, y máximos de especies de árboles, arbustos y lianas del sotobosque concentrados en la interfase mediterráneo-templada $-36^{\circ}$ y $40^{\circ} \mathrm{S}$ - entre las regiones del Maule y Biobío (Fig. 1A) (Villagrán \& Armesto 2005; Villagrán \& Hinojosa 2005; Villagrán et al. 1998; Villagrán 1995). Por otra parte, un ejemplo de la distribución longitudinal de la riqueza de briófitas dentro del ámbito austral-templado del Cono Sur ha sido establecida a lo largo de una transecta Pacífico-Atlántica en la Patagonia Austral chileno-argentina, $51^{\circ}-52^{\circ} \mathrm{S}$ (Hässel de Menéndez et al. 1984; Hässel de Menéndez \& Solari 1985). Los resultados muestran notables máximos de riqueza de briófitas en el sector chileno occidental, particularmente de las hepáticas, en el dominio de las tundras magallánicas y del bosque laurifolio subantártico de coigüe de Magallanes, Nothofagus betuloides (Mirb.) Oerst., mientras que los musgos se concentran en el área de transición hacia el bosque deciduo; en contraste, se observa una ostensible disminución de ambos grupos en el dominio del bosque subantártico deciduo de lenga, Nothofagus pumilio (P. et E.) Krasser y de la estepa patagónica argentina (Fig. 1B).

Desde una perspectiva biogeográfica, es interesante subrayar la elevada proporción de taxa de briófitas con distribución restringida o endémica del sur de Sudamérica, rasgo determinado en parte por el aislamiento de los ecosistemas de bosques de la región de otras áreas forestales del continente y del planeta. Al nivel genérico, el Cono Sur de Sudamérica exhibe una serie de endemismos, en gran medida monotípicos; los géneros endémicos de hepáticas se concentran particularmente en la región de los bosques templado-lluviosos laurifolios del sur de Chile, mientras que los de musgos se distribuyen más ampliamente a lo largo de Chile central-sur, en todo el ámbito de los bosques subtropicales y templados. (Tabla 2, Fig. 2). Al nivel específico, un ejemplo de los patrones de distribución global que exhiben las especies de hepáticas y antocerotes registradas para la Isla Grande de Chiloé $\left(41^{\circ} 47^{\prime}-43^{\circ} 30^{\prime} \mathrm{S}\right)$ muestra más de dos tercios de especies endémicas de los territorios chileno-argentinos del sur de Sudamérica; la mayoría de las restantes especies se distribuyen discontinuamente en regiones del Hemisferio Sur,
A

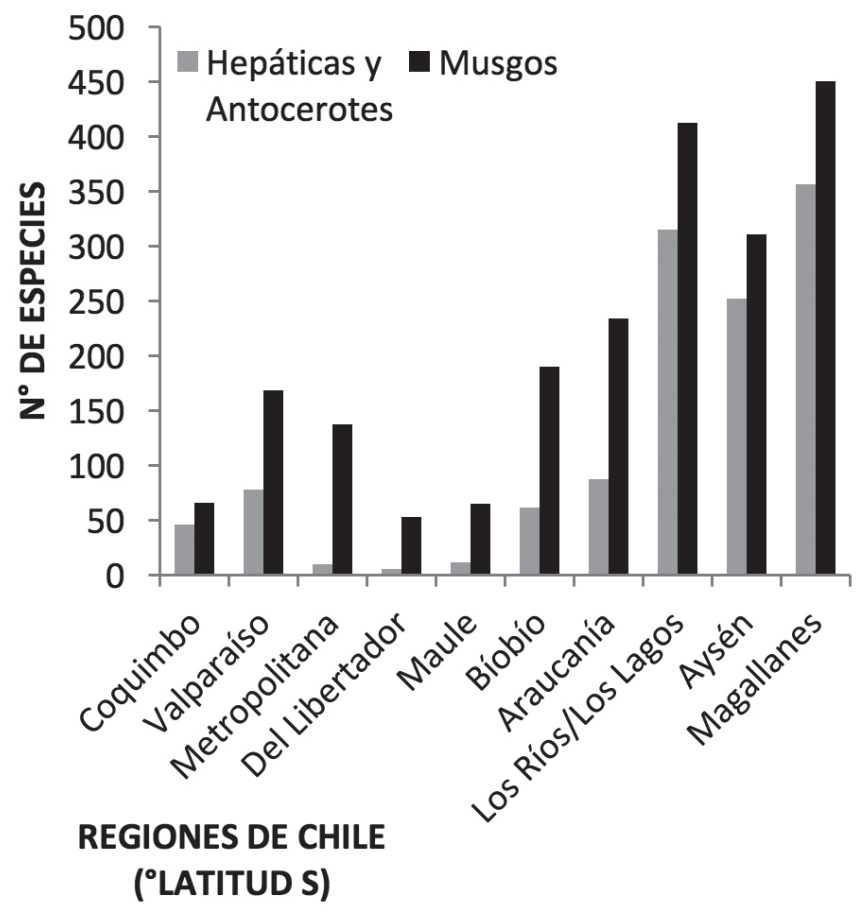

B

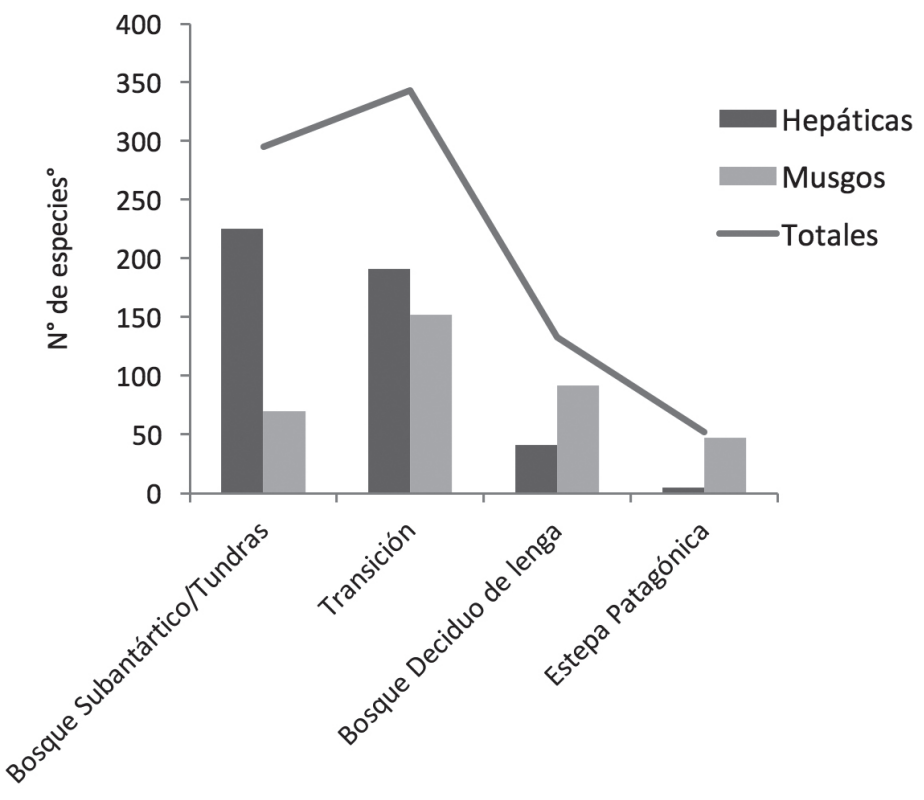

Figura 1. (a) Distribución latitudinal de la riqueza de hepáticas y de musgos a lo largo de las región mediterráneo-templada de Chile (fuente: Villagrán, Hässel de Menéndez \& Barrera 2005). (b) Distribución longitudinal de la riqueza de hepáticas y de musgos en las distintas formaciones vegetales a lo largo de un transecto este/oeste del sur de Sudamérica, $51-52^{\circ} \mathrm{S}$ (datos de Hässel de Menéndez et al. 1984). / (a) Latitudinal distribution of liverworts and moss richness along the Chilean Mediterranean-temperate region (source: Villagrán, Hässel de Menéndez \& Barrera 2005). (b) Longitudinal distribution of liverworts and moss richness in different plant formations along an east / west transect in the southern part of South America, 51-52 ${ }^{\circ} \mathrm{S}$ (data from Hässel de Menéndez et al. 1984). 
sean en territorios austral-antárticos continentales o islas circum-subantárticas, sea el Neotrópico, sea en distantes territorios de África y/o Australasia (Fig. 3a, Villagrán et al. 2005). Patrones biogeográficos similares han sido documentados para los musgos de la Isla Grande de Chiloé (Villagrán et al. 2003 y para la Región de Aysén adyacente
(Seki 1974; Larraín 2016). En contraste, un ejemplo de las hepáticas de la costa de Chile central muestra que, aunque se mantiene el predominio del elemento endémico del sur de Sudamérica, hay un incremento de los componentes con distribuciones amplias en el planeta, sean subtropicalandinas, anfitropicales o subcosmopolitas (Fig. 3b).

TABLA 2. Géneros endémicos de briófitas del Cono Sur de Sudamérica, distribución chilena y número de especies: M, Monotipic; B, Bitipic. (También en Georgias del Sur*; Juan Fernández, JF). / Endemic genera of bryophytes from the southern cone of South America, Chilean distribution and number of species: M, Monotipic; B, Bitipic. (Also in South Georgia *; Juan Fernández, J.F.).

\begin{tabular}{|c|c|c|}
\hline Géneros endémicos de hepáticas del cono sur de Sudamérica & $\mathrm{N}^{\circ} \operatorname{taxa}$ & Distribución en Chile \\
\hline Arctoscyphus Hässel & B & Los Ríos/Los Lagos a Magallanes \\
\hline Evasianthus Schust. and Eng.* & M & Chiloé. Magallanes \\
\hline Grollea Schust. & M & Magallanes \\
\hline Herzogiaria Fulf. & M & Magallanes \\
\hline Nothostrepta Schust. & B & Los Ríos/Los Lagos a Magallanes. JF \\
\hline Perdusenia Hässel & M & Chiloé. Magallanes \\
\hline Pigafettoa Massal. & M & Los Ríos/Los Lagos a Magallanes \\
\hline Pisanoa Hässel & M & Chiloé. Magallanes \\
\hline Protosyzygiella (Herzog) R.M. Schust. & M & Los Ríos/Los Lagos a Magallanes \\
\hline Syzygiella subg. Roivainenia (Perss.) Feldberg, Váňa, Hentschel et Heinrichs* & M & Araucanía a Magallanes \\
\hline Vetaforma Fulf. and Tayl.* & M & Los Ríos/Los Lagos a Magallanes \\
\hline \multicolumn{3}{|l|}{ Géneros endémicos de musgos } \\
\hline Ancistrodes Hampe & M & Maule a Aysén \\
\hline Arbusculohypopterygium Stech & M & Colchagua a Magallanes. JF \\
\hline Catagoniopsis Broth. & M & Coquimbo a Los Ríos. JF \\
\hline Chileobryon Enroth & M & Coquimbo a Los Ríos. JF \\
\hline Cladomniopsis Fleischer & M & Maule a Magallanes \\
\hline Costesia Thér. & M & Coquimbo a O'Higgins \\
\hline Cryphaeophilum M.Fleischer & M & Maule a Aysén \\
\hline Hebantia G.L.S.Merrill & M & Biobío a Los Ríos \\
\hline Larrainia W. R. Buck & M & Cabo de Hornos \\
\hline Looseria (Thér.) D.Quandt et al. & M & Biobío \\
\hline Mahua W.R.Buck & M & Los Ríos. Magallanes \\
\hline Matteria Goffinet & B & Los Ríos a Magallanes \\
\hline Neomeesia Deguchi & M & Aysén/Magallanes \\
\hline Ombronesus N.E.Bell, N.Pedersen \& A.E. Newton & M & Aysén \\
\hline Pararhacocarpus Frahm & M & Los Ríos a Magallanes \\
\hline Platyneuron (Brid.) Broth. & M & Biobío a Magallanes \\
\hline Pleurorthotrichum Broth. & M & Antofagasta a Valparaíso \\
\hline Ptychomniella (Broth.) W.R. Buck, C.J. Cox, A.J. Shaw \& Goffinet & M & Valparaíso a Magallanes. JF \\
\hline Schimperobryum Marg. & B & Valparaíso a Aysén. JF \\
\hline Skottsbergia Card. & M & Magallanes \\
\hline
\end{tabular}




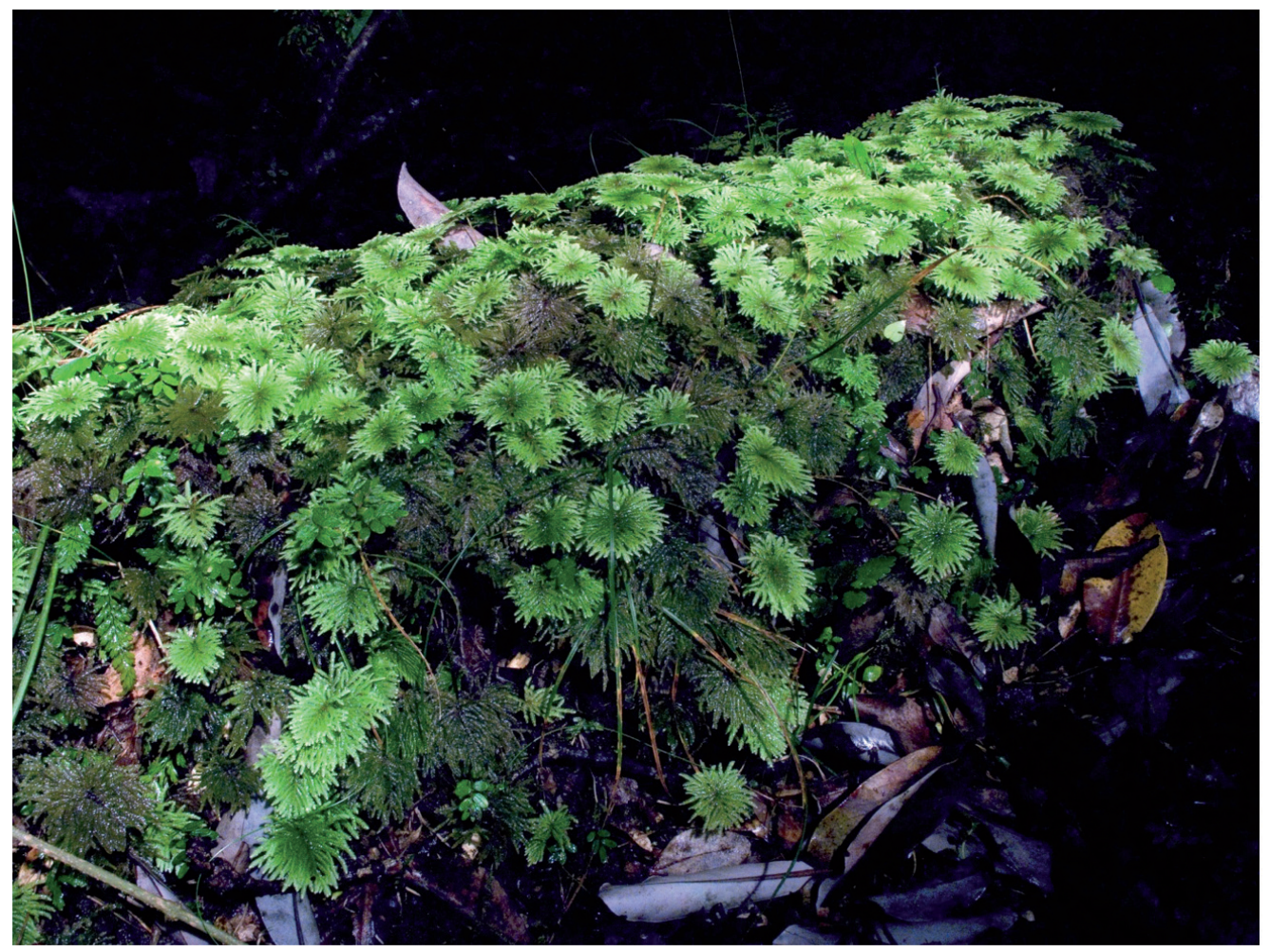

Figura 2. Arbusculohypopterygium arbuscula (Brid.) Stech, T. Pfeiffer \& W.Frey (Hypopterigiaceae), un ejemplo de un género de musgo endémico y monotípico del sur de Sudamérica. / Arbusculohypopterygium arbuscula (Brid.) Stech, T. Pfeiffer \& W. Frey (Hypopterigiaceae), an example of an endemic and monotypic genera of mosses from southern South America.

A

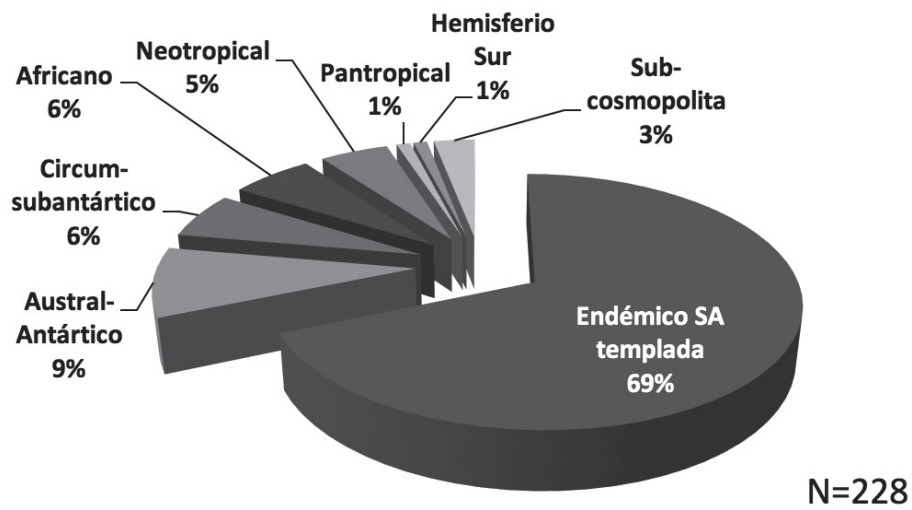

B

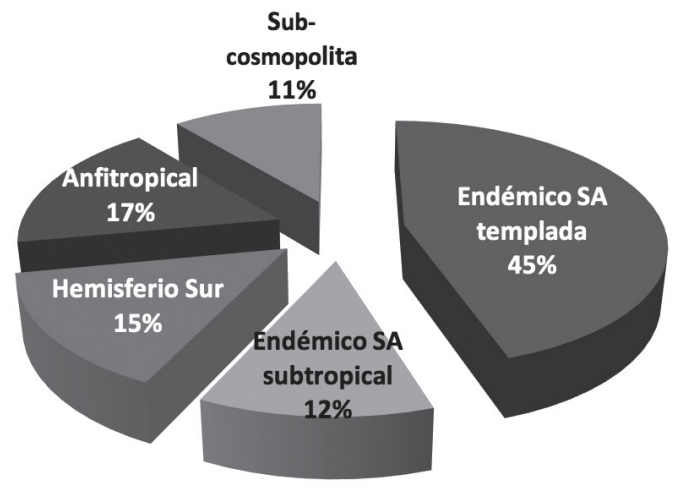

Fıgura 3. (a) Patrones de distribución de las especies de Hepáticas y Antocerotes de la Isla Grande de Chiloé, Chile, N= 228 especies (fuente: Villagrán, Hässel de Menéndez \& Barrera 2005). (b) Patrones de distribución de las especies de Hepáticas de la Región de Valparaíso, Chile, N=82 especies (datos de Hässel de Menéndez \& Villagrán 2007; Hässel de Menéndez \& Rubies 2009; Gradstein \& Cuvertino 2015; Gradstein 2016). / (a) Distribution patterns of liverworts and hornworts species of the Isla Grande de Chiloé, Chile, N = 228 species (source: Villagrán, Hässel de Menéndez \& Barrera 2005). (b) Distribution patterns of liverworts species from the Valparaíso Region, Chile, N = 82 species (data from Hässel de Menéndez \& Villagrán 2007; Hässel de Menéndez \& Rubies 2009; Gradstein \& Cuvertino 2015; Gradstein 2016). 
¿Qué procesos inciden en la notable diversidad y altos niveles de endemismo de las briófitas del Cono Sur de Sudamérica? ¿Y en la concentración de especies en el área de los bosques templado-Iluviosos siempreverdes de Chile? ¿Por qué la distribución bimodal de la riqueza dentro del dominio templado? ¿Cómo se interpretan las amplias disyunciones geográficas, sean austral-antárticas, neotropicales, anfitropicales o con otros distantes territorios del Hemisferio Sur y del planeta? Frente a estas cuestiones, en las dos primeras secciones del texto se consideran algunos rasgos de la historia biogeográfica de las briófitas chilenas, a la luz de las numerosas contribuciones sobre filogenia molecular publicadas en las dos últimas décadas, particularmente aquellas vinculadas con paleo-distribuciones intercontinentales asociadas a la historia de fragmentación de los mega-continentes Pangea y Gondwana. A continuación se examinan algunos casos de distribuciones disyuntas de especies de briófitas tanto dentro del territorio chileno como con el neotrópico, considerando un escenario Neógeno marcado por el levantamiento final de la Cordillera de los Andes y desarrollo de la Diagonal Árida (DA) de Sudamérica, procesos que han jugado un rol significativo en la evolución biogeográfica de la flora chilena moderna (cfr. Hinojosa \& Villagrán, 2005, 1997; Hinojosa 2003; Villagrán \& Hinojosa 2005, 1997; Schmithüsen 1956). Finalmente, en la última sección se consideran los relevantes efectos de las repetidas glaciaciones del Pleistoceno en la distribución moderna de los bosques chilenos y su flora briofítica asociada, con énfasis en los cambios de las lluvias y, por ende, en la posición e intensidad de la DA. Así, se resumen las evidencias procedentes del registro paleobotánico de polen, maderas y macrorestos del último ciclo glacialinterglacial del Cuaternario que documenta los prolongados períodos de expansión hacia el norte, descenso altitudinal y mayor continuidad del elemento subantártico templado-frío a lo largo de Chile central-sur durante las edades glaciales, en alternancia con su retracción y aislamiento durante los cortos períodos interglaciales. Esta dinámica ha incidido significativamente en procesos tales como la dispersión, extinción y recolonización y, por ende, en la genética de las poblaciones modernas, como lo muestran las numerosas contribuciones filogeográficas publicadas durante las dos últimas décadas, particularmente para poblaciones de Coníferas y Angiospermas chilenas (cfr. Villagrán et al. 2019; Heinrichs et al. 2009).

\section{EL REGISTRO FÓSIL Y LOS LINAJES ARCAICOS DE BRIOFITAS}

El registro fósil de briófitas se remontaal tiempo de colonización de los mega-continentes Pangea y Gondwana, antes del desmembramiento de Africa y Asia. Las primeras evidencias de plantas terrestres, tétradas (Tetraedraletes medinensis), esporas y enigmáticos macro-restos del Ordovícico/
Silúrico c. $470 \mathrm{Ma}$, han sido comparados con briófitas hoy relictuales. Sin embargo, los macrofósiles de briófitas más antiguos corresponden a una serie de formas muy parecidas a las actuales hepáticas talosas; los registros se remontan al Devónico inferior c. $409 \mathrm{Ma}$, como Grisellatheca salopensis (Clase Haplomitriopsida) ${ }^{1}$, y al Devónico superior/Carbonífero inferior, como Blasiites lobatus (Clase MarchantiopsidaBlasiidae), y Pallaviciniites devonicus y Metzgeriothallus metzgerioides (Clase Jungermanniopsida, Subclases Pelliidae y Metzgeriidae, respectivamente), además de los morfogéneros Hepaticitis langii, entre las hepáticas, y Muscites plumatus entre los musgos; desde el Pérmico al Cretácico, 290-146 Ma de años, el registro fósil documenta entre 35-25 hallazgos de restos de briófitas, los cuales aumentan a c. 200 en el Terciario, desde hace $66 \mathrm{Ma}$ de años (Brown et al. 2015; Shaw et al. 2011; Frey \& Stech 2005 a; Graham et al. 2004; Frahm 2001; Kenrick \& Crane 1997²).

De acuerdo con las filogenias moleculares, las briófitas más antiguas integran un pequeño grupo de la División Marchantiophyta, la Clase Haplomitriopsida. Esta categoría incluye dos linajes arcaicos relacionados, probablemente los antecesores de la primera divergencia del grupo en el Devónico Inferior: (i) la Subclase Treubiidae con la sola familia monofilética Treubiaceae, comprende dos géneros: el laurasiano Apotreubia con cuatro especies y el gondwánico Treubia con seis especies, este último representado en el sur de Chile por Treubia scapanioides Schust, desde Valdivia a Magallanes (Fig. 4, Hässel de Menéndez \& Rubies 2009; Hässel de Menéndez 1994). Los estudios moleculares evidencian inclusión de la especie chilena en el grupo gondwánico de especies de Tasmania, Nueva Zelanda y Australasia, la rama hermana de las especies laurasianas de Apotreubia (Frey \& Stech 2005a; Stech et al. 2002a). Los autores consideran a las Treubiaceae como uno de los linajes basales entre las hepáticas, y le atribuyen un origen Gondwánico a Treubia, mientras que Apotreubia podría haber llegado a Laurasia con el bloque de India durante el desmembramiento del megacontinente de Gondwana. (ii) Para la Subclase Haplomitriidae, con el único género Haplomitrium, se han documentado cinco

\footnotetext{
${ }^{1}$ En todo el texto, el nivel taxonómico de las categorías citadas siguen el sistema de clasificación de las hepáticas propuesto por Crandall-Stotler et al. 2009).

${ }^{2} \mathrm{~A}$ sugerencia de un revisor del texto, se recomienda la siguiente literatura adicional que trata sobre el registro fósil de briófitas: Jovet-Ast, S. 1967. Bryophyta. In: Boureau, E. (Ed.), Traité de paléobotanique. Tomo II. Bryophyta, Psilophyta, Lycophyta. Masson et Cie, Paris France, pp. 17-186. Oostendorp, C., 1987. The bryophytes of the Palaeozoic and the Mesozoic. Bryophytorum Bibliotheca 34, 1e112. Taylor, T.N., Taylor, E.L. \& Krings, M., 2009. Paleobotany. The Biology and Evolution of Fossil Plants. Academic Press/Elsevier, Amsterdam, Netherlands, pp. 1230.
} 
especies: una en el Hemisferio Norte, $H$. hookeri (Lyell ex Smith) Nees, dos en Nueva Zelanda, H. blumii (Nees) Schust. y H. mnioides (Lindberg) Schuster; y una del sur de Sudamérica, primeramente descrita como compartida con $\mathrm{H}$. gibbsiae (Steph.) Schust. de Nueva Zelada (Hässel de Menéndez 1970 Fig. 4) y recientemente consignada como $H$. chilensis Schuster, endémica y distribuida de Magallanes a Chiloé continental e insular (Hässel de Menéndez \& Rubies 2009; Cuvertino et al.
2012). Los análisis moleculares evidencian monofiletismo de Haplomitrium, y documentan una relación más estrecha entre las especies australes y mayor divergencia de la especie boreal (Stech \& Frey 2004). Estudios moleculares recientes sustentan fuertemente el reconocimiento de la Clase Haplomitriopsida y su posición como grupo hermano de las restantes clases de hepáticas (Villareal et al. 2016; Crandall-Stotler et al. 2009).

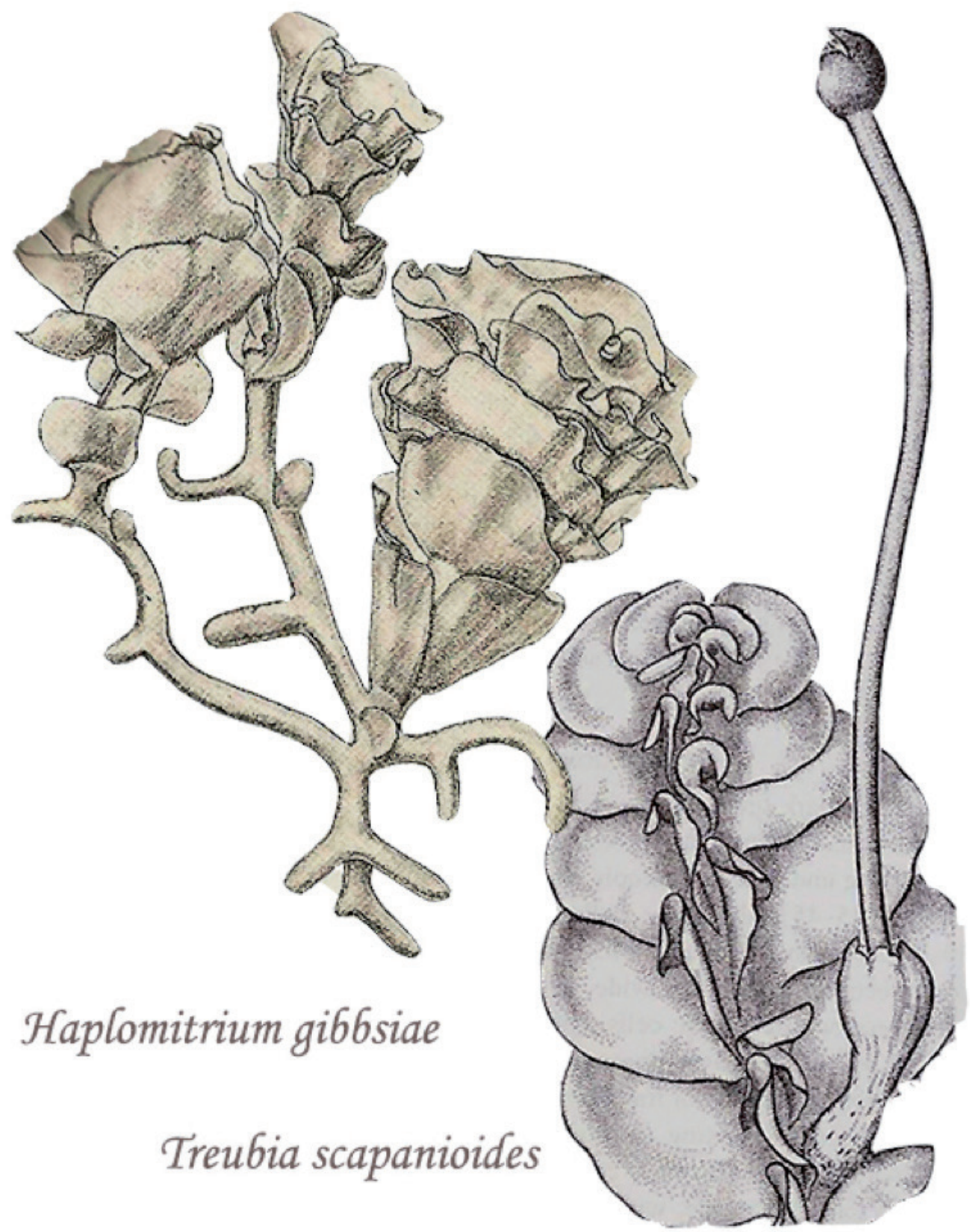

Fıgura 4. Clase Haplomitriopsida. Planta femenina de Haplomitrium gibbsiae (Steph.) Schust. (re-dibujado de Hässel de Menéndez 1970); planta femenina con esporofito de Treubia scapanioides Schust. (redibujado de Hässel de Menéndez 1994). / Class Haplomitriopsida. Female plant of Haplomitrium gibbsiae (Steph.) Schust. (re-drawn from Hässel de Menéndez 1970); female plant with sporophyte of Treubia scapanioides Schust. (re-drawn from Hässel de Menéndez 1994). 
Otros ejemplos de temprana evolución entre los grupos de hepáticas se presentan dentro de la Clase Marchantiopsida, con 32 géneros y c. 350 especies, con fósiles conocidos desde el Devónico superior al Permo-Triásico y Eoceno, y relaciones arcaicas evidenciadas ya por los primeros estudios moleculares del orden más diverso de la clase, las Marchantiales (Wheeler 2000). Sobre la base del registro fósil, las filogenias moleculares recientes señalan una edad de $295 \mathrm{Ma}$, correspondiente al Pérmico, para la diferenciación de la pequeña Subclase Blasiidae, con dos géneros, de todas las restantes Marchantiopsida incluidas en la Subclase Marchantiidae (Flores et al. 2018; Villareal et al. 2016). La primera divergencia al interior de las Marchantiidae, fechada en 262,9 Ma, señala al Orden Neohodgsoniales, con la única especie Neohodgsonia mirabilis (Perss.) Perss. de Nueva Zelanda, como el grupo hermano de todos los restantes linajes. Dentro de los restantes órdenes anidados, las ramas basales corresponden al Orden Sphaerocarpales, con las familias Riellaceae, con un único género Riella, y Sphaerocarpaceae, que incluye los géneros Geothallus y Spaherocarpus; Los restantes órdenes y familias de Marchantiidae contienen las grandes formas talosas complejas, la mayoría terrícolas y prostradas, que originaran el nombre de "hepáticas" para la división. La divergencia de las dos ramas principales de Marchantiidae con talos complejos se remonta al TriásicoJurásico, los Órdenes Lunulariales y Marchantiales con edades de divergencia de 228 Ma y 196,2 Ma, respectivamente (Villareal et al. 2016).

Así, las evidencias moleculares documentan la temprana divergencia de las hepáticas talosas complejas del diverso Orden Marchantiales, adaptadas a las condiciones más áridas del Triásico. La diversificación de la mayoría de los géneros de las alrededor de 15 familias que comprenden las Marchantiales se produce en el Cretácico y ocurrió en áreas abiertas, antes de la expansión de los bosques lluviosos tropicales con dosel cerrado dominados por Angiospermas. Las edades de divergencia de las familias más importantes del órden van desde 123,5 Ma, Marchantiaceae; 115,9 Ma, Ricciaceae; 111,3 Ma, Aytoniaceae; Cyathodiaceae, 99,04 Ma, todas anteriores al límite Cretácico/Terciario fechado en $66 \mathrm{Ma}$. Los análisis filogenéticos combinados de caracteres morfológicos y moleculares de las Marchantiopsida-Marchantiidae (Villareal et al. 2016; Flores et al. 2018) muestran que los tiempos de divergencia de los géneros con talos complejos pueden vincularse a una tendencia evolutiva hacia la complejidad de rasgos funcionales xeromorfos, adaptaciones que reflejarían las condiciones continentales y estacionalmente secas del elemento florístico que poblara los arcaicos megacontinentes Pangea y Gondwana, antes de la separación de África y Sudamérica en el Cretácico Inferior. A los primeros rasgos xerofíticos desplegados en el gametofito, como la elevación de los órganos sexuales en ramas complejas, sigue el desarrollo de cámaras aeríferas compartamentalizadas, poros epidérmicos especializados para el intercambio gaseoso y funcionamiento de células muertas para la conducción del agua en las ramas erectas. Se ha aceptado el concepto "síndrome de vida xerotaloide" (xerothalloides life syndrome, Frey \& Kürschner 1998) para referirse a este conjunto de estructuras morfológicas y estrategias de historia de vida que presentan diversas hepáticas talosas, especialmente dentro del Orden Marchantiales. Por ejemplo, los talos xeromorfos macizos con tendencia a la suculencia de Asterella, Plagiochasma, Riccia y Targionia, se consideran adaptaciones de resistencia a la sequía. En especies de Asterella y Targionia, la gruesa epidermis superior protege de la excesiva insolación y desecación a las cámaras aeríferas y tejidos acuíferos internos; rebordes cuticulares hidrofóbicos en torno a los poros epidérmicos para el intercambio gaseoso evitan la entrada de agua y el anegamiento de las cámaras aeríferas. En algunas especies de Riccia los talos tienen forma semiesférica y están protegidos de la insolación por células epidérmicas hialinas. Caracteres ancestrales, como ausencia de poros aeríferos, cámaras aeríferas vestigiales en el talo y carencia de estructuras asexuales especializadas, se han documentado en el género monotípico Dumortiera, de la Familia monogenérica Dumorteriaceae, una de las ramas basales del Orden Marchantiales (Forrest et al. 2011). Por otra parte, y en forma paralela a la tendencia hacia la complejidad de los rasgos estructurales del gametofito, se han evidenciado pérdidas de caracteres especializados en varias líneas derivadas de Marchantiales, por ejemplo, talos sin cámaras aeríferas compartamentalizadas y poros epidérmicos, ni ramas especializadas portadoras de los gametangios, como en el género Monoclea de la familia monogenérica Monocleaceae (Villareal et al. 2016).

En lo concerniente a la historia de vida, en la mayoría de las Marchantiopsida-Marchantiidae es característica la existencia efímera de los talos y reproducción sexual muy rápida durante la breve estación favorable, con persistencia solamente de las esporas durante la época de máxima aridez, una estrategia árido-pasiva equivalentes a la de las hierbas anuales. Sin embargo se han documentado algunos rasgos xerotolerantes, como en Plagiochasma rupestre L., cuyos talos sobreviven enrollados durante la temporada de sequía ("trockenschlaf"); las cápsulas de las especies de Targionia se rodean de un invólucro duro, ubicado en la zona distal cerca de la cara ventral del talo, y esta estructura persiste cuando la planta madre se seca. Dado el gran tamaño de las esporas de las Marchantiales, con diámetros promedios entre 40 y 90 $\mu \mathrm{m}$, las estrategias de historia de vida muchas veces están asociadas a la producción de un banco de esporas cercano a la planta madre. Un rasgo característico de la mayoría de los 
géneros es la presencia de ramas complejas y elevadas del gametofito, los gametangióforos, estructuras especializadas que portan los gametangios y esporofitos, posibilitando así la dispersión de las esporas a una cierta distancia, dependiendo del largo de la rama. También los movimientos en torsión de bandas higroscópicas espiraladas dentro del esporogonio -eláteres- contribuyen a la dispersión de las esporas. Algunas especies de Riccia forman cápsulas y esporas endógenas las cuales se liberan cuando se desintegra la planta madre. Ciertas especies de hepáticas dioicas, como Sphaerocarpus, y algunas especies de Riccia liberan sus esporas al estado de tétradas, con dos células femeninas y dos masculinas, compensando así la inconveniencia de la separación de los sexos.

\section{DISYUNCIONES INTERCONTINENTALES AMPLIAS DE MARCHANTIOPSIDA} CHILENAS

Gran parte de los componentes subtropicales, anfitropicales y subcosmopolitas de la estructura biogeográfica de las hepáticas de Chile central (Fig. 3b) pertenecen a las Marchanptiopsida-Marchantiidae, particularmente al Orden Marchantiales. Es interesante subrayar la destacada representatividad de la mayoría de los órdenes, familias y géneros de Marchanptiopsida-Marchantiidae en las regiones mediterráneas y áridas de Chile, por su relación con los arcaicos linajes de la clase que poblaron los mega-continentes Pangea y Gondwana. El conjunto de hepáticas talosas complejas del territorio se concentra particularmente en quebradas húmedas del litoral y Cordillera de la Costa de la región de Valparaíso, y alrededores de Santiago, en la región Metropolitana. En la Fig. 5 se muestran ejemplos de los géneros de Marchantiopsida-Marchantiidae representados en Chile y en la Tabla 3 se listan e indican los autores de las especies, de acuerdo a variadas fuentes (Gradstein \& Cuvertino 2015; Ardiles \& Fariña 2014; Hässel de Menéndez \& Rubies 2009; Hässel de Menéndez \& Villagrán 2007a; Villagrán et al. 2005; Mahú 1994, 1981, 1979³). En el Orden Sphaerocarpales, la familia Riellacese con el único género Riella, está representada por c. de 20 especies semi-acuáticas de amplia distribución, y en Sudamérica por cinco especies procedentes de cuerpos de agua salobres de las provincias de Buenos Aires, La Pampa, Río Negro y Neuquén, en Argentina: $R$. undulata Hässel, $R$. pampae Hässel, R. choconensis Hässel, R. americana Howe y R. gamundiae Hässel (Hässel de Menéndez 1987). La familia Sphaerocarpaceae está representado en Chile por dos especies de Sphaerocarpus registradas en el litoral, Cordillera de la Costa y valles interiores de Chile central: Sphaerocarpus stipitatus y S. texanus (Fig. 5.1), dentro de la misma área en

${ }^{3}$ Comunicación: Mahu M. 1979. Las Briófitas de la Quebrada Guallilemu, El Quisco, Chile. Abstract Segunda Reunión Nacional de Botánica, Santiago, Chile, p. 52. que los coleccionara tempranamente Bertero, en 1829 (cfr. Proskauer 1954). En el Orden Lunulariales, la única especie de la categoría, Lunularia cruciata (Fig. 5.2), está representada en Chile por dos subespecies, cruciata y thaxteri. Dentro del diverso Orden Marchantiales, con 15 familias, 27 géneros y c. 340 especies de amplia distribución, se encuentran representadas en Chile 8 familias y 13 géneros, la mayoría con una especie aislada en nuestro territorio (Fig. 5.3-8). En la Tabla 3 se indica el elemento biogeográfico al cual pertenecen las especies de Marchantiopsida chilenas, distribución en Chile continental y disyunciones que exhiben dentro del territorio nacional, sea con las islas de Juan Fernández o Pascua, sea con los Andes áridos del extremo norte de Chile.

Las disyunciones anfitropicales entre las floras xerofíticas de Angiospermas de Norte- y Sudamérica constituyen un fenómeno que ha sido enfatizado por décadas en la literatura, particularmente para la flora de desiertos. La mayoría de las Marchantiopsida talosas complejas presentes en Chile central exhiben este patrón biogeográfico anfitropical: ausencia en los bosques tropicales húmedos con dosel cerrado y distribución preferente en las zonas mediterráneas y subtropicales áridas de ambos hemisferios, por ejemplo, las especies de Sphaerocarpos, Corsinia, Cryptomitrium, Clevea, Dumortiera y algunas especies de Riccia y Targionia (Tabla 3). En el contexto biogeográfico de Sudamérica, merecen destacarse también las discontinuidades de los rangos de hepáticas talosas entre la costa mediterránea de Chile central con las regiones tropical-subtropicales áridas del Altiplano chileno y países limítrofes, por ejemplo: Riccia squamata, Asterella chilensis, Sauteria chilensis, Targionia stellaris; y/o compartidas con los Andes tropicales, como Marchantia berteroana var. polylepida, M. foliacea y Monoclea gottschei (Tabla 3). Entre las especies con distribuciones extensas en el globo hasta subcosmopolitas cabe mencionar: Plagiochasma rupestre, Reboulia hemisphaerica, Marchantia polymorpha, $M$. chenopoda, Ricciocarpus natans y Riccia sorocarpa (Tabla 3). Tanto las distribuciones amplias, como asimismo la presencia de varias especies en el Archipiélago de Juan Fernández e Isla de Pascua, sugieren un rol importante de eventos de dispersión a larga distancia, transporte probablemente favorecido por la vigorosa circulación de los vientos del Oeste (westerlies), como lo sugieren varios autores para distintos escenarios del Hemisferio Sur (e.g. Heinrichs et al. 2009; McGlone 2005; Muñoz et al. 2004). Sin embargo, las posibilidades de establecimiento exitoso no ocurren en cualquier lugar ni en cualquier escenario temporal y, en el caso de Sudamérica, probablemente han sido favorecidas por la expansión de formaciones áridas en gran parte del centro-sur de Argentina, costa Pacífica y Cordillera Occidental del continente, cambios asociados a la serie de acontecimientos geo-climáticos que marcaron el Neógeno de 
Sudamérica y que serán tratados en las secciones siguientes. En este contexto, es pertinente mencionar que, pese a la antigüedad de los linajes de hepáticas talosas complejas de la Clase Marchantiopsida y origen Cretácico/Paleógeno de los géneros, las edades de divergencia de algunas especies hoy subcosmopolitas son muy recientes, como Marchantia polymorpha y sus subespecies, las cuales diversifican en el Mioceno, entre 12 y $5 \mathrm{Ma}$ (Villareal et al. 2016).

TABLA 3. Hepáticas talosas complejas de la Clase Marchantiopsida-Subclase Marchantiidae representadas en la región mediterránea de Chile Central. Número de especies del género en Chile y global (Ch/G). Elementos Biogeográficos (EB): A. Anfitropical; SS, Sudamérica Subtropical; AT, Andes tropicales; STT, Sudamérica tropical-templada; AA, Austral-antártica; HS, Hemisferio Sur; Sc, Subcosmopolita. Distribución en Chile Continental e Insular: JF, islas de Juan Fernández; IP, Isla de Pascua. / Complex thallose liverworts of the Class Marchantiopsida-Subclass Marchantiidae represented in the Mediterranean region of central Chile. Number of species of the genus in Chile and globally (Ch / G). Biogeographic Elements (EB): A. Amphitropical; SS, Subtropical South America; AT, Tropical Andes; STT, tropical-temperate South America; AA, Austral-Antarctic; HS, Southern Hemisphere; Sc, Subcosmopolitan. Distribution in continental and insular Chile: JF, Juan Fernández Islands; IP, Easter Island.

\begin{tabular}{|c|c|c|c|c|}
\hline Orden/familia & Especies y subespecies & $\begin{array}{l}\mathrm{N}^{\circ} \mathrm{spp} \\
\mathrm{Ch} / \mathrm{G}\end{array}$ & $\mathrm{Eb}$ & Distribución en Chile \\
\hline $\begin{array}{l}\text { Sphaerocarpales/ } \\
\text { Spaherocarpaceae }\end{array}$ & $\begin{array}{l}\text { Sphaerocarpus stipitatus Bisch. ex Lindenb. } \\
\text { Sphaerocarpus texanus Austin }\end{array}$ & $2 / 7$ & $\begin{array}{l}A \\
A\end{array}$ & $\begin{array}{l}\text { R. Valparaíso. Elqui, Valdivia } \\
\text { R. Valparaíso. Valdivia }\end{array}$ \\
\hline Lunulariales/Lunulariaceae & $\begin{array}{l}\text { Lunularia cruciata (L.) Dumort. } \\
\text { L. cruciata spp. thaxteri (Evanset Herz.) Schust. }\end{array}$ & $1 / 1$ & $\begin{array}{l}\text { A } \\
\text { SS }\end{array}$ & $\begin{array}{l}\text { R. Valparaíso, Elqui. Concepción- } \\
\text { Chiloé. JF } \\
\text { R. Valparaíso. Concepción. } \\
\text { Llanquihue. JF }\end{array}$ \\
\hline Marchantiales/Corsiniaceae & Corsinia coriandrina (Spreng.) Lind. & $1-2 / 1$ & A & R. Valparaíso \\
\hline \multirow[t]{4}{*}{ Marchantiales/Aytoniaceae } & Cryptomitrium tenerum (Hook.) Aust. & $1 / 3$ & A & R. Valparaíso. Aysén \\
\hline & Asterella chilensis (Nees \& Montag) Evans & $1 / 46$ & SS & R. Valparaíso. Santiago. Malleco \\
\hline & Plagiochasma rupestre (Forst.) Steph. & $1 / 16$ & $\mathrm{~S}$ & $\begin{array}{l}\text { R. Valparaíso. Santiago-Valdivia. } \\
\text { Andes Parinacota. JF }\end{array}$ \\
\hline & Reboulia hemisphaerica (L.) Raddi & $1 / 1$ & Sc & R. Valparaíso \\
\hline \multirow[t]{2}{*}{ Marchantiales/Cleveaceae } & Clevea spathysii (Lindenb.) Müll. Frib. & $1 / 3$ & A & R. Valparaíso. Chiloé. Magallanes. JF \\
\hline & Sauteria chilensis (Lindenb.ex Mont.) Grolle & $1 / 2$ & SS & R. Valparaíso. Cachapoal-Valdivia \\
\hline \multirow[t]{2}{*}{ Marchantiales/Targioniaceae } & Targionia hypophylla L. & $2 / 3$ & $A$ & $\begin{array}{l}\text { R. Valparaíso. Metropolitana. } \\
\text { Valdivia. Andes Parinacota }\end{array}$ \\
\hline & Targionia stellaris (K. Müll.) Hässel & & AT & Altiplano Chile \\
\hline \multirow[t]{4}{*}{$\begin{array}{l}\text { Marchantiales/ } \\
\text { Marchantiaceae }\end{array}$} & $\begin{array}{l}\text { Marchantia berteroana Lehm et Ldbg. } \\
\text { Marchantia berteroana var. polylepida Herz. }\end{array}$ & & $\begin{array}{l}\text { HS } \\
\text { STT }\end{array}$ & $\begin{array}{l}\text { R. Valparaíso. Concepción- } \\
\text { Magallanes. JF, IP } \\
\text { Santiago-Cachapoal.Magallanes. JF }\end{array}$ \\
\hline & Marchantia polymorpha L. & $4-5 / 36$ & Sc & $\begin{array}{l}\text { R. Valparaíso. Santiago-Magallanes. } \\
\text { Andes Parinacota. JF }\end{array}$ \\
\hline & Marchantia foliacea Mitt. & & AA & Valdivia a Magallanes. JF \\
\hline & Marchantia chenopoda L. & & Sc & R. Valparaíso. Chiloé \\
\hline \multirow[t]{6}{*}{ Marchantiales/Ricciaceae } & Ricciocarpus natans (L.) Corda & $1 / 1$ & Sc & R. Valparaíso \\
\hline & Riccia ciliata subsp. canescens (Steph.) Schuster & & A & R. Valparaíso. Cachapoal \\
\hline & Riccia crystallina L. & & A & R. Valparaíso. Cachapoal. Valdivia \\
\hline & Riccia nigrella DC. & $5 / 154$ & $A$ & R. Valparaíso. Santiago \\
\hline & Riccia sorocarpa Bischoff & & Sc & R. Valparaíso \\
\hline & Riccia squamata Nees & & SS & R. Valparaíso. Valdivia. \\
\hline Marchantiales/Monocleacee & Monoclea gottschei subsp. gottschei Lindberg & $1 / 2$ & STT & Valdivia-Aysén. JF \\
\hline $\begin{array}{l}\text { Marchantiales/ } \\
\text { Dumortieraceae }\end{array}$ & Dumortiera hirsuta (Sw.) Nees & $1 / 3$ & A & Chiloé. IP \\
\hline
\end{tabular}



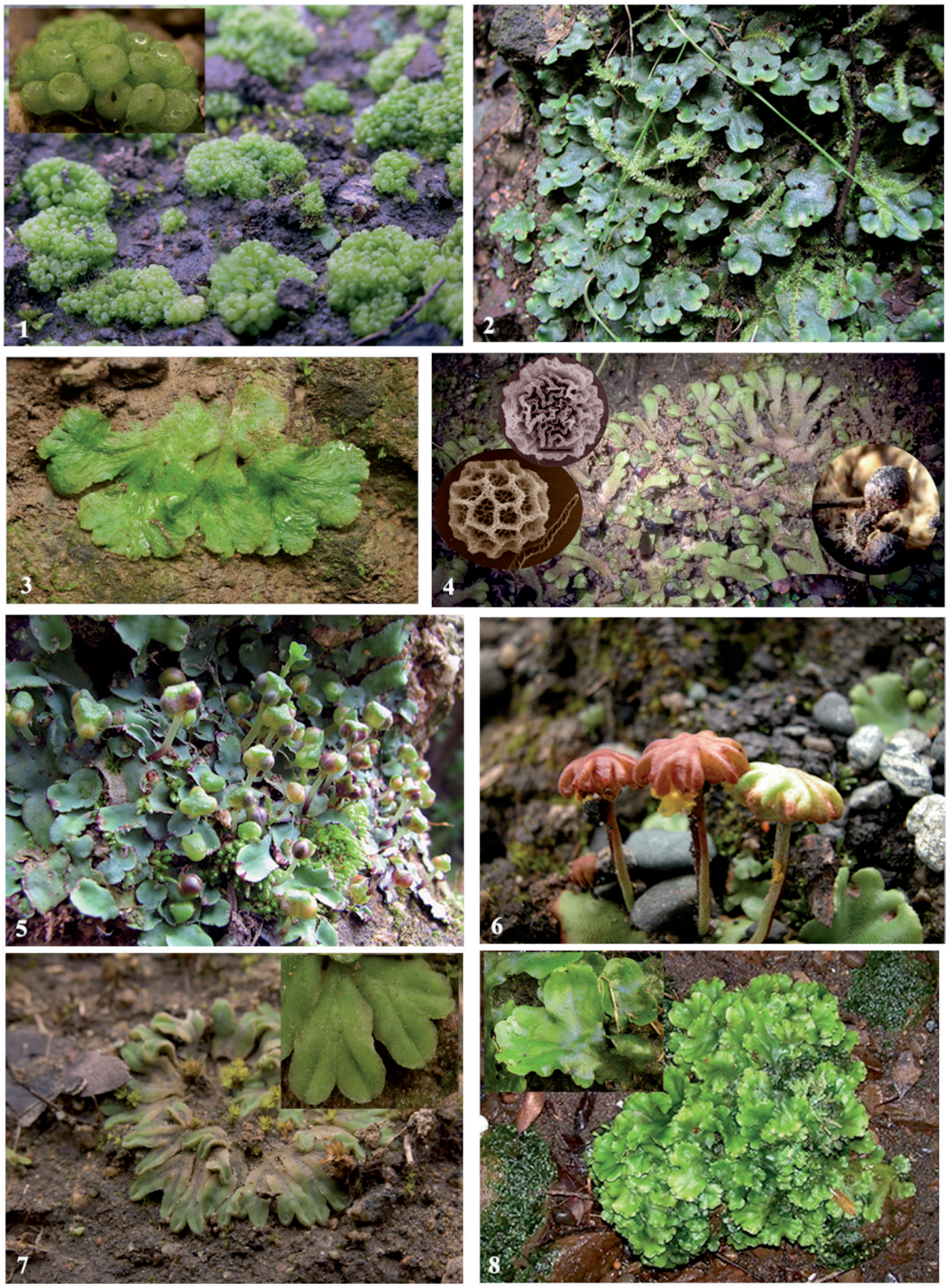

Fıgura 5. Algunos ejemplos de hepáticas talosas complejas de la Clase Marchantiopsida, Subclase Marchantiidae, Órdenes Sphaerocarpales, Lunulariales y Marchantiales representadas en la región mediterránea de Chile Central: 1) Sphaerocarpus texanus Austin; 2) Lunularia cruciata (L.) Dumort.; 3) Cryptomitrium tenerum (Hook.) Aust.; 4) Targionia hypophylla L.; 5) Plagiochasma rupestre (Forst.) Steph.; 6) Marchantia berteroana Lehm et Ldbg.; 7) Riccia sorocarpa Bischoff; 8) Monoclea gottschei Lind. subsp. gottschei Lindberg. / Some examples of complex thallose liverworts of the Class Marchantiopsida, Subclass Marchantiidae, Orders Sphaerocarpales, Lunulariales and Marchantiales represented in the Mediterranean region of central Chile: 1) Sphaerocarpus texanus Austin; 2) Lunularia cruciata (L.) Dumort.; 3) Cryptomitrium tenerum (Hook.) Aust.; 4) Targionia hypophylla L.; 5) Plagiochasma rupestre (Forst.) Steph.; 6) Marchantia berteroana Lehm et Ldbg.; 7) Riccia sorocarpa Bischoff; 8) Monoclea gottschei Lind. subsp. gottschei Lindberg. 
Además de la Clase Marchantiopsida, están representados en Chile central hepáticas talosas simples pertenecientes a linajes arcaicos de la Clase Jungermanniopsida, Subclase Pelliidae, registrados desde el Devónico superior al Pérmico: (i) La Familia Fossombroniaceae con dos géneros y c. 92 especies, categoría consideradas aislada y relicta (Frey \& Stech 2005 a). El género más prolífero es Fossombronia, concentrado principalmente en Australia y con cinco especies registradas para la región de Valparaíso, entre las cuales dos han sido descritas recientemente por las características de las esporas, F. valparaisiana Hässel y F. lophoscypha Hässel (Hässel \& Villagrán 2007 a, b) (Fig. 6. 1-4). El segundo género es Austrofossombronia, con dos especies de los Andes de Perú, Bolivia y Venezuela, una de las cuales -Austrofossombronia peruviana (Gottsche \& Hampe) R.M.Schust. ex Stotler, Crand.Stotl. \& A.V.Freire-, ha sido recientemente registrada en bofedales del Altiplano de la región chilena de Tarapacá, a 4614 m s.n.m. (Gradstein et al. 2016). (ii) La Familia Pallaviciniaceae, con nueve géneros y c. 60 especies, registra tres de las cuatro especies chilenas del género Symphyogyna en el litoral de Valparaíso, S. circinata Nees \& Mont., S. rubritincta A. Evans, y S. hochstetteri Nees \& Mont. (Fig. 6, 5-7)

\section{Gondwana y disyunciones Paleo-Australes}

La composición biogeográfica de las briófitas de la región árido-mediterránea del subtrópico de Chile, con una importante proporción de elementos de distribución global amplia en el planeta, contrasta con la de la zona templada del Cono Sur del territorio, donde dominan los elementos endémicos y los de distribución preferente en el Hemisferio Sur (Fig. 3a, b). Los altos niveles de diversidad que muestran los análisis biogeográficos de las especies de briófitas del Cono Sur de América, en gran medida asociados a los ecosistemas de bosques templado-lluviosos de Chile y Argentina, así como la elevada proporción de géneros endémicos y monotípicos (Tabla 2), probablemente sean una consecuencia del prolongado aislamiento que ha afectado a la biota de este territorio durante gran parte de su historia geológica. Entre otros componentes biogeográficos de las briófitas del sur de Sudamérica destaca una serie importante de géneros y especies que exhiben disyunciones con distantes territorios continentales del Hemisferio Sur, elemento que ha sido considerado relicto de distribuciones paleo-australes en el mega-continente de Gondwana. A este respecto, el registro paleobotánico documenta la rica y diversa flora de Angiospermas de los bosques cálido-lluviosos que poblaran el sur de Sudamérica durante el Paleógeno, cuando había continuidad entre los territorios continentales del Hemisferio Sur (cfr. Hinojosa 2003, Hinojosa \& Villagrán 1997). Un ejemplo paradigmático de distribución austral-antártica de la flora chilena es Nothofagus, único miembro de la familia
Nothofagaceae, con un registro fósil que se remonta al Cretácico y con 35 especies vivientes distribuidas en los distintos territorios gondwánicos, diez representadas en Chile. La información biogeográfica disponible documenta numerosos casos similares entre las Angiospermas, como Laurelia, Eucryphia, Lomatia, Orites, Gevuina, Griselinia, Luzuriaga, entre los componentes forestales leñosos, Donatia, Phyllachne, Astelia, Tribeles, entre los cojines de tundras magallánicas (cfr. Villagrán 2018, Villagrán \& Hinojosa 1997, 2005). Patrones similares han sido descritos para líquenes, hongos y distintos grupos de animales, como Coleópteros, Anfibios, Marsupiales, entre otros.

Entre los musgos los estudios moleculares sugieren que varios de los casos de distribuciones austral-antárticas continentales tendrían un origen gondwánico. Un destacado ejemplo de distribuciones paleoaustrales se manifiesta en la familia Hypopterygiaceae, con 24 a 26 especies y 7 géneros, entre los cuales un género monotípico es endémico del sur de Sudamérica, Arbusculohypopterygium arbuscula (Brid.) Stech, T.Pfeiffer \& W.Frey, y otros dos géneros chilenos exhiben disyunciones trans-antárticas, Lopidium e Hypopterygium (Fig. 7, 1-34). Las evidencias moleculares muestran una posición basal de Arbusculohypopterygium, la rama hermana de las especies de Lopidium (Stech et al. 2002 b). Por otra parte, se observa baja divergencia molecular entre el grupo de poblaciones de Lopidium concinnum (Hook.) Wils. de Chile y Brasil con las de Nueva Zelanda, la rama hermana de las especies de África del género. También dentro de otro género de la familia, Hypopterygium, -el más diverso con 10 a 14 especies- las poblaciones de $\mathrm{H}$. didictyon Müll. Hal. de Chile y Nueva Zelanda exhiben baja divergencia genética y constituyen la rama hermana de todas las demás especies del género, distribuidas ampliamente en el Hemisferio Sur (Frey et al. 1999; Pfeiffer et al. 2000). Para estos casos de especies vicariantes con tasas bajas de evolución molecular y morfológica, y sin rasgos de dispersión a larga distancia, se ha consignado el término de esteno-evolución (Frey et al. 2010, 1999).

Entre las hepáticas, también se han postulado distribuciones paleoaustrales de origen gondwánico para algunos miembros de la Familia Pallaviciniaceae, -un grupo arcaico, con fósiles del Devónico medio y centros de diversidad en Australasia y Sudamérica-, con cinco géneros representados en Chile ${ }^{4}$. Entre ellos, tres especies de hábito dendroide del

\footnotetext{
${ }^{4}$ Pallaviciniopsida representadas en Chile: Hymenophyton pedicellatum Steph.; Symphyogyna podophylla (Thunb.) Mont. \& Nees, S. hochstetteri Nees \& Mont., S. circinata Nees \& Mont., S. rubritincta A.Evans; Pallavicinia xiphoides (Hook. f. \& Taylor) Trevis; Jensenia pisicolor (Hook. f. \& Taylor) Grolle (Hässel de Menéndez et al. 2009; Hässel de Menéndez 1961, 1962).
} 


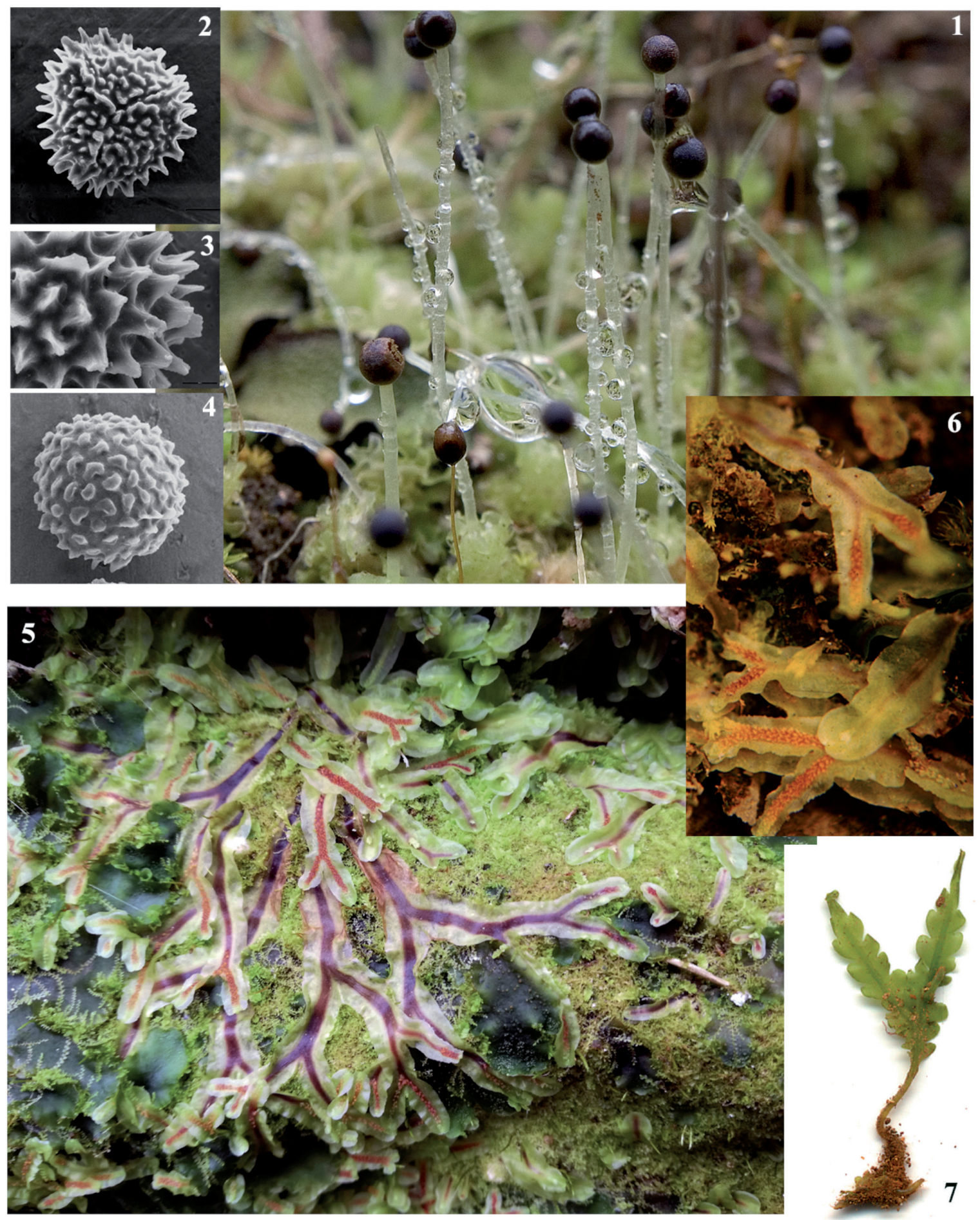

Figura 6. Algunos ejemplos de hepáticas talosas simples de las Clase Jungermanniopsida, Subclase Pelliidae, Ordenes Fossombroniales y Pallaviciniales representadas en la región mediterránea de Chile Central: 1-4) Familia Fossombroniaceae. Fossombronia valparaisiana Hässel, hábito (1), espora en visión proximal (2), detalle de la exina espinulosa (3). Fossombronia lophoscypha Hässel, espora (4). 5-7) Familia Pallaviciniaceae, Symphyogyna circinata Nees \& Mont., hábito (5) y detalle de los gametangios de la planta masculina (6). S. rubritincta A. Evans, hábito (7). / Some examples of simple thallose liverworts of the Class Jungermanniopsida, Subclass Pelliidae, Orders Fossombroniales and Pallaviciniales represented in the Mediterranean region of central Chile: 1-4) Fossombroniaceae family. Fossombronia valparaisiana Hässel, habit (1), spore in proximal view (2), detail of the spinulose exine (3). Fossombronia lophoscypha Hässel, spore (4). 5-7) Pallaviciniaceae family, Symphyogyna circinata Nees \& Mont., habit (5) and detail of the gametangia of a male plant (6). S. rubritincta A.Evans, habit (7). 
género Symphyogyna exhiben una distribución Gondwánica amplia en el Hemisferio Sur, con una especie en los Andes de Colombia en Sudamérica, S. bogotensis Stephani; una segunda, S. hymenophyllum (Hook.) Mont., de Australia, Tasmania y Nueva Zelanda; y una tercera compartida entre África y el sur de Sudamérica, S. podophylla (Thunb.) Mont. \& Nees, distribuida en Chile entre Valdivia y Magallanes (Fig. 7, 5-6). Las evidencias genéticas muestran una relación molecular más estrecha entre los especímenes de S. podophylla de Sudamérica y África; en una rama hermana se agrupan los especímenes de $S$. hymenophyllum de Australasia y $S$. bogotensis de Colombia (Schaumann et al. 2003). De acuerdo con los autores, el complejo dendroide de Symphyogyna sería un remanente de la flora gondwánica, antes de la separación de África y Sudamérica, cuando S. podophylla se extendía continuamente en ambos territorios. Después de la fragmentación final del sur del Gondwana, S. hymenophyllum habría evolucionado separadamente en Australasia, mientras que $S$. bogotensis probablemente habría diferenciado a partir de algún antecesor gondwanico y sobrevivido en refugios glaciales en las vertientes orientales andinas. Sin embargo, los autores no descartan eventos de dispersión a larga distancia para explicar la distribución del complejo, posibilidad que también ha sido sugerida por los estudios moleculares para otros géneros de Pallaviciniaceae, como Pallavicinia y Jensenia (Schaumann et al. 2004).

El tema de la dispersión a larga distancia ha adquirido mayor relevancia en la última década y ha sido planteado reiteradamente en la interpretación de los resultados de los estudios moleculares más recientes (cfr. Heinrichs et al. 2009, 2006). En contraste con el conjunto de briófitas paleoaustrales, probablemente gondwánicas, que han pemanecido largos períodos geológicos sin experimentar cambios evolutivos, también se han documentado varios casos de especies compartidas que han desarrollado subespecies, indicando que un antecesor común evolucionó en taxa separados en regiones geográficas separadas, después del desmembramiento del Gondwana (Frey et al. 2010). Por ejemplo, en la diversa familia Polytrichaceae, con c. 200 especies y 19 géneros, el género Polytrichadelphus con cerca de 10 especies mayormente andinas, incluye una especie común a Nueva Zelanda y Patagonia, P. magellanicus (Hedw.) Mitt. (Fig. 7, 7). Sobre la base de estudios moleculares se ha propuesto separar las poblaciones de ambos territorios en dos subespecies vicariantes, $P$. magellanicus subsp. magellanicus de Patagonia y $P$. magellanicus subsp. innovans (Müll. Hal.) Stech, Pfeiffer \& Frey (Stech et al. 2002c). Un patrón similar se observa en la especie chilena de Polytrichaceae de mayor tamaño, Dendroligotrichum dendroides (Brid. ex Hedw.) Broth., representada en Chile por la subsp. dendroides (Fig. 7, 8) y en Nueva Zelanda por la subsp. microdendron (C.Muell.) G.L.Sm. Casos análogos se han documentado para hepáticas Pallaviciniaceae de los géneros Pallavicinia, Jensenia e Hymenophyton, y Marchantiales, como las subespecies de Marchantia polymorpha y Monoclea gottschei, como se ha mencionado anteriormente. En la última década se ha acentuado en la literatura la discusión en torno a taxa austral-antárticos con escasa o nula variación genética intraespecífica pero con capacidad de dispersión, rasgo que posibilitarían el flujo génico y la homogenización genética de poblaciones disyuntas (Frey et al. 2010). Este podría ser el caso Lembophyllaceae entre los musgos, hasta hace poco una pequeña familia mayoritariamente epífita y con distribución paleoaustral; estudios moleculares recientes ha ampliado su circunscripción a c. de 13 géneros que amplían la distribución (Quandt et al. 2009); sin embargo, la delimitación intergenérica mantiene cierta ambigüedad debido a la variación extremadamente baja de las secuencias (Quandt et al. 2000). Dentro del nivel específico, tampoco se han encontrado secuencias divergentes entre las poblaciones de Weymouthia cochlearifolia (Schwägr.) Dixon y W. mollis (Hedw.) Broth. compartidas entre Nueva Zelanda/Australia y Chile. Dispersión a larga distancia sería una posibilidad de explicación de la escasa divergencia genética de las secuencias intraespecíficas de Weymouthia; alternativamente, se ha sugerido una tasa de evolución muy baja en el tiempo geológico, en el caso de que las poblaciones trans-antárticas se hubieran separado durante el desmembramiento del dominio austral del Gondwana, ocurrido a fines del Eoceno, 33,9 $\mathrm{Ma}$ (Quandt et al. 2001).

Entre los antocerotes se han citado también ejemplos de conexiones históricas gondwánicas. Este pequeño grupo monofilético ha sido incluido formalmente en la División Anthocerotophyta, con una diversidad de c. 14 géneros y c. 150-220 especies aún en revisión. Por varias décadas, la singular mezcla de caracteres, como la presencia de rasgos funcionales supuestamente ancestrales, como pirenoides en el cloroplasto del gametofito, o aparentemente derivados, como estomas en el esporofito, han motivado hipótesis contrapuestas acerca de las relaciones filogenéticas entre las briófitas y las plantas vasculares (Tracheophyta). Los estudios moleculares de la primera década de este siglo han intervenido en la controversia, ya sea considerando a los antocerotes como el grupo hermano de las Tracheophyta o, alternativamente, como el grupo hermano de todas las plantas terrestres (Tracheophyta) (cfr. Qiu et al. 2006; Groth-Malonek \& Knoop 2005; Nishiyama et al. 2004; Wall \& Herbeck 2003; Nickrent et al. 2000). También en los estudios moleculares más recientes persiste esta ambigüedad y tampoco han podido ser definitivamente resueltas las interpretaciones alternativas de la evolución de estos rasgos funcionales en los modelos de topologías propuestas para las ramas más 
antiguas de plantas terrestres (Puttick et al. 2018; Rensig 2018). Pese a la relevancia evolutiva del grupo, la profusa diversidad de nombres de taxa y una sistemática filogenética establecida en tiempos muy recientes han incidido fuertemente en las sucesivas clasificaciones propuestas en las dos últimas décadas. En 1986 se re-describe una especie de Anthoceros de las Antillas como Leiosporus dussii (Steph.) Hässel, única especie de un nuevo género monotípico, Leiosporoceros Hässel, y una nueva familia, Leiospocerotaceae Hässel (Hässel de Menéndez 1986); la misma autora, en un análisis cladístico de los ocho géneros de antocerotes reconocidos a esa fecha, y sobre la base de los caracteres ancestrales de esporas y pseudo eláteres de Leiosporocerus, propone el nuevo Orden Leiosporocerotales (Hässel de Menéndez 1988). Los estudios moleculares posteriores establecen una posición basal de Leiosporoceros, el grupo hermano de todos los restantes géneros de antocerotes (Duff et al. 2004; Stech et al. 2003). Sobre este fundamento se propone una nueva clasificación formal de los antocerotes en dos Clases: Leiosporocerotopsida, que incluye solamente el Orden Leiosporocerotales, y Anthocerotopsida, que integra todos los restantes antocerotes (Frey \& Stech 2005b). Más recientemente, el polifiletismo que registran algunos géneros en los estudios moleculares ha llevado a la proposición de nuevas combinaciones taxonómicas, las cuales han sido incorporadas en las filogenias moleculares, además de la ampliación de los datos con los nuevos taxa descritos. Los resultados muestran la integración de los géneros en cinco clados bien resueltos: Grupo 1): Leiosporoceros (1 especie), el taxon basal hermano de todos los restantes antocerotes; Grupo 2): Anthoceros (c. $83 \mathrm{spp}$ ), Folioceros (17 spp) y Sphaerosporoceros (2 spp); Grupo 3): Notothylas (21 spp), Phaeoceros (c. 41 spp) y Paraphymatoceros (1-2 spp); Grupo 4): Megaceros (8-11 spp), Dendroceros (43 spp), Nothoceros (7-10 spp), Phaeomegaceros (7-11 spp); Grupo 5): Phymatoceros (2 spp). Las edades inferidas con dos modelos de reloj molecular indican una edad que varía entre 160,19 (Jurásico Superior) y 212,92 Ma (Triásico Superior) para la divergencia de la rama basal, la Clase Leiosporocerotopsida y c. 145 Ma (Cretácico inferior) para la divergencia de la Clase Anthocerotopsida. Dentro de esta última se reconocen hoy dos órdenes: Anthocerotales, con la única familia Anthocerotaceae, y Notothyladales, con las Familias Notothyladaceae, Dendrocerotaceae y Phymatoceraceae (Villareal et al. 2015; Duff et al. 2009).

De acuerdo con las nuevas evidencias moleculares recién reseñadas, la posición taxonómica de algunos de los 6 géneros y 15 taxa de antocerotes registrados para Chile (Hässel de Menéndez \& Rubies 2009) ha experimentado algunos cambios. Las dos especies clasificadas como
Megaceros han sido transferidas a Nothoceros; cuatro especies catalogadas como Phaeoceros han sido transferidas a la familia Dendrocerotaceae y a un nuevo género, Phaeomegaceros. De particular interés en las relaciones gondwánicas de los antocerotes del sur de Chile es la reconstrucción de áreas ancestrales, propuestas sobre la base de los resultados moleculares ya citados, y considerando solamente edades $<55 \mathrm{Ma}$ (Eoceno inferior). El área ancestral adjudicada a la rama molecular que integra la familia Dendrocerotaceae ha sido definida como "sur templada" y abarca el sur de Sudamérica, Australia y Nueva Zelanda, al sur de $25^{\circ} \mathrm{S}$ de latitud (Villarreal et al. 2015). Así, los autores proponen un origen en el Hemisferio Sur para los siguientes géneros de Dendrocerotaceae con distribución austral-antártica (las especies chilenas y sus autores se indican en la Tabla 4): (i) Phaeomegaceros (Fig. 8, 1-3), con c. 11 especies, con cuatro taxa chilenos, dos en Nueva Zelanda y dos en los Andes neotropicales, estos últimos probablemente dispersadas a larga distancia desde el sur, de acuerdo a la sugerencia de los autores recién citados; (ii) Nothoceros, con diez especies a saber: dos especies chilenas (Fig. 8, 4), una en Nueva Zelanda y las restantes de amplia distribución en Sudamérica, África, Malasia e islas del Pacífico; (iii) Dendroceros, un género epífito con c. 40 especies de distribución tropical amplia y representada en Chile solamente por $D$. cichoraceus (iv) Megaceros, con 11 especies principalmente de Nueva Zelanda y Australia. De acuerdo con Villareal y colaboradores (2015), las Dendrocerotaceae podrían haber dispersado desde un área ancestral templado-austral hacia Asia y África, y desde allí al Neotrópico. Las paleo-distribuciones australes de la familia sugieren el poblamiento de los linajes en el dominio gondwánico sur, antes del desmembramiento final del Gondwana Occidental, como lo señala la edad de divergencia de la rama Dendrocerotaceae hace alrededor de $50 \mathrm{Ma}$, en el Eoceno inferior. Sin embargo, las edades de divergencia de la mayoría de los géneros en el OligocenoMioceno (entre 28,73 y $11,96 \mathrm{Ma}$ ) indican que las actuales distribuciones de varios de ellos podrían ser producto de eventos de dispersión a larga distancia. En lo que concierne a las restantes familias de antocerotes, están representadas en Chile central las familias Anthocerotaceae con el género Anthoceros y Nothothyladaceae con los géneros Phaeoceros y Paraphymatoceros (Tabla 4). Este último es un género de antocerote nuevo para la ciencia cuyo tipo procede de la costa de Valparaíso, Paraphymatoceros Hässel, e incluye la nueva especie chilena P. diadematus Hässel (Fig 8, 5-7), - -llamada así por la corona de báculas en cada una de las áreas triangulares de la cara proximal de la espora (Hässel de Menéndez 2006; Hässel de Menéndez \& Villagrán 2007). 


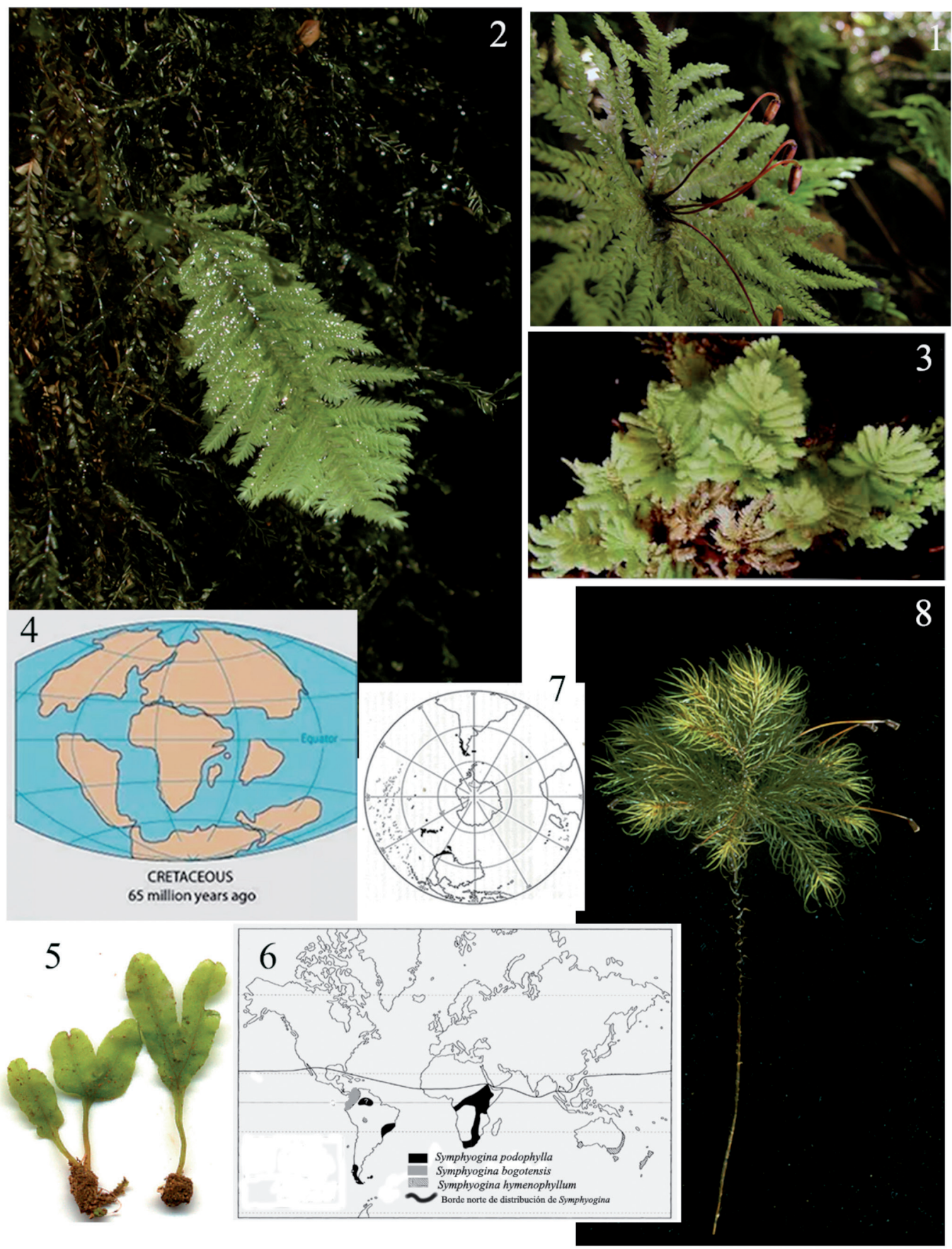

FiguRA 7. Ejemplos de musgos y hepáticas con distribuciones austral-antárticas continentales y probable origen gondwánico: 1-3) Familia Hypopterigiaceae, Arbusculohypopterygium arbuscula (Brid.) Stech, T.Pfeiffer \& W.Frey con esporogonios (1), Lopidium concinnum (Hook.) Wils. (2), Hypopterygium. didictyon C.Müll. (3). 4-6), Familia Pallaviciniaceae, Symphyogyna podophylla (Thunb.) Mont. \& Nees (5); reconstrucción del Gondwana Occidental (modificado de Allègre 1988) (4); distribución en el Hemisferio Sur de las tres especies de hábito dendroide del género Symphyogyna (modificado de (Schaumann et al. 2003) (6). (7-8) Familia Polytrichaceae, Polytrichadelphus magellanicus (Hedw.) Mitt., distribución austral-antártica (7); Dendroligotrichum dendroides (Brid. ex Hedw.) Broth. subsp. dendroides (8). / Examples of mosses and liverworts with continental Austral-Antarctic distributions and probable Gondwanic origin: 1-3) Family Hypopterigiaceae, Arbusculohypopterygium arbuscula (Brid.) Stech, T. Pfeiffer \& W.Frey, with sporogonia (1), Lopidium concinnum (Hook.) Wils. (2), Hypopterygium. didictyon C.Müll. (3). 4-6) Family Pallaviciniaceae, Symphyogyna podophylla (Thunb.) Mont. \& Nees (5); reconstruction of West Gondwana (modified from Allègre 1988) (4); distribution in the Southern Hemisphere of the three species of dendroid habit of the genus Symphyogyna (modified from (Schaumann et al. 2003) (6). 7-8) Family Polytrichaceae. Polytrichadelphus magellanicus (Hedw.) Mitt., Austral-Antarctic distribution (7); Dendroligotrichum dendroides (Brid. ex Hedw.) Broth. subsp. dendroides (8). 

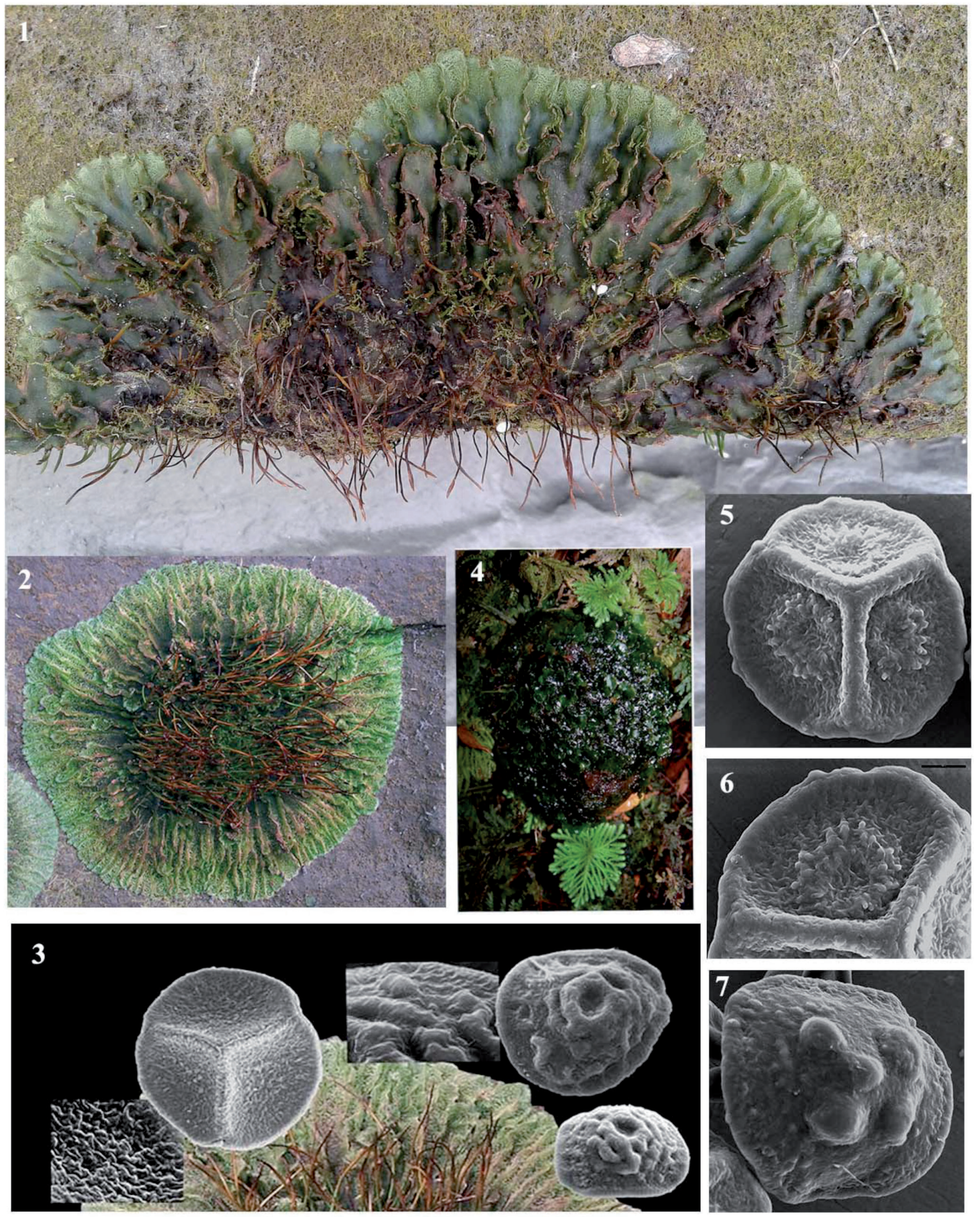

Figura 8. Algunos ejemplos de antocerotes de la Clase Anthocerotopsida: 1-4) Familia Dendrocerotaceae, Phaeomegaceros squamuligerus (Spruce) J.C. Villarreal, hábito (1-2); morfología de las esporas (3); Nothoceros fuegiensis (Stephani) J.C. Villarreal, hábito (4). 5-7) Familia Notothyladaceae, Paraphymatoceros diadematus Hässel, vista proximal de la espora y detalle de la corona de las báculas (5-6); Exina tuberculada de la cara distal de la espora (7). / Some examples of hornworts of the Anthocerotopsida Class. 1-4) Dendrocerotaceae family, Phaeomegaceros squamuligerus (Spruce) J.C. Villarreal, habit (1-2); spore morphology (3); Nothoceros fuegiensis (Stephani) J.C. Villarreal, habit (4). 5-7) Notothyladaceae Family, Paraphymatoceros diadematus Hässel, proximal view of the spore and detail of the crown of the bacula (5-6); Tuberculated exine from the distal spore surface (7). 
TABLA 4. Antocerotes de la Clase Anthocerotopsida representadas en la región subtropical-templada de Chile. Riqueza de especies global y en Chile. Distribución en Chile continental e insular, JF, islas de Juan Fernández. Elemento Biogeográfico al nivel genérico: australantártico (AA); tropical-templado (T/T); anfitropical (A); subcosmopolita (Sc). / Hornworts of the Anthocerotopsida Class represented in the subtropical-temperate region of Chile. Global and Chilean species richness. Distribution in continental and insular Chile, JF, Juan Fernández islands. Biogeographic Element at the generic level: Austral-Antarctic (AA); Tropical-Temperate (T / T); Amphitropical (A); Subcosmopolitan (Sc).

\begin{tabular}{|c|c|c|c|c|}
\hline Orden/familia & Género & $\begin{array}{l}\mathrm{N}^{\circ} \mathrm{spp} \\
\mathrm{G} . / \mathrm{ch}\end{array}$ & Especie & $\begin{array}{l}\text { Distribución } \\
\text { en Chile }\end{array}$ \\
\hline $\begin{array}{l}\text { ANTHOCEROTALES/ } \\
\text { ANTHOCEROTACEAE }\end{array}$ & Anthoceros Sc & $87 / 4$ & $\begin{array}{l}\text { A. punctatus L. var. dolichocarpus } \\
\text { A. serratus Steph. } \\
\text { A. patagonicus Hässel } \\
\text { A. peruvianus Steph. }\end{array}$ & Valparaíso. Magallanes. JF \\
\hline \multirow[t]{2}{*}{$\begin{array}{l}\text { NOTOTHYLADALES/ } \\
\text { NOTOTHYLADACEAE }\end{array}$} & Phaeoceros Sc & $32 / 3$ & $\begin{array}{l}\text { P. dendroceroides (Stephani) } \\
\text { Hässel } \\
\text { P. propaguliferus (Steph.) Hässel } \\
\text { P. carolinianus (Michx.) Prosk. }\end{array}$ & $\begin{array}{l}\text { Valparaíso } \\
\text { Concepción } \\
\text { Valdivia }\end{array}$ \\
\hline & Paraphymatoceros A & $4 / 1$ & P. diadematus Hässel & $\begin{array}{l}\text { Valparaíso } \\
\text { Santiago }\end{array}$ \\
\hline \multirow{5}{*}{$\begin{array}{l}\text { NOTOTHYLADALES/ } \\
\text { DENDROCEROTACEAE }\end{array}$} & Dendroceros $\mathrm{T} / \mathrm{T}$ & $40 / 1$ & D. cichoraceus (Mont.) Gottsche & Chiloé \\
\hline & Nothoceros AA & $10 / 2$ & $\begin{array}{l}\text { Nothoceros endiviaefolius (Mont.) } \\
\text { J. Haseg. ex J. C. Villarreal, Hässel } \\
\text { de Menéndez \& N. Salazar } \\
\text { Nothoceros fuegiensis (Stephani) J. } \\
\text { C. Villarreal }\end{array}$ & Valdivia a Magallanes. JF \\
\hline & \multirow{3}{*}{ Phaeomegaceros AA } & \multirow{3}{*}{$11 / 3-4$} & $\begin{array}{l}\text { Phaeomegaceros chiloensis } \\
\text { (Steph.) J.C. Villarreal }\end{array}$ & Valparaíso/ Chiloé \\
\hline & & & $\begin{array}{l}\text { Phaeomegaceros skottsbergii } \\
\text { (Steph.) R.J. Duff, J.C. Villarreal, } \\
\text { Cargill et Renzaglia }\end{array}$ & J.F. Chiloé \\
\hline & & & $\begin{array}{l}\text { Phaeomegaceros } \\
\text { squamuligerus (Spruce) J.C. } \\
\text { Villarreal subsp. squamuligerus } \\
\text { subsp hässeli J.C. Villarreal, Cargill } \\
\text { \& Goff }\end{array}$ & $\begin{array}{l}\text { Cautín/ Valdivia/ Osorno/ } \\
\text { Chiloé }\end{array}$ \\
\hline
\end{tabular}

\section{ANDES Y DISYUNCIONES NEOTROPICALES}

De particular importancia en la estructura biogeográfica de los bosques chilenos es la presencia de una serie de plantas vasculares y de briófitas cuyas distribuciones exhiben amplias disyunciones con los bosques lluviosos tropicales de la costa Atlántica del sur de Brasil, vertiente oriental de los Andes de Perú y Bolivia y Andes ecuatoriales. Si bien en gran medida el componente neotropical de los bosques chilenos tiene su origen en las floras que poblaron el Gondwana occidental durante el Paleógeno, bajo condiciones climáticas más cálidas y lluviosas, las actuales disyunciones florísticas probablemente tengan conexión con la serie de acontecimientos tectónicos y climáticos que marcan el escenario biogeográfico del continente durante el Neógeno. De acuerdo con los antecedentes paleo-climáticos, desde el Mioceno inferior las temperaturas y las precipitaciones globales experimentan un marcado aumento que culmina con un máximo termal en el Mioceno medio; a partir del óptimo térmico se inicia una sostenida tendencia de descenso de las temperaturas, asociado al desarrollo del casquete de hielo permanente en la Antártica y el consecuente reforzamiento de la Corriente del Perú y del Anticiclón Subtropical del Pacífico Sur. Paralelamente, el incremento de la tasa del levantamiento andino, a partir del Mioceno superior, genera un fuerte efecto 
de sombra de lluvia en los sistemas de vientos dominantes del continente, la circulación del este y el cinturón de los Oeste (westerlies) (Zachos et al. 2001; Gregory-Wodzicki 2000; Reynols et al. 1990). Los efectos combinados de estos factores determinan el desarrollo de la Diagonal Árida (DA), una franja continua de clima árido que cruza el territorio en sentido SE-NO, desde el extremo SE de Sudamérica hasta c. del ecuador en la costa Pacífica (Villagrán 2018, Villagrán \& Hinojosa 2005, 1997; Abraham et al. 2000; Garleff et al. 1991). La DA actúa como barrera para la dispersión de la flora más higrófila a lo largo del corredor andino y se instituye así como el factor principal que determina el actual aislamiento de los bosques subtropical-templados de la costa Pacífica de Chile, uno de los rasgos más característicos de la biogeografía de Sudamérica (Hueck 1966).

De acuerdo con los antecedentes paleobotánicos de Chile central, durante el óptimo climático del Mioceno Medio se produce la expansión de un bosque de carácter más moderno, consignados como "Paleoflora Subtropical Neógena". Sobre la base del examen de la relación fisionomía foliar/clima de floras fósiles, se ha propuesto que estos bosques evolucionaron en el subtrópico de Sudamérica bajo condiciones climáticas con temperaturas relativamente cálidas y un régimen hídrico bi-estacional, con lluvias estivales procedentes del este e invernales procedentes de los westerlies. Este sistema climático no tendría análogos modernos y solamente pudo haber imperado con una Cordillera de los Andes de baja altitud, ya que las elevaciones actuales determinan un severo efecto de sombra de lluvia en ambas vertientes andinas (Hinojosa \& Villagrán 2005; Hinojosa 2003). La gradual fragmentación y aislamiento de los bosques subtropicales del Mioceno, estaría asociada al levantamiento andino y desarrollo de la DA, con la consecuente expansión de formaciones xéricas a lo largo de su recorrido (Latorre et al. 1996). La mayor continuidad de comunidades mésicas a lo ancho del Subtrópico de Sudamérica constituye un escenario relevante en la interpretación biogeográfica de las notables disyunciones genéricas que hoy exhibe el componente leñoso neotropical de los bosques chilenos, principalmente miembros de las familias Myrtaceae (Myrceugenia, Blepharocalyx, Ugni y Myrteola), Escalloniaceae (Escallonia), Winteraceae (Drimys), Salicaceae (Azara), Elaeocarpaceae (Crinodendron), Quillajaceae (Quillaja), Bromeliaceae (Greigia), Alstroemeriaceae (Bomarea), Calceolariaceae (Calceolaria), entre otros (cfr. Villagrán 2018). Estos patrones sugieren la existencia de bosques más extensos y relativamente más contínuos a lo ancho del Subtrópico de Sudamérica, durante el Oligoceno-Mioceno (Landrum 1981). Los estudios moleculares en Myrtaceae sudamericanas (Pérez et al. 2014, 2017; Murillo et al. 2012) muestran que Myrceugenia, el género arbóreo más diverso de los bosques chilenos y con más especies disyuntas con el Neotrópico, exhibe una edad de divergencia entre 24-23 Ma de otros géneros de Myrtaceae chilenas, lapso correspondiente a la interfase Oligoceno/ Mioceno. Dentro del grupo de especies de Myrceugenia, la rama que incluye las especies de la costa Pacífica de Chile central-sur diverge durante el Mioceno, mientras que las rama anidada que integra las especies de la costa Atlántica del sur de Brasil muestra una edad de divergencia posterior a $14 \mathrm{Ma}$, en el Mioceno Superior/Plioceno. Estos resultados sugieren dispersión del género desde el SO y diversificación más reciente en el Neotrópico. Un ejemplo similar entre las briófitas es Hymenodontopsis mnioides (Hook.) N.E. Bell, A.E. Newton \& D. Quandt. (Aulacomniaceae). Las evidencias filogeográficas procedentes de las poblaciones sudamericanas del musgo, distribuidas desde Costa Rica a Cabo de Hornos, muestran dicontinuidad areal y divergencia genética entre el grupo de poblaciones andino-templadas de Chile y el grupo hermano que integra las restantes poblaciones andinotropicales de Sudamérica. La divergencia de ambas ramas ha sido asociada al aislamiento de las poblaciones australes con el desarrollo de la DA y Desierto de Atacama, último evento para el que los autores proponen una fecha $>14 \mathrm{Ma}$, Mioceno medio. La diferenciación poblacional dentro de cada grupo se habría producido con posterioridad y separadamente dentro de cada área (McDaniel \& Shaw 2003).

A este contexto Neógeno se ha vinculado la existencia de comunidades relictas de neblina de la costa semi-árida de Chile. Los ejemplos más notables son los fragmentos de bosques higrófilos aislados en cimas montañosas de las Alturas de Talinay ( $30^{\circ} 40^{\prime}$ S, $450-700$ m s.n.m.), inmersos en una matriz de matorrales xerofíticos (Villagrán et al. 2004a; Villagrán \& Armesto 1980; Troncoso et al. 1980). En la actualidad los relictos persisten gracias al microclima húmedo que proporciona la condensación de las neblinas en las cimas costeras. En la costa árida y semi-árida de Chile los episodios de neblina se producen cuando la topografía costera intercepta el manto de nubosidad de los estratocúmulos marinos. El aporte de hasta $1000 \mathrm{~mm}$ anuales de precipitación por neblinas en los relictos de las Alturas de Talinay compensaría el reducido aporte de las lluvias regionales, las cuales no sobrepasan promedios anuales de $200 \mathrm{~mm}$ y son insuficientes para sostener comunidades forestales (Kummerow 1966). El análisis del ciclo anual de las neblinas muestra que los días nublados son máximos en primavera y mínimos en invierno. La variabilidad interanual de las frecuencias de neblinas en Fray Jorge exhibe signo opuesto a la variabilidad de las Iluvias en Chile nor-central: las frecuencias más altas ocurren con temperaturas superficiales del mar más frías y temperaturas del aire más cálidas que las normales; este escenario fortalecería la inversión térmica y llevaría a un manto de nubosidad estratocúmulo más persistente, condiciones 
cercanas a las anomalías "La Niña". En contraste, las anomalías positivas de las precipitaciones en Chile nor-central asociadas a eventos "El Niño" se relacionan a lapsos con menos neblina (Garreaud et al. 2008).

La mayoría de los componentes florísticos de los bosques relictos exhiben disyunciones de más de $700 \mathrm{~km}$ con los bosques templado-lluviosos del sur de Chile, particularmente con el Bosque Valdiviano, con rangos continuos de distribución al sur de $36^{\circ} \mathrm{S}^{5}$. Los árboles dominantes, Aextoxicon punctatum Ruiz et Pav., olivillo; Myrceugenia correaefolia (Hook. et Arn.) O.Berg., petrilla; y Drimys winteri J.R.Forst. et G.Forst., canelo, se desarrollan también en hábitats azonales de la costa de Chile central, como quebradas húmedas o suelos pantanosos. Entre los géneros leñosos, Azara, Myrceugenia, Drimys y Griselinia exhiben disyunciones transandinas, particularmente con el sur de Brasil. En la explicación de las relaciones florísticas y disyunciones que exhibe la flora vascular de los relictos, tanto con los bosques templado-lluviosos como con el Neotrópico, distinguidos botánicos de finales del siglo XIX y primera mitad del XX han postulado diversas hipótesis y considerado diferentes contextos temporales. Así, Gualterio Looser en 1935, Carlos Skottsberg en 1948 y Carlos Muñoz y Edmundo Pisano en 1947, atribuyen a los relictos un origen postglacial, glacial y pre-glacial, respectivamente, mientras que Federico Philippi en 1984 y Josef Schmithüsen en 1956 plantean un origen terciario para la comunidad. En contraste con las hipótesis de origen glacial de los relictos, las hipótesis que sostienen un origen terciario de la comunidad interpretan las actuales disyunciones neotropicales genéricas como una consecuencia de la fragmentación de los bosques del subtrópico de Sudamérica, en el Plio-Pleistoceno, por el levantamiento final de los Andes y desarrollo de la DA. El exámen de los planteamientos de estos autores y las posteriores evidencias florísticas, geo-climáticas y paleoecológicas en favor de cada una de las hipótesis han sido discutidas latamente en la literatura (cfr. Troncoso et al. 1980; Villagrán \& Armesto 1980; Villagrán et al. 2004 a). Estudios filogeográficos más recientes en poblaciones arbóreas de los relictos son concordantes con algunas de estas hipótesis. Pérez y colaboradores (2017) proponen expansión de rango de Myrceugenia correifolia durante la última glaciación Llanquihue y fragmentación en el Holoceno Temprano a

\footnotetext{
${ }^{5}$ Entre los árboles y arbustos de los relictos, exhiben disyunciones con el sur de Chile: Azara microphylla Hook. f., chiñchiñ; Griselinia scandens (Ruiz et Pav.) Taubert, yelmo; Rhaphithamnus spinosus (Juss.) Moldenke, espino chauchao. Entre las epífitas y enredaderas, Lapageria rosea Ruiz et Pav., copihue; Nertera granadensis (Mutis ex L.f.) Druce, queillénchucao, chaquirita; Mitraria coccinea Cav., botellita; Sarmienta scandens (J.D. Brandis ex Molina) Pers., medallita; y tres especies de Peperomia.
}

Medio. Por otra parte, la divergencia genética entre las poblaciones Aextoxicon punctatum y Drimys winteri de los relictos y las restantes poblaciones a lo largo de Chile centralsur (Jara et al. 2012; Núñez-Ávila \& Armesto 2006) sugiere a estos autores un aislamiento más antiguo de la comunidad.

Quizás las criptógamas asociadas aporten mayor claridad al problema de los relictos ya que evidencian los casos más notables de endemismo y de amplias disyunciones geográficas, tanto dentro del territorio chileno como con el Neotrópico, particularmente las hepáticas. Entre las c. de 30 especies de musgos documentadas para Fray Jorge (Villagrán et al 2004 a), restringen su distribución a estas comunidades: Funaria integra (Müll.Hal.) Lindb. var. serrulata Broth. ${ }^{6}$, Mielichhoferia demissa Müll.Hal., Tortula perarmata Broth. y Ptychomnium cygnisetum (Müll. Hal.) Besch var. chilense Broth.7, las cuatro endémicas de Chile. Un grupo de ocho especies exhibe discontinuidades de sus rangos en Chile central y se distribuyen en forma continua solamente al sur de la interfase subtropical-templada $\left(37^{\circ}-39^{\circ} \mathrm{S}\right)$ : Eurhynchium corralense (Lor.) Jaeg., Rigodium adpressum Zomlefer, Syntrichia robusta (Hook. f. \& Grev.) Zand., Weymouthia mollis (Hedw.) Broth., Porothamnium arbusculans (Müll.Hal.) Ochyra, y Ptychomnion cygnisetum (Müll.Hal.) Kindb. Al sur de $41^{\circ} \mathrm{S}$, Orthodontium pellucens (Hook.f.) Schimp..$^{8}$; al sur de $45^{\circ}$ S, Bryum perlimbatum Cardot. Las restantes especies tienen rangos relativamente continuos en Chile central. Es interesante destacar que la mayoría de los musgos de los relictos son comunes a distintas formaciones de bosques templado-lluviosos del sur de Chile. Oberdorfer (1960) destaca que los ensambles de criptógamas

\footnotetext{
${ }^{6}$ Funaria integra var. serrulata no aparece en Catálogo Müller 2009 (CM) y, de acuerdo a datos no publicados de un revisor, es sinónimo de Entosthodon apophysatus, distribuido en las regiones VII y VIII.

${ }^{7}$ Otros cuatro taxa consignados como restringidos a Fray Jorge en la revisión realizada por el briólogo chileno Jorge Cuvertino, coautor de la publicación citada, son: Tortula perarmata registrada como especie válida en Catálogo He $1998(\mathrm{CH})$ y, de acuerdo a un revisor, sinónimo de Pseudocrossidium leucocalyx (Mont.) Thér., distribuida en Limarí, Santiago y Valparaíso. Tortula flavipes Broth. es consignada en $\mathrm{CH}$ como hom.illeg. Por otra parte, Ptychomnium cygnisetum (Müll. Hal.) Besch var. chilense Broth. no figura en CM ni CE y el nombre proviene de la colección de tipos del MNHN, SGO 88978. IV R., Coquimbo, Fray Jorge. In silva ad ramos copiose, $670 \mathrm{msm}$. Col. Skottsberg, C. $\mathrm{N}^{\circ}$ 240, 15-81917. Sintipo. Ptychomnium aciculare (Brid.) Mitt., de acuerdo a un revisor, correspondería a identificación errónea de P.cygnisetum (cfr. Hattaway 1984, Monograph of the Ptychomniaceae, tesis doctoral)

${ }^{8}$ De acuerdo a un revisor, O. pelluscens, registrado en $\mathrm{CM}$ y $\mathrm{CH}$ es un taxón neotropical que no crece en Chile y todos los reportes de Chile son incorrectos y se refieren a $O$. gracile o a $O$. lineare (Meijer 1952, The genus Orthodontium)
} 
asociadas a los bosques laurifolios de Chile conforman un estrato propio, no imputable a ninguna asociación forestal en particular. Florísticamente, taxa de musgos de los relictos tales como Ptychomnium cygnisetum, Porothamnium arbusculans y Weymouthia mollis son clasificados como especies características de todas las asociaciones de bosques templado-Iluviosos perennifolios del sur de Chile, la Clase Wintero-Nothofagetea (Oberdorfer 1960).

En lo que concierne a las hepáticas, dominan las formas foliosas de la Subclase Jungermanniidae de la Clase Jungermanniopsida, particularmente epífitas y epifilas del Orden Porellales. De las c. de 43 especies registradas para los relictos de Fray Jorgey Talinay (en la Tabla 5 se listan las especies e indican sus autores), siete taxa restringen su distribución a estas comunidades dentro del territorio continental chileno: Blepharolejeunea securifolia, Odontolejeunea lunulata, Austrolejeunea talinayi, Plagiochila talinayii, P. frayjorgensis, Porella chilensis var. fernandeziensis y Frullania reicheana (Fig. 9). Otras 28 especies exhiben notables disyunciones de sus rangos de distribución en Chile central, con continuidad a partir de la transición mediterráneo-templada, al sur de $36^{\circ} \mathrm{S}$, o mayormente desde Chiloé al sur $\left(42^{\circ} \mathrm{S}\right)$, e incluso al sur de Aysén y en Magallanes, como Lepidozia fueguiensis, Cololejeunea fernandeziana y Drepanolejeunea araucariae var. chilensis, exhibiendo hiatos de hasta $14^{\circ}$ de latitud (Tabla 5) (Hässel de Menéndez \& Rubies 2009; Hässel de Menéndez \& Villagrán 2007a; Villagrán et al. 2004a, 2005; Arnell 1956). Las restantes especies exhiben continuidad de sus rangos a lo largo de Chile central. En general, las especies se asocian a todos los tipos de bosques subtropicales y templado-lluviosos de Chile: Esclerófilo, Maulino, Valdiviano, Nordpatagónico y Subantártico. En referencia a la composición biogeográfica (Tabla 5), un grupo de especies pertenece al componente endémico de Chile continental e insular. Otras se distribuyen también en regiones tropicales y subtropicales del globo, particularmente en los Andes neotropicales, como Blepharolejeunea securifolia, Odontolejeunea lunulata; también en el NO de Argentina, como Plagiochila talinayi en Tucumán; o Juan Fernández, como Porella chilensis var. fernandeziensis; o África tropical, como Metzgeria epiphylla, M. violácea, Frullania ecklonii, Tylimanthus limbatus9, Hyalolepidozia bicuspidata; o exhiben patrones circum-atlánticos o anfitropicales, como Colura calyptrifolia y Microlejeunea ulicina.

Entre las hepáticas coleccionadas por el matrimonio

\footnotetext{
${ }^{9}$ Se conserva el nombre T. limbatus tal como figura en Catálogo Hässel \& Rubies 2009 (CHR). Su nombre actual sería Acrobolbus limbatus de acuerdo a un revisor.
}

Skottsberg en el relicto Cerro Talinay (Arnell 1956) se registran poblaciones epitalosas de la familia Lejeuneaceae, como, Cololejeunea fernandeziana y Aphanolejeunea asperrima creciendo sobre el helecho epífito Hymenophyllum peltatum (Poir.) A.N. Desv.; o Drepanolejeunea cfr. Iancifolia y Microlejeunea ulicina, sobre Frullania reicheana y Plagiochila heterodonta. En Talinay hemos observado también Lejeuneaceae sobre los talos corticícolas de Metzgeria. Recientemente, se ha documentado Lejeunea globosiflora para Chile central, en Zapallar, sobre talo de Porella (Tabla 5) (Hässel \& Villagrán 2007). Nuestro registro de 30 hojas en los relictos de Fray Jorge y Talinay muestra que la mayoría de las especies epifilas son Lejeuneaceae; más de la mitad se desarrollan sobre hojas de Aextoxicon punctatum, Griselinia scandens, Myrceugenia correifolia y, en menor proporción, sobre Drimys winteri, Rhaphithamnus spinosus y Lapageria rosea. En Chiloé abundan las Lejeuneaceae epifilas en microclimas especiales, particularmente en hábitats de bosques muy húmedos y sombríos cercanos al mar. En pequeñas fosas aledañas al Golfo de Compu se ha registrado la composición y frecuencias de epifilas en 86 hojas de Myrceugenia planipes (Hook. \& Arn.) O. Berg, Laureliopsis philippiana (Looser) Schodde, Griselinia racemosa (Phil.) Taub., Caldcluvia paniculata (Cav.) D. Don y Gevuina avellana Molina (Fig. 10) (Villagrán et al. 2005). Resulta sorprendente que las diminutas biocenosis epifilas de esta comunidad concentren una fuerte proporción de las hepáticas disyuntas con los relictos de neblina, con c. de 1500 km de separación (en la Tabla 5 se indican los autores de las especies que se citan a continuación). Nuevamente destaca la familia Lejeuneaceae con especies comunes con relictos tales como Lejeunea globosiflora, Aphanolejeunea asperrima, Colura calyptrifolia, Harpalejeunea marginalis, $\mathrm{H}$. parasítica $a^{10}$ y Microlejeunea ulicina; entre las hepáticas epifilas registradas, pertenecientes a otras familias también disyuntas con los relictos, destacan: Radula decora y R. flavifolia, entre las Radulaceae; Metzgeria decipiens, entre las Metzgeriaceae; Plagiochila heterodonta y P. rufescens, entre las Plagiochilaceae (Fig. 10). En microclimas húmedos similares ubicados en regiones distante se han registrado espectros genéricos muy similares, como en Panamá y Andes tropicales de Ecuador (Schäffer-Verwimp 2014, Schäffer-Verwimp et al. 2006); o en Nueva Caledonia en bosques mixtos de hábitats de baja altitud, sombríos y aledaños a cursos de agua (Hürlimann 1999).

\footnotetext{
${ }^{10}$ Se conserva el nombre H. parasitica tal como figura en Catálogo Hässel \& Rubies 2009 (CHR). Un revisor sugiere que podría tratarse de $H$. marginalis.
} 


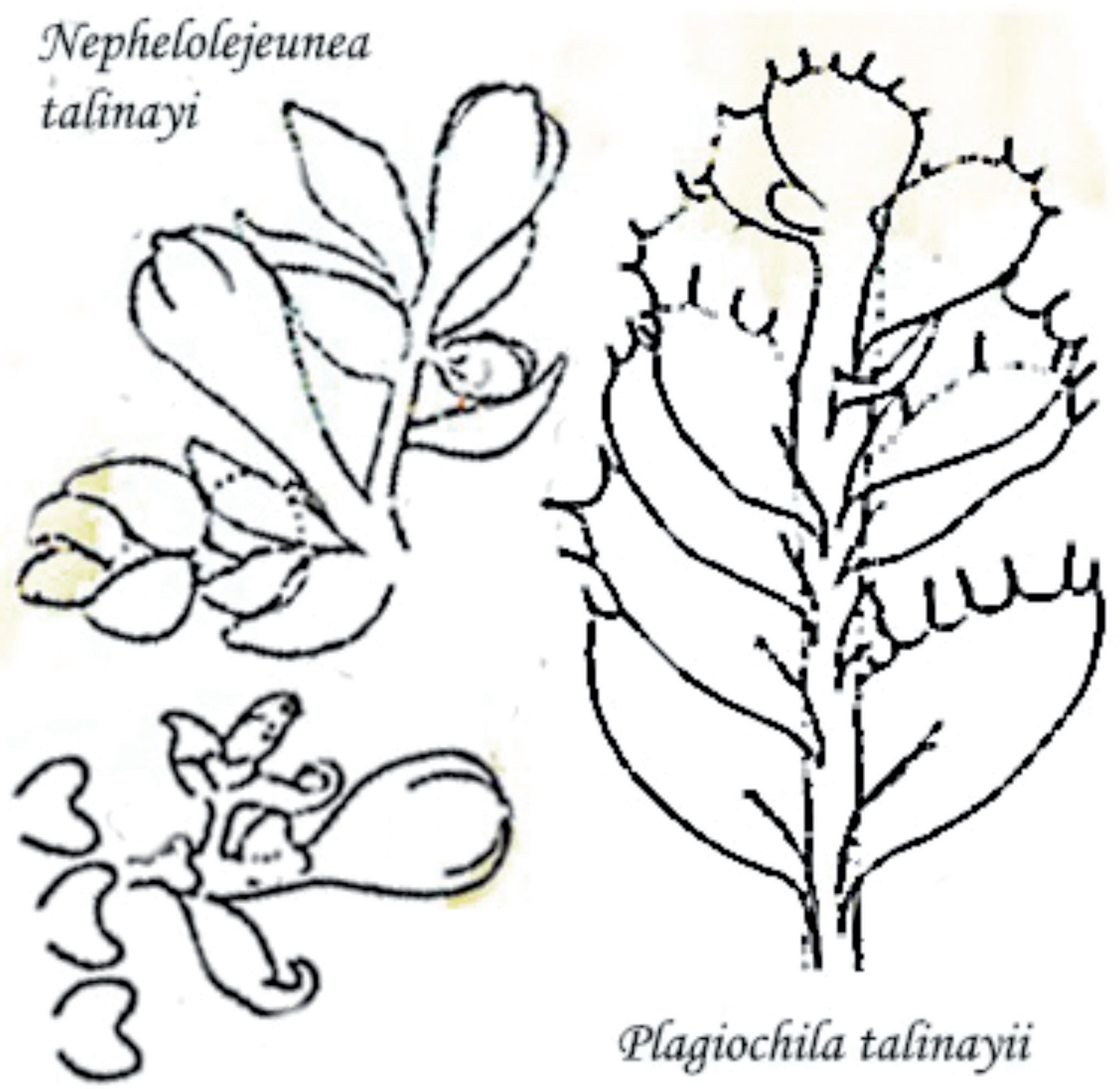

Figura 9. Dos ejemplos de especies endémicas de los bosques relictos de neblina del Norte Chico, Chile: Austrolejeunea talinayi (S. Arn.) Pocs y Plagiochila talinayi S.W. Arnell, (re-dibujados de Arnell 1956). / Two examples of endemic species of Norte Chico relict cloud forests, Chile: Austrolejeunea talinayi (S. Arn.) Pocs and Plagiochila talinayi S.W. Arnell, (re-drawn from Arnell 1956).

TABla 5. Especies de Hepáticas representadas en los relictos de neblina del Norte Chico, Chile. Disyunciones con el sur del territorio. Distribución en Chile continental e insular (JF, Archipiélago Juan Fernández). Límite norte del rango latitudinal continuo de la especie (LN). Elementos biogeográficos (EB): E, Endémico; T, Tropical (Ta, tropical andino, Taf, también en Africa, Tca, tropical circum-atlantico); AA, Austral-antártico; HS, Hemisferio Sur; A, Anfitropical; Sc, Subcosmopolita. / Liverworts species represented in the relict cloud forests of Norte Chico, Chile. Disjunctions with the south of the territory. Distribution in continental and insular Chile (JF, Juan Fernández Archipelago). Northern limit of the species continuous latitudinal range (LN). Biogeographic Elements (EB): E, Endemic; T, Tropical (Ta, tropical Andean, Taf, also in Africa, Tca, tropical circum-Atlantic); AA, Austral-Antarctic; HS, Southern Hemisphere; A, Amphitropical; Sc, Subcosmopolitan.

\begin{tabular}{lccl}
\hline Especies & EB & LN & Distribución en Chile \\
\hline Austrolejeunea talinayi (S.Arn.) Pocs & E & $30^{\circ} 30^{\prime}$ & Restringida relictos \\
Blepharolejeunea securifolia (Steph.) R.M. Schust. & $\mathrm{Ta}$ & $30^{\circ} 30^{\prime}$ & Restringida relictos. Tb. Andes tropicales \\
Frullania reicheana Steph. & $\mathrm{E}$ & $30^{\circ} 30^{\prime}$ & Restringida relictos \\
Odontolejeunea lunulata (F.Weber) Schiffner & $\mathrm{Ta}$ & $30^{\circ} 30^{\prime}$ & Restringida relictos. Tb. Andes tropicales \\
\hline
\end{tabular}




\begin{tabular}{|c|c|c|c|}
\hline Especies & EB & $\begin{array}{l}\text { LN } \\
\text { LAT. } S\end{array}$ & Distribución en Chile \\
\hline Plagiochila frayjorgensis Hässel de Menéndez & $\mathrm{E}$ & $30^{\circ} 30^{\prime}$ & Restringida relictos \\
\hline Plagiochila talinayi S.W. Arnell & $\mathrm{Ta}$ & $30^{\circ} 30^{\prime}$ & Restringida relictos. Tb. Tucumán, Argentina \\
\hline $\begin{array}{l}\text { Porella chilensis (Lehm. \& Lindenb.) Trev. var. fernandeziensis (Herz) } \\
\text { Swails }\end{array}$ & $\mathrm{E}$ & $30^{\circ} 30^{\prime}$ & Restringida relictos \\
\hline Frullania magellanica Web \& Nees & AA & 32 & JF. Valparaíso a Tierra del Fuego \\
\hline Lejeunea globosiflora (Steph.) Steph. & $\mathrm{E}$ & 32 & Zapallar. Chiloé. Magallanes \\
\hline Lepidozia laevifolia (Hook. f. \& Tayl.) Gottsche \& al. & A & 32 & JF. Chile central a Magallanes \\
\hline Leptoscyphus chilensis (De Not) Hässel & $\mathrm{E}$ & 32 & JF. Valparaíso/Cabo de Hornos \\
\hline Leptoscyphus chiloscyphoideus (Lindenb. ex Lehm.) Gottsche & $\mathrm{E}$ & 32 & JF. Valparaíso/Talcahuano/Magallanes \\
\hline Lunularia cruciata (L.) Dumort. ex Lindb. & A & 30 & JF Elqui/ Valparaíso/Concepción/Chiloé \\
\hline Metzgeria divaricata A. Evans & $\mathrm{E}$ & 33 & JF. Santiago a Brunswick 5330'S \\
\hline $\begin{array}{l}\text { Schistochila lehmanniana (Lindenb.) Steph. var. quadrifida (Evans) } \\
\text { Hässel }\end{array}$ & AA & 30 & Coquimbo. Magallanes \\
\hline Chiloscyphus aequifolius (Nees \& Mont.) Hässel & $\mathrm{E}$ & 36 & JF. Maule a Chiloé \\
\hline Harpalejeunea parasítica (Hook. f. \& Taylor) Steph. & $\mathrm{E}$ & 39 & JF. Corral a Tierra del Fuego \\
\hline Metzgeria decipiens (C. Massal.) Schiffn. \& Gottsche & HS & 39 & JF. Corral a Tierra de Fuego \\
\hline Porella chilensis (Lehm. \& Lindenb.) Trev. var. chilensis & $\mathrm{Ta}$ & 36 & JF. Constitución hasta $51^{\circ} \mathrm{S}$ \\
\hline Porella chilensis (Lehm. \& Lindenb.) Trev. var. microloba (Herz) Swails & $\mathrm{E}$ & 36 & JF. Chile Central \\
\hline Radula flavifolia (Tayl.) Tayl. ex Gott. Lindenb. \& Nees & $\mathrm{E}$ & 36 & JF. Maule a Cabo de Hornos \\
\hline Aphanolejeunea asperrima (Steph.) Steph. & $\mathrm{E}$ & 42 & JF. Chiloé \\
\hline Chiloscyphus leptanthus (Hook. f. Taylor) J.J. Engel \& R.M. Schust. & $\mathrm{E}$ & 42 & JF. Chiloé \\
\hline Chiloscyphus pallidevirens (Hook. f. Taylor) Taylor in Gottsche \& al. & $\mathrm{E}$ & 42 & JF. Chiloé \\
\hline Colura calyptrifolia (Hook.) Dumort. & Tca & 42 & JF. Chiloé a Tierra del Fuego \\
\hline Frullania ecklonii (Spreng.) Spreng. & Taf & 42 & JF. Chiloé. \\
\hline Frullania fertilis De Not. & $\mathrm{E}$ & 40 & Chiloé \\
\hline Frullania spatiloba Steph. & $\mathrm{E}$ & 42 & JF. Chiloé \\
\hline Harpalejeunea marginalis (Hook. f. Taylor) Steph. & $\mathrm{E}$ & 42 & JF. Chiloé \\
\hline Hyalolepidozia bicuspidata (Mass.) S.Arnell ex Grolle & Taf & 41 & JF. Llanquihue a Magallanes \\
\hline Metzgeria epiphylla A. Evans & Taf & 42 & Chiloé \\
\hline Metzgeria violacea (Arch.) Dumort. & Taf & 42 & JF. Chiloé \\
\hline Microlejeunea ulicina (Tayl.) Steph. & A & 42 & Chiloé \\
\hline Plagiochila heterodonta (Hook. f. \& Tayl.) Gottsche \& al. & Sc & 40 & JF. Valdivia a Tierra del Fuego \\
\hline Plagiochila rufescens Steph. & $\mathrm{E}$ & 42 & Chiloé/Patagonia Occidental \\
\hline Plagiochila subpectinata Besch. \& C. Massal (P. fagicola Schiffn.) & $\mathrm{E}$ & 41 & JF. Llanquihue a Magallanes \\
\hline Radula decora Gottsche ex Steph. & $\mathrm{Ta}$ & 40 & JF. Valdivia a Isla. Virtudes $51^{\circ} 31^{\prime} \mathrm{S}$ \\
\hline Riccardia patens Hässel & $\mathrm{E}$ & 40 & Valdivia a Tierra del Fuego \\
\hline Tylimanthus limbatus Steph. & Taf & 40 & JF. Corral a Isla Desolación $53^{\circ} \mathrm{S}$ \\
\hline Lepidozia fueguiensis Steph. & Sc & 44 & Aysén a Tierra del Fuego \\
\hline Cololejeunea fernandeziana Solari & $i$ & 51 & JF. Pto. Toro $51^{\circ} \mathrm{S}$ a Seno Otway $53^{\circ} 30^{\prime}$ \\
\hline Drepanolejeunea araucariae Steph. var. chilensis Herzog & Sc & 51 & JF. Isla Piazzi $51^{\circ} \mathrm{S}$ \\
\hline Lophocolea divaricata Herzog & $i$ & $i$ & JF. Sur de Chile ' ¿' \\
\hline
\end{tabular}




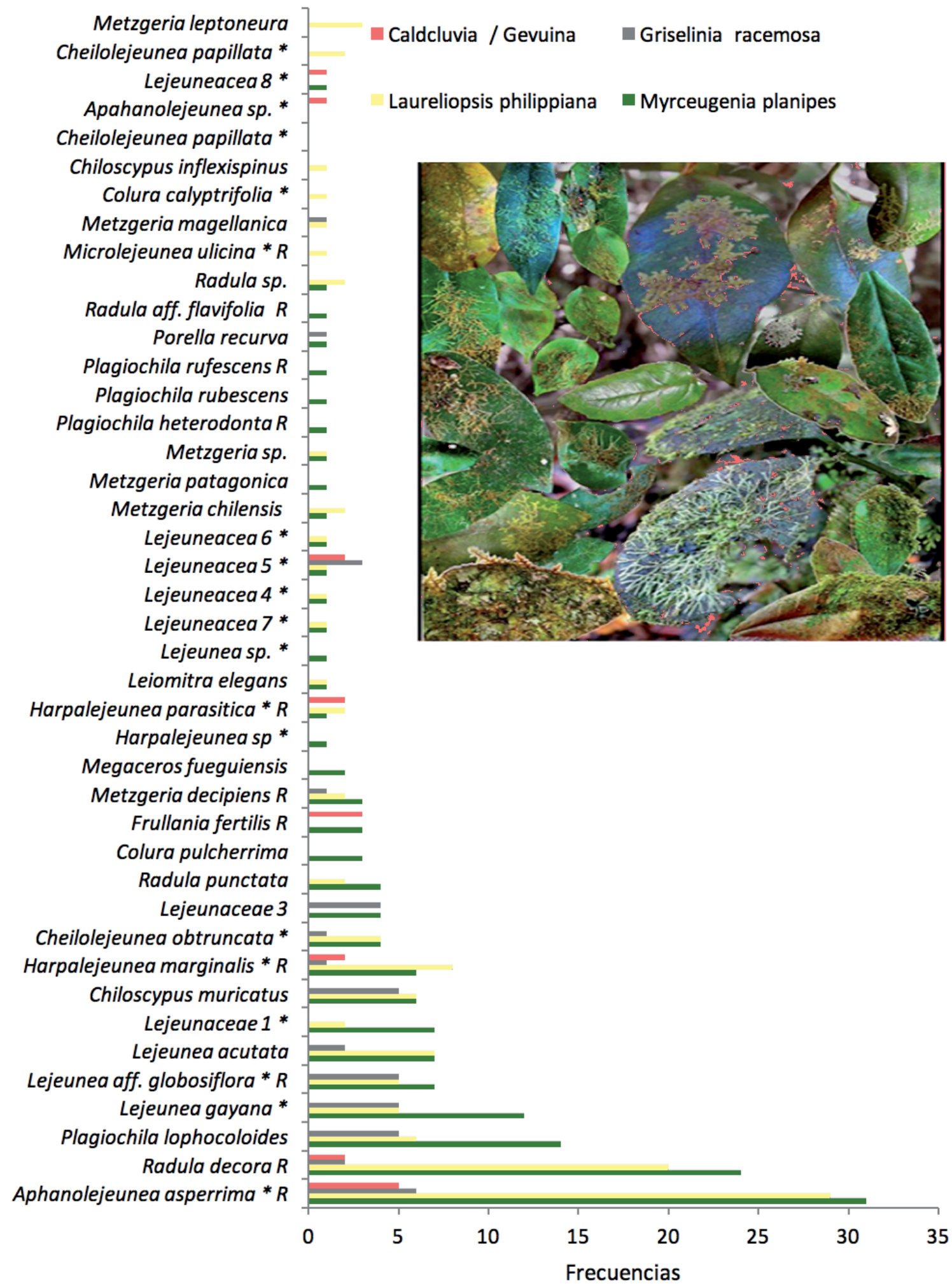

Figura 10. Frecuencias de hepáticas epifilas en bosque higrófilo, Poza Golfo de Compu, Isla Grande de Chiloé, Chile, $\mathrm{N}=86$ hojas. ${ }^{*}=$ Familia Lejeuneaceae. $R$ = especies compartidas con los relictos. La foto ilustra las briófitas epifilas de algunas de las hojas examinadas (fuente: Villagrán, Hässel de Menéndez \& Barrera 2005). / Frequencies of epiphyllous liverworts in a rainforest in Poza Golfo de Compu, Isla Grande de Chiloé, Chile, $\mathrm{N}=86$ leaves. ${ }^{*}=$ Lejeuneaceae Family. $\mathrm{R}=$ species shared with the relict. The photo illustrates the epiphyllous bryophytes of some of the leaves examined (source: Villagrán, Hässel de Menéndez \& Barrera 2005). 
Como se dijo antes, en lo que concierne a las relaciones biogeográficas de las hepáticas de los relictos merece una mención especial el Orden Porellales, el linaje más diverso entre las hepáticas foliosas y que incluye la mayoría de las especies epifilas. Destaca la familia Lejeuneaceae, la más rica en especies entre todas las briófitas, con más de 90 géneros y 1000 especies distribuidas principalmente en los trópicos húmedos. Particularmente, la familia abunda en los bosques nublados de los Andes neotropicales, comunidades donde la familia aporta c. del $70 \%$ de todas las hepáticas y c. del $90 \%$ de las hepáticas epifilas, y donde sobre 25 especies pueden crecer en una sola hoja. A excepción de Austrolejeunea, todos los géneros de Lejeuneaceae de los relictos están representados en el neotrópico, por ejemplo en los Andes de Ecuador (Schaffer-Verwimp et al. 2006). Los estudios filomoleculares de la Subfamilia Lejeuneoideae, que contiene gran parte de la diversidad de la Familia Lejeuneaceae (Gradstein et al. 2006, Wilson et al. 2007), apoyan la divergencia de la rama correspondiente a la Tribu Lejeuneeae, el grupo más diverso y complejo, de un grupo basal correspondiente a la Tribu Brachiolejeuneeae. Las Lejeuneeae integran tres grupos anidados aún no bien resueltos, entre los cuales el grupo basal incluye los géneros Cheilolejeunea y Aureolejeunea, ambos representados en el sur de Chile ${ }^{11}$. A las otras dos ramas derivadas se integra la serie de géneros representados en los relictos, como Drepanolejeunea, Austrolejeunea, Colura, Cololejeunea, Aphanolejeunea, Harpalejeunea. Microlejeunea y Lejeunea. Estos taxa más derivados comparten una serie de rasgos funcionales, como reducción de estructuras, reproducción asexual y tendencia hacia el desarrollo de gametofitos taloides neoténicos, observada también en especies epifilas de Radula de América tropical, también del Orden Porellales. Probablemente se trate de una adaptación al efímero hábitat que ofrece una hoja, donde es necesario completar rápidamente el ciclo de vida e iniciar una nueva recolonización.

Dentro de la Clase Jungermanniopsida- Jungermanniidae, un caso similar a las Lejeuneaceae se da en Plagiochila de la familia Plagiochilaceae del Orden Jungermanniales. Plagiochila tiene una amplia distribución en los trópicos del Hemisferio sur y es el género más rico en especies entre las hepáticas foliosas, con c. de 700 especies; en Chile están representadas 50 especies y cinco en los relictos, entre las cuales dos se restringen a estas comunidades, Plagiochila

\footnotetext{
${ }^{11}$ Cheilolejeunea, género pantropical con c. 80 especies, integra 9 a 10 especies chilenas distribuidas entre Valdivia y Magallanes y tres especies epifilas endémicas de Chile: Ch. papillata Solari, Ch. warnstorfii (Steph.) Solari y Ch. obtruncata (Mont.) Solari (Hässel y Rubies 2009). Aureolejeunea está representada en Chile por A. lumae (Herzog) van Slageren, Región de Los Lagos.
}

frayjorgensis y $P$. talinayi y tres exhiben disyunciones con el sur de Chile, P. heterodonta, P. rufescens, P. subpectinata (Hässel de Menéndez 2004 a y b, 1983). Las evidencias moleculares (Heinrichs et al. 2005, 2006, 2009) muestran que las especies de Plagiochila de la sección Alternantes, de Australasia y Cono Sur de Sudamérica, correspondería al linaje más antiguo, probablemente gondwánico, y habrían jugado un rol significativo como antecesores de la diversificación posterior de las especies en el Neotrópico. Gran parte de las especies de esta sección basal son endémicas del sur de Chile y Argentina, como Plagiochila subpectinata Besch. \& C. Massal. (=P. obcuneata Steph.; P. fagicola Schiffn.), P. obovata Steph., P. hookeriana Lindenb., P. chonotica Taylor, P. equitans Gottsche y P. ansata (Hook.f. \& Taylor) Gottsche (Hässel de Menéndez 2004 a, b). La rama hermana de la sección Alternantes constituye un robusto grupo anidado de las restantes 18 Secciones del género, las cuales integran principalmente las especies de Plagiochila del Neotrópico, Asia y África. Algunas de estas secciones incluyen especies del Cono Sur de Sudamérica, como la sección Duseniae, con Plagiochila dusenii Steph.; la Sección Durae, con P. dura De Not.; y la Sección Arrectae, con P. rubescens (Lehm. \& Lindenb.) Lehm. $\&$ Lindenb.

En la interpretación de las disyunciones continentales de ambas familias de Jungermaniopsida recién tratadas, los datos moleculares apoyan la evolución temprana de los linajes basales en conexión con eventos geológicos asociados a la fragmentación del Gondwana (e.g. Schuster 1979); sin embargo, estos mismos datos muestran que la diversificación de las especies es relativamente reciente y vinculada a la generación de hábitats nuevos asociados a la expansión de los bosques de Angiospermas, después de la fragmentación del Gonwana (Gradstein et al. 2006, Wilson et al. 2007). En las secciones anteriores hemos mencionado ya varios ejemplos de diversificación y expansión neógena relativamente reciente de especies y subespecies, por ejemplo dentro de los géneros: Myrceugenia entre las Angiospermas; Dendroceros y Phaeomegaceros, entre los antocerotes; Polytrichadelphus, Hypopterygium e Hymenodontopsis, entre los musgos; Marchantia polymorpha, Monoclea (Meissner et al. 1998), Jensenia y Pallavicinia, entre las hepáticas. Para el caso de los relictos que nos atañen, la importante proporción de hepáticas colonizadoras de hojas, la presencia de la mayoría de ellas en las islas de Juan Fernández, las amplias distribuciones tropicales, y las notables disyunciones geográficas neotropicales de las especies sugieren eventos de dispersión a larga distancia, probablemente después del levantamiento andino (Heinrichs et al. 2005). Sin embargo, la corta viabilidad de las esporas de las especies epifilas y, en general, la baja tolerancia a la salinidad de las hepáticas foliosas, dificultaría su dispersión y establecimiento en 
espacios abiertos. El desarrollo óptimo de briófitas epífitas y epifilas requiere de nichos especializados, como un dosel arbóreo cerrado y humedad constante en el sotobosque ya que, por sus cualidades poiquilohídricas, reaccionan en forma muy sensible a las variaciones ambientales. En los relictos de neblina, la intercepción y condensación de neblinas es clave para la mantención de estas condiciones ecológicas. Esta "lluvia horizontal" es también esencial para la dispersión de las diminutas hepáticas epifilas, con ciclos de vida muy cortos y adaptados a la limitada vida de una hoja. En general, las epifilas predominan en los bosques lluviosos tropicales, pero su abundancia es mayor en los bosques montañosos nublados del Neotrópico, entre 1.000 y $2.000 \mathrm{~m}$. En el sur de Chile las copiosa y regulares lluvias, y el drenaje desde los suelos y bosques aledaños saturados de humedad, favorecerían el aporte continuo de agua dulce que requieren las comunidades costeras de hepáticas para su colonización (Engel \& Schuster 1973). En bosques templado-lluviosos del sur de Chile han sido estudiadas las interacciones complejas entre las condiciones de luz, la humedad relativa del aire y la posibilidad del bosque para captar neblina, que afectan la abundancia de epifitas y epifilas (Woda et al. 2006).

La integración de las evidencias anteriormente discutidas favorece la interpretación de la comunidad relicta como un remanente de la flora de bosques que poblaron la costa subtropical de Chile a fines del Neógeno. La pérdida de gran parte del área de estos bosques, y la correspondiente expansión de formaciones vegetales xéricas a lo largo del dominio subtropical chileno, se debería al desarrollo de la DA en el Plio-Pleistoceno. Durante las repetidas glaciaciones del Pleistoceno, como lo postulara una hipótesis de Troncoso y colaboradores formulada en 1980 , el clima más húmedo y frío en Chile central-sur, y la eventual intensificación de las frecuencias de neblinas en Chile central-norte, probablemente habría permitido una mayor continuidad de los hábitats de la comunidad relictual a lo largo de la costa de Chile nor-central. Durante los interglaciales más secos se habría producido el refugio y aislamiento de remanentes de bosques relictos en la costa semiárida. Esta dinámica de cambios distribucionales de los bosques subtropical-templados de Chile durante los repetidos ciclos glacial-interglaciales del Cuaternario ha sido ampliamente documentada por el registro fósil de pólen y de macrofósiles que se discute en la última sección. La sobrevivencia cuaternaria de la flora de la comunidad relictual en la costa semi-árida habría sido posible gracias al levantamiento tectónico de las Alturas de Talinay, acaecido en dos fases del Pleistoceno medio ( 670 mil y 325 mil años); esta topografía habría permitido la intercepción de las neblinas costeras proporcionando así los microclimas apropiados para el establecimiento exitoso de las especies (Villagrán et al 2004). Una interesante conclusión de los estudios climáticos más recientes es que la humedad procedente de neblinas, a las cuales se supedita la existencia de los bosques relictos y el establecimiento efectivo de sus epífitas y epifilas, exhibe signo opuesto a la variabilidad de las lluvias regionales que posibilitan el desarrollo del matorral de la región semi-árida (Garreaud et al. 2008). Podemos concluir que las distintas hipótesis planteadas en torno a la cuestión del origen de los relictos no constituyen reales alternativas ya que se conectan a un contexto común. Como lo recalcara ya tempranamente Croizat (1962), el problema del origen de los relictos es complejo y requiere de la consideración de perspectivas y enfoques metodológicos diversos, y contextos tempo/ espaciales adecuados, para responder a tres preguntas distintas pero interrelacionadas: la edad de los fragmentos de bosques aislados que encontramos hoy en las cimas de Talinay, la edad de la comunidad representada y el origen biogeográfico de los elementos componentes de la flora.

GLACIACIONES, CAMBIOS DE LA DIAGONAL ÁRIDA Y RIQUEZA DE BRIÓFITAS La accidentada geomorfología del paisaje de la región templada de Chile constituye la más evidente impronta de la magnitud de los cambios geo-climáticos ocurridos durante las repetidas glaciaciones del Pleistoceno. La investigación glacial se ha focalizado en la región de los Lagos, particularmente en el borde occidental de la cadena de lagos, Seno de Reloncaví y costa oriental de la Isla Grande de Chiloé, un territorio de significativa relevancia biogeográfica por su posición en el borde nor-occidental del Hielo Patagónico, que descendiera hasta mar al sur de Chiloé durante el Ultimo Máximo Glacial (UMG) de la Glaciación Llanquihue (GLL). El límite de extensión máxima que alcanzara el Hielo Patagónico durante el UMG (Fig. 11) ha sido fechado entre 29.400 y 14.450 $\mathrm{C}^{14}$ años $\mathrm{AP}$, con depresiones promedio de temperaturas de verano estimadas en $6-8^{\circ} \mathrm{C}$ (cfr. Denton et al. 1999; Heusser et al. 1999; Veit \& Garleff 1996; Hollin \& Schilling 1981). Las reconstrucciones de las paleo-temperaturas antárticas y las marinas a la latitud de la región de Los Lagos $\left(41^{\circ} \mathrm{S}\right)$, durante los más de 100,000 años que durara la GLL, muestran marcadas oscilaciones, las cuales han sido correlacionadas con los estadíos isotópicos marinos (Marine Isotope Stages, MIS) (Fig. 11). Desde el término del último Interglacial (MIS 5e) se observa que los descensos máximos de temperatura o estadiales son interrumpidos por lapsos relativamente más cálidos o interestadiales: Los lapsos de reavances máximos de glaciares o estadiales han sido fechados entre c. 68.000 y 62.000 años cal (MIS 4) y entre 33.600 y 17.700 años cal (MIS 2 correspondiente al UMG). Los lapsos relativamente más cálidos o interestadiales muestran fechas anteriores a 70.000 años cal (MIS 5a-5d) y entre 60.000 y 25.000 años cal (MIS-3). (cfr. Villagrán et al. 2019). 

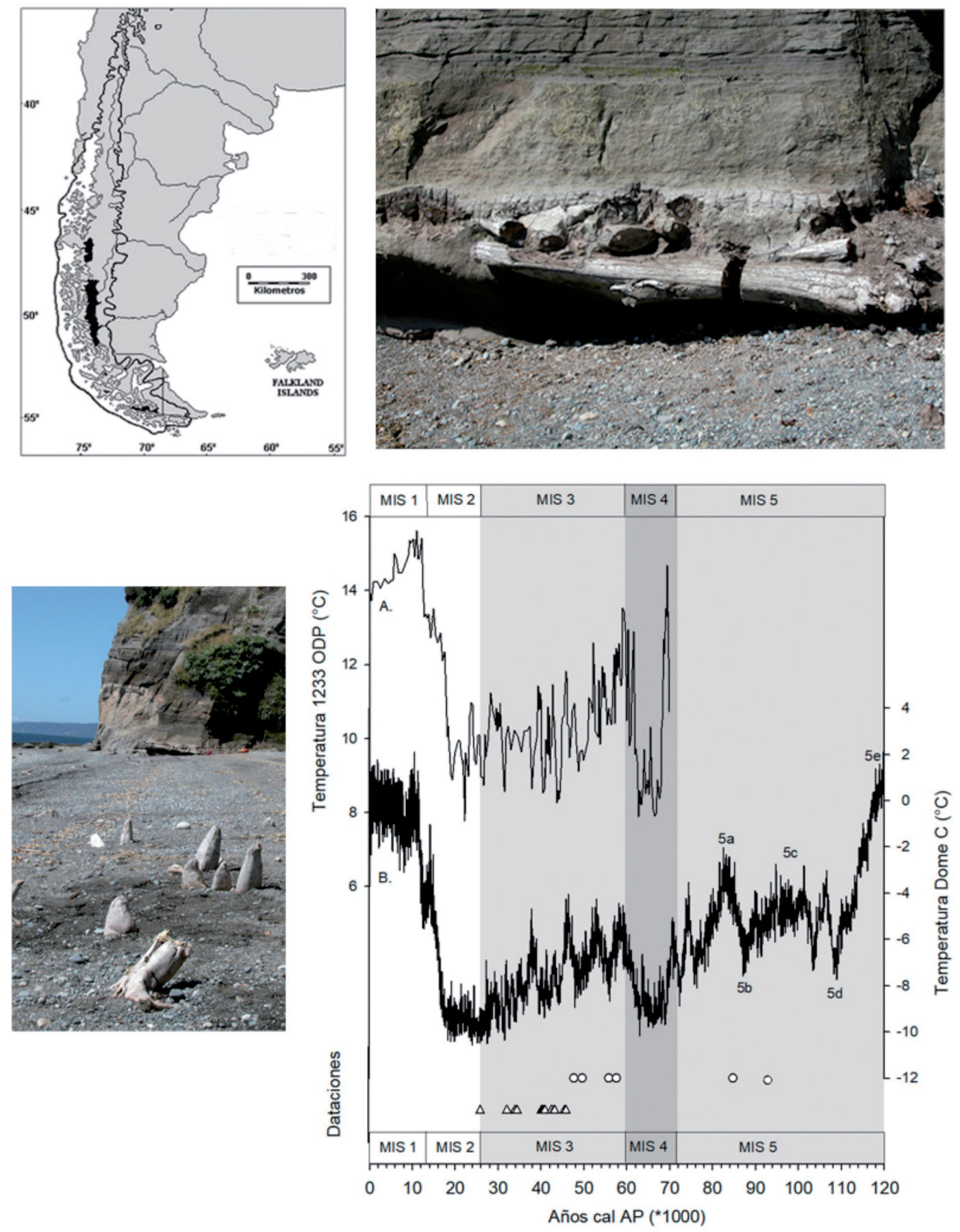

Figura 11. Extensión del Hielo Patagónico durante el último Máximo glacial (UMG) de la Glaciación Llanquihue (GLL) (fuente: Hollin \& Schilling 1981) y reconstrucción de las paleo-temperaturas de Antártica (Dome C) y oceánicas (latitud 41 S, testigo1233-ODP) durante todo el transcurso de la GLL. Se muestra la correlación de las temperaturas con los estadíos isotópicos marinos (MIS-1 a MIS-5). Los símbolos señalan las dataciones finitas disponibles, tanto calibradas (triángulos) como no calibradas (círculos) (fuente: Villagrán et al. 2019). Las fotos muestran troncos fósiles de Fitzroya cupressoides (arriba) y Pilgerodendron uviferum (abajo) del sitio Punta Pirquén en la costa oriental de la Isla Grande de Chiloé (fuente: Villagrán et al. 2004b). / Extension of the Patagonian ice during the Last Glacial Maximum (LGM) of the Llanquihue Glaciation (GLL) (source: Hollin \& Schilling 1981) and reconstruction of the Antarctic (Dome C) and oceanic paleo-temperatures (latitude $41^{\circ} \mathrm{S}$, Core 1233-ODP) during the entire course of the GLL. The correlation of temperatures with the marine isotopic stages (MIS-1 to MIS-5) is shown. The symbols indicate the available finite data, both calibrated (triangles) and uncalibrated (circles) (source: Villagrán et al. 2019). The photos show fossil woods of Fitzroya cupressoides (top) and, Pilgerodendron uviferum (bottom) from the Punta Pirquén site on the eastern coast of Chiloé's Isla Grande (source: Villagrán et al. 2004b). 
Recientemente, el registro paleobotánico de sitios glaciales se ha extendido temporalmente a todo el transcurso de la GLL, abarcando lapsos interestadiales poco investigados. Las evidencias paleo-ecológicas proceden de más de una treintena de hallazgos de troncos fósiles, madera, polen y macro-restos vegetales contenidos en capas orgánicas de depósitos glaciales costeros, distribuidos discontinuamente en las regiones de Los Ríos y de Los Lagos (Abarzúa et al. 202012; Villagrán et al. 2019, 2004b; Gómez 2019; Roig et al. 2001; Heusser 1981; Klohn 1976). Los depósitos más antiguos proceden de la costa de Valdivia y han sido fechado en 94.000 OSL ${ }^{13}$ años AP, lapso correspondiente al estadío MIS $5 c$, uno de los primeros interestadiales de la GLL. La mayoría de los restantes sitios fosilíferos han sido fechados entre en 38.740 $C^{14}$ años AP y 61.000 años AP, edades correspondientes al lapso interestadial MIS 3. Estos sitios exhiben alternancia de capas de limos lacustres y turbas que subyacen a los depósitos del UMG. Las capas orgánicas contienen poblaciones de troncos sub-fósiles en excelente estado de preservación y, entre las maderas examinadas, destacan coníferas tales como alerce (Fitzroya cupressoides (Molina) I.M. Johnst. ), ciprés de las Guaitecas (Pilgerodendron uviferum (D.Don) Florin) (Fig. 11), mañíos (Saxegothaea conspicua Lindl., Podocarpus nubigena Lindl.), asociadas a Nothofagaceae como Nothofagus betuloides (Mirb.) Oerst, y N. dombeyi (Mirb.) Oerst., coihue. Esta composición y el espectro de polen asociado, con registro de taxa de hábitats de humedales, sugiere el desarrollo de un mosaico vegetacional de bosque NordpatagónicoSubantártico, turberas de Cyperaceae y tundras magallánicas, ambiente indicador de condiciones climáticas muy lluviosas durante los interestadiales relativamente más cálidos de la GLL temprana a media.

La vegetación imperante durante la GLL tardía, en el lapso correspondiente al UMG (MIS 2) y fechado entre 29,400 y $14,550 C^{14}$ años AP (Fig. 11), es documentada por registros polínicos continuos procedentes de Chiloé y Biobío (Abarzua et al. 2014; Heusser et al. 1999; Villagrán 1988, 1990). El espectro polínico registrado revela un escenario paleoecológico con comunidades de tundras magallánicas, con cojines de Astelia pumila (G. Forst.) R.Br., Donatia fascicularis J.R. Forst. \& G. Forst., Lepidothamnus fonckii Phil., Poaceae y Asteraceae, en coexistencia con bosquetes de Nothofagus y coníferas. La flora de tundras magallánicas, con requerimientos templado-fríos y muy lluviosos, pertenece principalmente al

\footnotetext{
${ }^{12}$ Comunicación de: Abarzúa, A. M., Martel-Cea, A., Hidalgo, B., Vega, R. y Pino, M. Vegetación y clima durante MIS-5 en la costa valdiviana. LXII Reunión Anual Sociedad de Biología de Chile. p. 64. Valdivia, Chile, Marzo 2020.

${ }^{13}$ OSL, Optically Stimulated Luminescence (luminiscencia estimulada ópticamente).
}

elemento austral-antártico de los ecosistemas de bosques chilenos y se distribuye hoy continuamente al sur de $49^{\circ}$ $\mathrm{S}$, con rangos montañosos disyuntos en las regiones de Los Ríos y de Los Lagos. La presencia de este elemento en sitios de baja altitud de ambas regiones durante la GLL evidencia una distribución más amplia y continua en el Valle Longitudinal de estos territorios, área ocupada actualmente por bosques templado-lluviosos más calidófilos dominados por angiospermas. Siguiendo al colapso de los glaciares piedemontes, numerosos registros polínicos del Tardiglacial, después de 14.000 años AP, y Holoceno (últimos 11.700 años AP, (MIS 1, Fig 11) documentan la rápida expansión del bosque Nordpatagónico, seguida por el bosque Valdiviano, en los sitios bajos de las regiones de Los Lagos y de Los Ríos (cfr. modelo Villagrán 2001). Paralelamente, y durante estos mismos lapsos temporales, los registros polínicos de mayor altitud evidencian el ascenso altitudinal de las Coníferas y tundras en ambas cordilleras de estas regiones (Heusser 1982; Villagrán 1991, 1980), y el inicio de la colonización en las áreas glaciadas de las regiones de Aysén y Magallanes (Bennett et al 2000; Lumley \& Switsur 1993) y Magallanes (Heusser 1989).

Los escasos antecedentes de macro-fósiles de briófitas registrados para el último ciclo glacial-interglacial del Pleistoceno son concordantes con los cambios climáticovegetacionales recién descritos. En la Tabla 6 se muestra la posición geográfica y edades de los depósitos documentados para la Región de Los Lagos y de Los Ríos y en la Tabla 7 se listan los macrofósiles de musgos de estos sitios y los autores de las especies que se citan en los siguientes párrafos: (i) Un depósito del Holoceno Medio de la costa NO de la isla de Chiloé (Fig. 12) (Londoño et al. 2020) registra polen e improntas foliares que evidencian desarrollo de bosque tipo Valdiviano costero en el área, con predominio de Aextoxicon punctatum y distintas especies de Myrtaceae; entre estas últimas, árboles indicadores de comunidades con humedad edáfica, como el chequén, Luma chequen (Molina) A.Gray, Blepharocalyx sp. y Myrceugenia sp., sugieren una densa vegetación local de bosques azonales asociados a ambientes pantanosos o ribereños. (ii) Un paleo-ambiente local similar ha sido documentado para un depósito cercano y de edad equivalente, situado en la desembocadura del Río Huicha (Gómez 2019). La presencia de restos foliares de fuinque, Lomatia ferruginea (Cav.) R.Br., Drimys winteri y diversas Myrtaceae sugiere desarrollo de bosques densos y húmedos en las proximidades del sitio. En concordancia con las condiciones ecológicas sugeridas por el polen y los restos foliares, los macrofósiles de musgos registrados en ambos sitios corresponden en gran medida a especies que habitan comúnmente en bosques, algunas epífitas como Weymouthia cochearifolia y W. mollis, otras en suelos o en la base de troncos 
muy húmedos bajo dosel cerrado, como Rigodium toxarium y especies de Porothamnium (Tabla 7, columnas 1 y 2). (iii) También para el Holoceno medio, el registro de macrorestos foliares de la secuencia Río Caunahué I (Tabla 6), en la precordillera de la región de Los Ríos (Castillo et al. 2011) ${ }^{14}$, documenta desarrollo local de Bosque Nordpatagónico, representado por Nothofagus dombeyi; tineo, Weinmannia trichosperma Cav.; tepa, Laureliopsis philippiana, asociado a componentes valdivianos como ulmo, Eucryphia cordifolia Cav. y Aextoxicon punctatum. Entre los macrofósiles de musgos, el sitio registra especies asociadas a hábitats acuáticos, como Vittia pachyloma, Racomitrium lamprocarpum y Warnstorfia sarmentosa. Sin embargo, es interesante destacar que el conjunto de especies asociadas a bosques con dosel cerrado son compartidas con los depósitos litorales Huapilacuy II y Río Huicha (Tabla 7, columnas 1, 2, 3), pese a la composición arbórea distinta de estos sitios.

En comparación con los tres sitios precedentes, otros depósitos de las regiones de Los Ríos y Los Lagos muestran un marcado contraste en la composición de macrofósiles de briófitas (Tabla 7, columna 4, 5, 6): (i) El análisis de polen de dos turberas del Holoceno Medio a Tardío, situadas en los Andes de la región de Los Lagos (Villagrán 1980), registra desarrollo regional de bosque deciduo de raulí/ roble, Nothofagus tipo alpina (Poepp. \& Endl.) Oerst. /obliqua (Mirb.) Oerst. en asociación con bosques perennifolios de Nothofagus tipo dombeyi y coníferas. El examen de macrorestos vegetales evidencia fases locales de expansión de turberas del musgo Drepanocladus, en alternancia con turbas de Cyperaceae, Juncaceae y Juncaginaceae, ensambles que sugieren desarrollo local de "turberas pradeñas de
Cyperaceae" (Seggenwiesenmoore) y de "turberas marrones" (Braunmoore), de acuerdo con la clasificación propuesta para Tierra del Fuego por Roivainen (1954). En concordancia con este ambiente, los macro-restos de briófitas rescatados corresponden a especies de turberas de amplia distribución en la región templada de Chile (Tabla 7, Fig 13), a excepción de Scorpidium revolvens, a la fecha reportado solamente para Magallanes (Müller 2009). (ii) Río Caunahue II, en la precordillera de la región de Los Ríos (Castillo et al. 2011), registra macrorestos foliares mayormente de Nothofagus dombeyi durante la transición Pleistoceno/Holoceno. El lapso exhibe una gran diversidad y abundancia de especies de musgos de hábitats abiertos, sea sobre el suelo, sea en turberas o en hábitats acuáticos (Tabla 7). Todas estas especies tienen hoy rangos extensos de distribución en la región subtropicaltemplada de Chile, a excepción de Distichophyllum fuegianum restringida hoy a algunas islas del extremo austral del territorio chileno-argentino, y Bryum densifolium, registrada solo en Ñuble. (iii) Para el depósito Molulco, situado en el Golfo de Compu, Chiloé, correspondiente al lapso interestadial MIS-3 de la última glaciación Llanquihue, se han estudiado maderas, polen y macro-restos (Villagrán et al. 2019, 2004 b, 1995). El espectro polínico muestra predominio arbóreo de Nothofagus tipo dombeyi, asociado a la conífera Fitzroya cupressoides. El examen de macro-restos fósiles registra vegetación palustre y acuática representada por Asteraceae, Poaceae (Anthoxanthum), utrículos de Juncaceae (Juncus) y de Cyperaceae (Carex, Eleocharis) y micro- y megasporas del helecho acuático Isoetes savatieri Franchet. Entre los musgos se registran especies de Bryum y otras aún no determinadas y cercanas a Amblystegiaceae.

TABLA 6. Situación geográfica y edades de los sitios fosilíferos con macrofósiles de musgos de las Regiones de Los Ríos y de Los Lagos, Chile. / Geographic location and ages of the fossiliferous sites with macrofossils of mosses from the Los Ríos and Los Lagos Regions, Chile.

\begin{tabular}{lccl}
\hline \multicolumn{1}{c}{ Sitios fosilíferos } & Lat. S-Long. O & Altitud m s.n.m. & \multicolumn{1}{c}{ Años AP } \\
\hline 1. Huapilacuy II & $41^{\circ} 47^{\prime}-73^{\circ} 54^{\prime}$ & litoral & $6450 \pm 30 / 6060 \pm 30 \mathrm{C}^{14}$ \\
2. Río Huicha & $41^{\circ} 51^{\prime}-73^{\circ} 44^{\prime}$ & litoral & $6119 \pm 25 \mathrm{C}^{14}$ \\
3. Río Caunahué I & $40^{\circ} 07^{\prime}-72^{\circ} 14^{\prime}$ & 140 & $4994 / 5300 \mathrm{cal}$ \\
4a. El Frutillar & $41^{\circ} 19^{\prime}-72^{\circ} 23^{\prime}$ & 920 & $2390 \pm 70 \mathrm{C}^{14}$ \\
4b. La Cumbre & $41^{\circ} 03^{\prime}-71^{\circ} 49^{\prime}$ & 975 & $6335 \pm 70 \mathrm{C}^{14}$ \\
5. Río Caunahué II & $40^{\circ} 07^{\prime}-72^{\circ} 14^{\prime}$ & 140 & $15.446 / 13.214 \mathrm{cal}$ \\
6. Molulco & $42^{\circ} 51^{\prime}-73^{\circ} 45^{\prime}$ & 24 & $>45.000 \mathrm{C}^{14}$ \\
\hline
\end{tabular}

\footnotetext{
${ }^{14}$ Comunicación de Castillo, L., Larraín, J., Vera, F., Pérez, F., Hinojosa, L.F. 2011. Diversidad de paleobriófitas en depósito de macrorrestos vegetales en río Caunahue, Chile. En: XXII Reunión Anual Sociedad de Botánica de Chile, Resumen 168. Puerto Varas, Chile.
} 


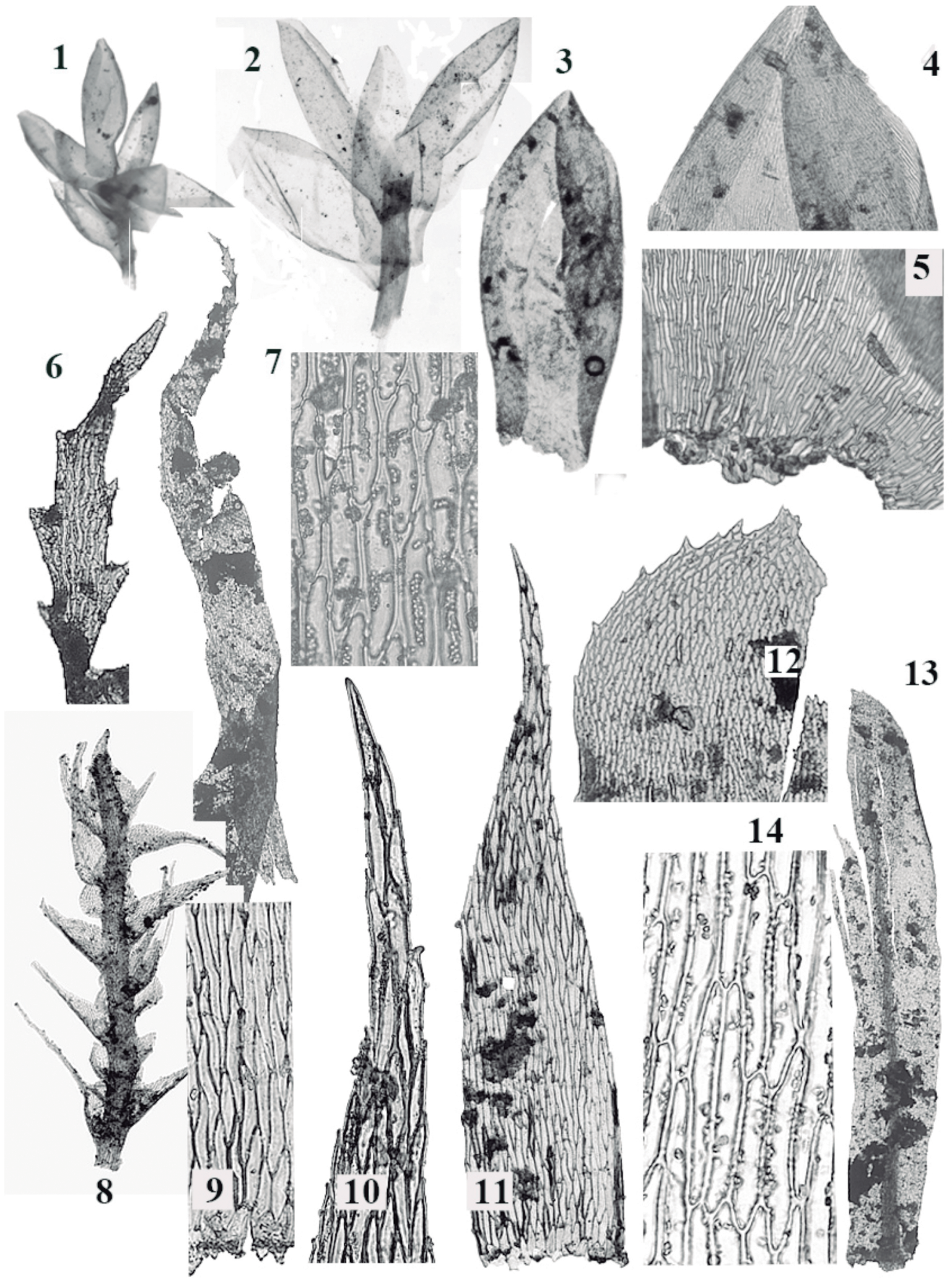

Figura 12. Macro-restos de musgos del sitio Huapilacuy II del Holoceno Medio, costa NW Chiloé, Región de Los Lagos, Chile: 1-5 Weymouhia cochlearifolia. 6-7 Ptychomnium cygnisetum. 8 Rigodium cfr. toxarium. 9-11 Eucamptodon perichaetialis. 12-14 Porothamnium arbusculans (fuente: Londoño et al. 2020). / Macro-rests of mosses from the Middle Holocene site Huapilacuy II, NW Chiloé coast, Los Lagos Region, Chile: 1-5 Weymouhia cochlearifolia. 6-7 Ptychomnium cygnisetum. 8 Rigodium cfr. toxarium. 9-11 Eucamptodon perichaetialis. 12-14 Porothamnium arbusculans (source: Londoño et al. 2020). 
TABLA 7. Composición florística de los macro-restos de musgos registrados para sitios fosilíferos del último ciclo glacial interglacial en las Regiones de Los Lagos (LL) y de Los Ríos (LR) del sur de Chile. Los geositios se señalan con números 1-6: Huapilacuy II (columna 1), Río Huicha (2), Río Caunahué I (3), Frutillar/La Cumbre (4), Río Caunahué II (5), Molulco (6). Hábitats (H) preferentes de las especies: S, Suelo; A, Acuáticos; T, Turberas; B, Bosques. Elementos biogeográficos (EB): E, Endémico; CC, Circum-subantártico; AA, AustralAntártica; STT, Sudamérica templada/tropical; TA, Templado amplio; Sc, Subcosmopolita. Especies en relictos de neblina de la zona semi-árida de Chile se señalan con *. En Antártica chilena**. (+) Andes tropicales; (++) También en África. / Floristic composition of the macro-rests of mosses recorded for fossiliferous sites of the last interglacial-glacial cycle in the Los Lagos (LL) and Los Ríos (LR) regions of southern Chile. The geosites are indicated with numbers 1-6: Huapilacuy II (column 1), Río Huicha (2), Río Caunahué I (3), Frutillar / La Cumbre (4), Río Caunahué II (5), Molulco (6), Interestadial MIS-3. Preferred habitats (H) of the species: S, Soil; A, Aquatic; T, Peatlands; B, Forests. Biogeographic Elements (EB): E, Endemic; CC, Circum-subantarctic; AA, Austral-Antarctic; STT, temperate / tropical South America; TA, Broad Temperate; Sc, Subcosmopolitan. Species also of relict cloud forests from the semi-arid zone of Chile are indicated

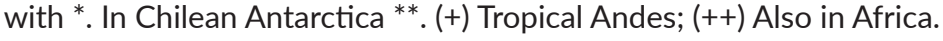

\begin{tabular}{|c|c|c|c|c|c|c|c|c|c|}
\hline Macrofósiles musgos & Familia & 1 & 2 & 3 & 4 & 5 & 6 & $\mathrm{H}$ & EB \\
\hline Porothamnium panduraefolium (Mill. Hal.) Mitt & Neckeraceae & & & $\mathrm{x}$ & & $\mathrm{x}$ & & $\mathrm{B}$ & $\mathrm{E}$ \\
\hline Zygodon pentastichus (Mont.) Müll. Hal. & Orthotrichaceae & & & $x$ & & $x$ & & $\mathrm{~B}, \mathrm{~T}$ & STT \\
\hline Hymenodontopsis mnioides Bell, Newton \& D.Quandt & Aulacomniaceae & & $\mathrm{x}$ & $\mathrm{x}$ & & & & $\mathrm{B}, \mathrm{T}$ & AA \\
\hline Porothamnium arbusculans (Mill. Hal.) Ochyra & Neckeraceae & $\mathrm{x}$ & & $x$ & & $\mathrm{x}$ & & B & $E^{*}$ \\
\hline Rigodium toxarion var. toxarion (Schwaegr.) Jaeg. & Lembophyllaceae & $\mathrm{x}$ & $\mathrm{x}$ & $x$ & & & & B & $\mathrm{STT}^{*}++$ \\
\hline Weymouthia cochlearifolia (Schwägr.) Dixon. & Lembophyllaceae & $x$ & & $x$ & & $x$ & & B & AA \\
\hline Weymouthia mollis (Hedw.) Broth & Lembophyllaceae & $\mathrm{x}$ & $x$ & $x$ & & $x$ & & $\mathrm{~B}$ & $\mathrm{AA}^{*}$ \\
\hline Eucamptodon perichaetialis (Mont.) Mont. & Dicranaceae & $\mathrm{x}$ & & & & & & $\mathrm{T}$ & $\mathrm{E}$ \\
\hline Scorpidium revolvens (Sw.) Rubers & Amblystegiaceae & & & & $x$ & & & $\mathrm{~T}$ & TA \\
\hline Brachythecium sp. & Brachytheciaceae & & & $x$ & $x$ & & & $\mathrm{~T}$ & $i$ \\
\hline Breutelia cfr. integrifolia (Taylor) A. Jaeger & Bartramiaceae & & & $x$ & $x$ & & & $\mathrm{~T}$ & $\mathrm{CC}+$ \\
\hline Syntrichia robusta Zander & Pottiaceae & & & & $x$ & & & $\mathrm{~T}$ & AA \\
\hline Racomitrium lamprocarpum (Müll.Hal.) A.Jaeger & Grimmiaceae & & & $\mathrm{x}$ & & & & A & STT++ \\
\hline Warnstorfia sarmentosa (Wahlenb.) Hedenas & Amblystegiaceae & & & $x$ & & & & A & $\mathrm{TA}+$ \\
\hline Vittia pachyloma (Mont.) Ochyra & Amblystegiaceae & & & $x$ & & & & A & $\mathrm{CC}++$ \\
\hline Drepanocladus longifolius (Mitt.) Broth. ex Paris & Amblystegiaceae & & & & & $x$ & & A & $\mathrm{TA}^{* *}+$ \\
\hline Hypnum campoanum Brotherus & Hypnaceae & & & & & $x$ & & $\mathrm{~S}$ & E \\
\hline Blindia magellanica Schimp. & Selogeriaceae & & & & & $\mathrm{x}$ & & $\mathrm{S}$ & TA \\
\hline Breutelia dumosa Mitt. & Bartramiaceae & & & & & $\mathrm{x}$ & & $\mathrm{S}$ & $\mathrm{E}$ \\
\hline Philonotis krausei Brotherus & Neckeraceae & & & & & $x$ & & $\mathrm{~S}$ & $\mathrm{E}+$ \\
\hline Pohlia nutans (Hedw.) Lindb. & Mniaceae & & & & & $x$ & & $\mathrm{~T}, \mathrm{~S}$ & TA \\
\hline Pohlia wahlenbergii Andrews & Mniaceae & & & & & $x$ & & $\mathrm{~S}$ & $\mathrm{TA}^{* *+}$ \\
\hline Racomitrium didymum (Mont.) Lorentz & Grimmiaceae & & & & & $x$ & & $\mathrm{~S}$ & AA \\
\hline Symblepharis krausei (Lorentz) Ochyra \& Matteri & Dicranaceae & & & & & $\mathrm{x}$ & & A & $\mathrm{E}^{* *}$ \\
\hline Amblystegiaceae & Amblystegiaceae & & & & & $x$ & $\mathrm{x}$ & $i$ & $i$ \\
\hline Bryum spp. & Byaceae & & & & & & $x$ & $i$ & $\dot{i}$ \\
\hline Bryum cfr. argenteum Hedwig & Bryaceae & & & & & & $x$ & $\mathrm{~S}$ & $\mathrm{Sc}$ \\
\hline
\end{tabular}




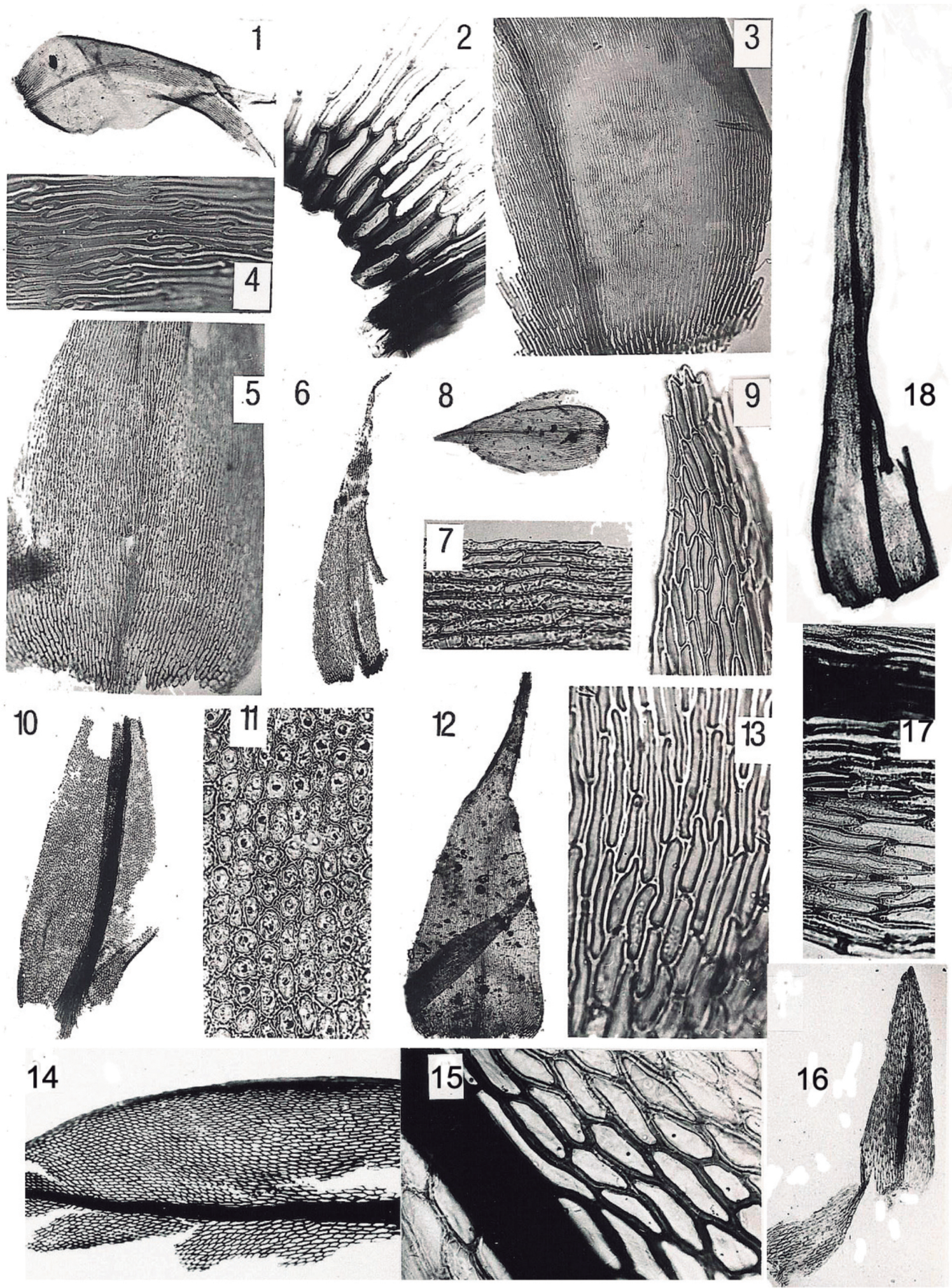

Figura 13. Macro-restos de musgos de dos turberas andinas de la Región de Los Lagos, La Cumbre y El Frutillar: 1-4 Scorpidium revolvens. 5-7 Warnstorfia fluitans. 8-9 Brachythecium sp. 10-11 Syntrichia robusta. 12-13 Drepanocladus sp. 14-15 Bryum cfr. laevigatum. 16-17 Hygroamblystegium sp. 18 Breutelia cfr. integrifolia (fuente: Villagrán 1980). / Macro-rests of mosses from two Andean peat bogs in the Los Lagos Region, La Cumbre and El Frutillar: 1-4 Scorpidium revolvens. 5-7 Warnstorfia fluitans. 8-9 Brachythecium sp. 1011 Syntrichia robusta. 12-13 Drepanocladus sp. 14-15 Bryum cfr. laevigatum. 16-17 Hygroamblystegium sp. 18 Breutelia cfr. integrifolia (source: Villagrán 1980). 
En síntesis, la comparación regional y temporal de los ensambles de macrofósiles de musgos permite establecer algunas diferencias florísticas y biogeográficas entre los sitios reseñados. Por una parte, se observa una cierta homogeneidad en la composición de musgos asociados a los bosques con dosel cerrado que caracterizan los tres primeros depósitos, independientemente de la distinta composición arbórea. Las especies comunes a estos tres sitios fosilíferos se desarrollan hoy en diferentes tipos laurifolios de bosques subtropicales y templado-lluviosos chilenos, con amplios rangos de distribución que se extienden generalmente desde Biobío/Valdivia hasta Aysén/Magallanes, algunas disyuntas con los relictos de neblina de la costa semi-árida de Coquimbo, como se destacara anteriormente (Müller, 2009; Villagrán et al. 2005, 2004). Oberdorfer (1960) subraya que los ensambles de criptógamas asociadas a los bosques laurifolios de Chile conforman un estrato propio, no imputable a ninguna asociación forestal en particular. Así, taxa tales como, Porothamnium arbusculans y especies de Weymouthia, son clasificados en general como especies características de los "bosques laurifolios templado-lluviosos del sur de Chile" (Clase Wintero-Nothofagetea Oberdorfer). En lo referente a la distribución global, varios taxa pertenecen al componente biogeográfico endémico del territorio, como las especies de Porothamnium; o al austral-antártico, como las especies de Weymouthia; o extienden sus rangos en Sudamérica hasta los Andes del Neotrópico, como Zygodon pentastichus, y Rigodium toxarium o sur de Brasil, como Ptychomnium cygnisetum (Tabla 7). Por otra parte, y en contraste con este ensamble de musgos asociados a bosques, los registros alto-andino del Holoceno Medio, y los registros tardiglacial e interestadial, muestran una composición de especies con distribución más amplia en el planeta, la cual se asocia a paleo-comunidades tipo mosaico de parque arbolado y vegetación abierta de turberas, suelos o acuáticas. En relación a la composición biogeográfica, la mayoría de estas especies se encuentran en las zona templadas de ambos hemisferios, como Scorpidium revolvens, Warnstorfia fluitans, Blindia magellanica, Dicranella campylophylla, Pohlia nutans, algunas distribuidas desde la Antártica chilena hasta los altos Andes neotropicales, como Drepanocladus longifolius y Pohlia wahlenbergii. Otras especies se retringen a las regiones templadas del Hemisferio Sur, sean endémicas del sur de Sudamérica, como Hypnum campoanum, Distichophyllum fuegianum, Philonotis krausei; sean australantárticas, como Dicranoloma billardierei, Fissidens rigidulus, Racomitrium didymum; sean circum-subantárticas, como Bryum cfr. laevigatum y Breutelia cfr. integrifolia (Tabla 7).

Aunque no existe registro de hepáticas en depósitos fosilíferos de Chile, algunos rasgos de sus hábitats y distribución actual sugieren una historia similar a la de los musgos. Por ejemplo, un muestreo altitudinal de los ensambles de hepáticas epífitas asociadas a los bosques Valdiviano, Nordpatagónico y Subantártico con coníferas, en la Cordillera de la Costa de Chiloé (Villagrán et al. 2005) (Fig. 14) muestra los siguientes rasgos: (i) La mayoría de la especies son comunes a todos los tipos forestales representados en el gradiente altitudinal, destacando por sus mayores frecuencias especies de Plagiochila, como P. chonotica Taylor, P. flexicaulis Mont, P. rubescens (Lehm. \& Lind.) Lehm. \& Lind. y P. bispinosa Lind.ex Gottsche, además de Bazzania peruviana (Nees) Trevis y Tylimanthus kunkeliii ${ }^{15} \mathrm{Hässel} \&$ Solari. (ii) Un grupo se restringe a los escalones superiores del transecto, sobre 450 m, dominados por un mosaico de bosques NordpatagónicoSubantártico, coníferas como Fitzroya cupressoides y Pilgerodendron uviferum, y hábitats abiertos de tundras magallánicas. (iii) En lo que concierne a la distribución chilena, todas las especies del transecto examinado ostentan rangos de distribución amplios en el territorio, algunas en los relictos de neblina como Plagiochila heterodonta (Hook.f. \& Taylor) Gottsche, extendiéndose la mayoría hasta Magallanes. Una excepción es $P$. rubescens, que se distribuye desde Valparaíso a Aysén. La amplitud de los rangos de distribución de las hepáticas es consistente con la composición relativamente homogénea que exhibe la mayoría de las especies de musgos asociadas a los distintos tipos de bosques templado-lluviosos de Chile. Concordantemente, el examen de la relación entre la amplitud de los rangos de distribución y la riqueza de especies de musgos, hepáticas y antocerotes no muestran una tendencia latitudinal significativa dentro de la zona templada (Fig.15). Este patrón contrasta con el observado en las angiospermas de los bosques chilenos, las cuales muestran una tendencia significativa de disminución de la riqueza de especies con el incremento de amplitud de los rangos latitudinales (Arroyo et al. 1996).

En síntesis, de los antecedentes paleobotánicos reseñados se desprende que la región chilena situada en el margen NO del Hielo Patagónico ha sido ocupada sucesivamente por diversas comunidades templado-lluviosas durante el último ciclo glacial-interglacial del Cuaternario. Esta dinámica ha dejado una profunda "marca biogeográfica" en la distribución y riqueza de las briófitas. Así, uno de los máximos en la concentración de especies del grupo, situado en las regiones de Los Ríos y de Los Lagos, puede ser interpretado como remanente de la expansión glacial hacia latitudes bajas que experimentaron las comunidades australes, adaptadas a condiciones templado-frías (Villagrán et al. 2005). Testimonio actual de esta dinámica histórica es, por ejemplo, la presencia del grupo de hepáticas subantárticas aisladas en las cimas de

\footnotetext{
${ }^{15}$ Se conserva nombre T. kunkelii con que la especie es consignada en Catálogo Hässel \& Rubies 2009.
} 
la Cordillera de Piuchué recién mostrada. Un patrón similar ha sido documentado para las angiospermas del complejo de Tundras Magallánicas, una comunidad vegetal exclusiva de Austrosudamérica que hoy tiene continuidad en la región de Aysén, al sur del Archipiélago de las Guaitecas. Al norte de esta región, la comunidad es discontinua y aislada en cimas andinas, y particularmente en la Cordillera de la Costa, entre $36^{\circ}$ y $40^{\circ} \mathrm{S}$, con hiatos distribucionales que alcanzan varios cientos de kilómetros (Ruthsatz \& Villagrán 1991). Por otra parte, probablemente los rangos de numerosas especies de briófitas asociadas a bosques más calidófilos habrían sido alcanzados durante el calentamiento del Holoceno Temprano a Medio, como lo muestran los registros de polen, hojas y macrorestos fósiles documentados anteriormente.

Entre las preguntas planteadas en la introducción se buscaba una explicación para los altos niveles de diversidad y endemismo de las briófitas de la región templada y los patrones bimodales en la concentración de la riqueza, con máximos en las regiones de Los Ríos/ Los Lagos y en Magallanes. Se ha planteado una hipótesis que atribuye este rasgo común a ambas regiones como una consecuencia de la adición de especies pertenecientes a las distintas comunidades templado-lluviosas que habrían ocupado tanto los bordes NO como SE del Hielo Patagónico (Villagrán et al. 2005, 2019). La persistencia de la flora de briófitas en áreas muy húmedas, aledañas a las severamente afectadas por la cercanía de glaciares, sería una consecuencia de su reducido tamaño, rasgo que habría permitido su sobrevivencia en pequeños refugios o «microrefugios», por ejemplo, en fragmentos discontinuos de bosques, poblaciones o individuos aislados de árboles dentro de las zonas afectadas. En el caso particular de Magallanes, el máximo en la riqueza de especies y endemismos de briófitas observado guardaría estrecha relación con la posición del margen SE del Hielo Patagónico en el área. La región fue cubierta prácticamente en su totalidad por glaciares durante la GLL y la recolonización desde el norte habría sido alcanzada gradualmente, en concomitancia con el retroceso del hielo, como lo sugiere el gradiente de disminución de la riqueza observado hoy entre Chiloé y Aysén. Sin embargo, el máximo de endemismos y de riqueza de especies en Magallanes exige la consideración de un efecto sumatorio de recolonización postglacial, probablemente desde refugios de los sectores insulares muy oceánicos del extremo SE del continente. En el Cono Sur de América, la región austral situada al este del Canal Beagle constituye un área de margen glacial, específicamente el borde Atlántico SE del Hielo Patagónico. La importancia de esta fuente de procedencia de poblaciones de briófitas es sugerida por las líneas isopolen, trazadas sobre la base de los registros de polen de Magallanes, las cuales señalan un patrón de recolonización postglacial de sentido este-oeste (Villagrán et al. 1995). Asimismo, un examen biogeográfico de las plantas vasculares de Tierra del Fuego (Posadas 1996) muestra que las áreas con mayor grado de endemismo se distribuyen al SE del Canal Beagle y en Isla Navarino. En concordancia con este patrón, la distribución latitudinal actual de la riqueza de hepáticas y antocerotes a lo largo de Argentina e islas adyacentes, exhibe un considerable máximo en el extremo sudeste del continente, en Tierra del Fuego e islas Navarino y De los Estados, con valores cercanos al doble que las regiones adyacentes de estepa patagónica situadas hacia el noroeste, y más de cinco veces mayores que el resto del territorio argentino (Fig. 16. Hässel \& Rubies 2009).

\section{En conclusión:}

(i) Los repetidos cambios de distribución que han experimentado los ecosistemas templado-lluviosos de Chile durante los ciclos glacia-interglaciales del Cuaternario habrían posibilitado la evolución de los nichos de Briófitas, e incrementado su riqueza a partir de los arcaicos linajes Cretácico-Terciarios.

(ii) Las regiones con clima oceánico adyacentes al Hielo Patagónico, tanto del borde pacífico como atlántico, habrían constituido reservorios glaciales y fuentes para la dispersión de especies de briófitas en el Holoceno y esta dinámica se reflejaría en la actual concentración y distribución bimodal de la riqueza del grupo en la zona templada del Cono Sur.

(iii) La riqueza de briófitas de los bosques templado-lluviosos de Chile constituye un importante patrimonio botánico como núcleo de biodiversidad de la nación. 


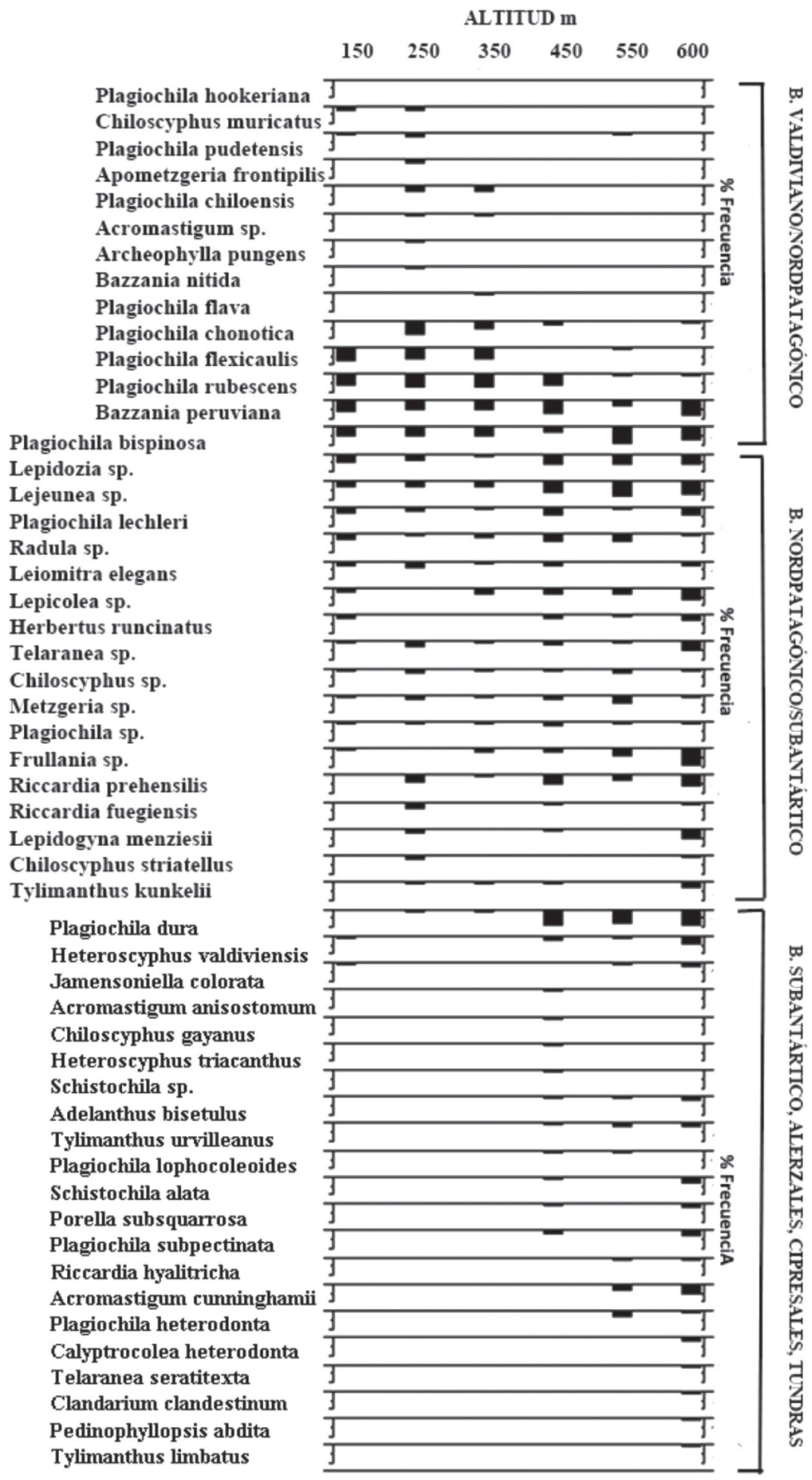

Figura 14. Variación altitudinal de las frecuencias de hepáticas epífitas en la vertiente oriental de la Cordillera de Piuchué, Isla Grande de Chiloé. Las frecuencias relativas fueron obtenidas en un muestreo de 10 árboles en seis escalones altitudinales entre 150 y $600 \mathrm{~m}$ s.n.m. (modificado de Villagrán, Hässel de Menéndez \& Barrera 2005). / Altitudinal variation in the frequencies of epiphytic liverworts on the eastern slope of the Piuchué Cordillera, Isla Grande de Chiloé. Relative frequencies were obtained from a sampling of 10 trees in six altitudinal steps between 150 and 600 m a.s.l. (modified from Villagrán, Hässel de Menéndez \& Barrera 2005). 

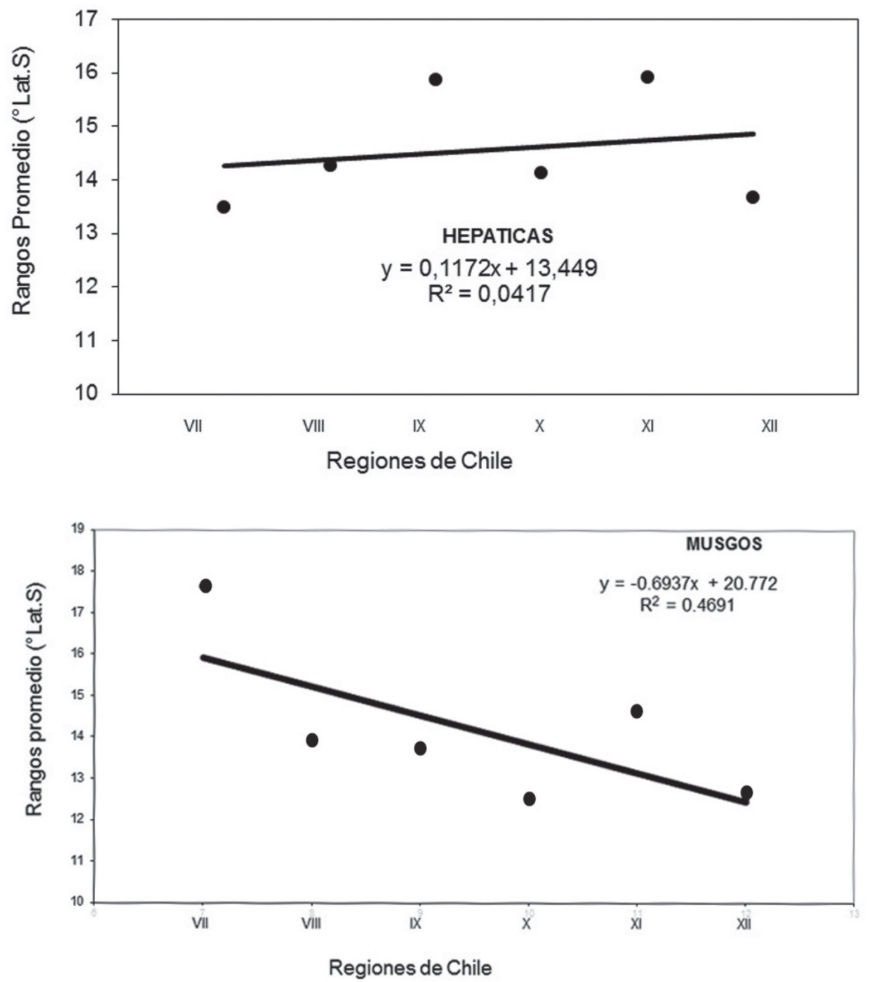

Figura 15. Relación entre amplitud de rangos latitudinales promedio de distribución y riqueza de especies de hepáticas y de musgos a lo largo de las regiones administrativas de Chile (datos de Hässel \& Rubies 2009; He 1998). / Relationship between mean latitudinal range amplitude of distribution and species richness of liverworts and mosses along the administrative regions of Chile (data from Hässel \& Rubies 2009, He 1998).

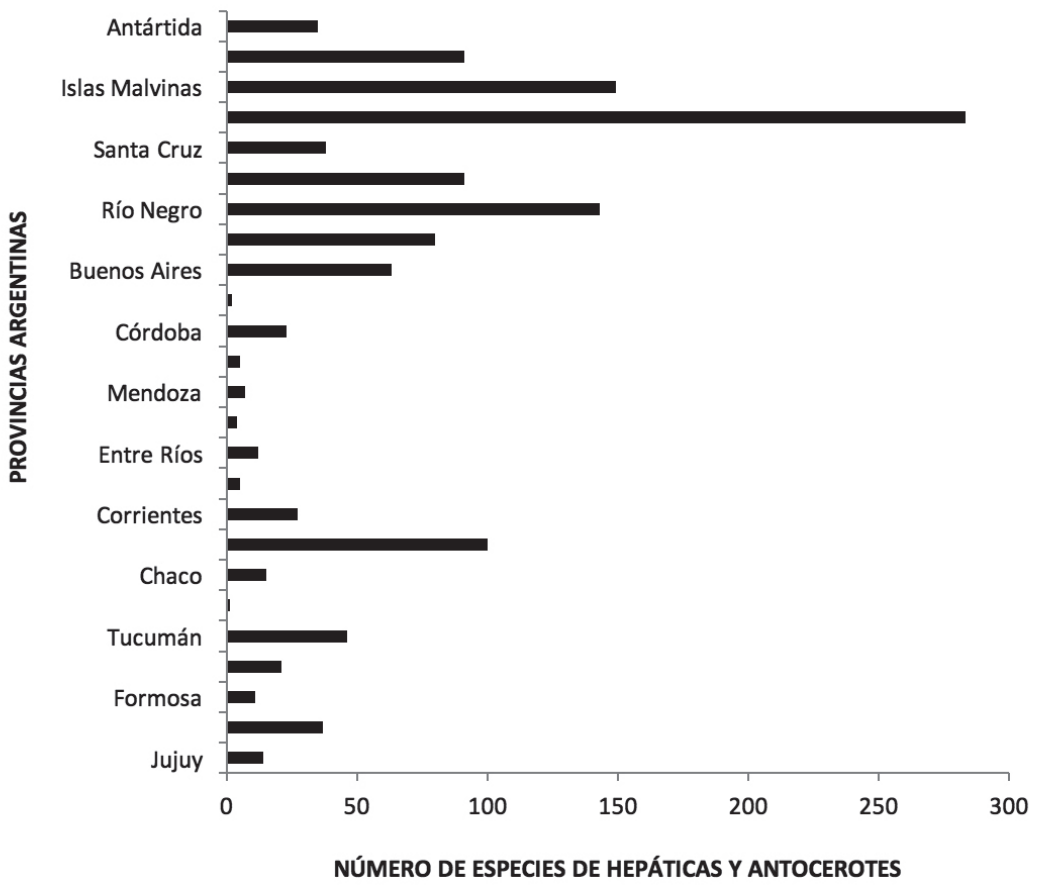

Figura 16. Distribución de la riqueza de hepáticas y antocerotes a lo largo de las provincias de Argentina (fuente datos Hässel de Ménéndez \& Rubies 2009). / Latitudinal distribution of liverworts and hornworts richness along the Argentinian provinces (fuente datos: Hässel de Ménéndez \& Rubies 2009). 


\section{AGRADECIMIENTOS}

Esta publicación es un homenaje póstumo a la Dra. Gabriela Hässel de Menéndez, del Museo "Bernardino Rivadavia" de Buenos Aires. Durante las investigaciones conjuntas llevadas a cabo en el Archipiélago de Chiloé, costa de Valparaíso y relictos de neblina del Norte Chico de Chile, las indagaciones que constituye la base de este texto, la autora de esta contribución tuvo el privilegio de disfrutar de la amistad de Gabriela durante la última década de su vida, y de compartir algo de su vasta experiencia de más de 50 años de estudios científicos de las briófitas del Cono Sur de América. Se agradecen también los valiosos comentarios de dos revisores anónimos.

\section{REFERENCIAS}

Abarzúa, A.M., Pinchicura, A.G., Jarpa, L., Martel-Cea, A., Sterken, M., Vega, R., Pino, M. 2014. Environmental responses to climatic and cultural changes. En: Dillehay, T. (Eds.), The Teleoscopic Polity: 123-141. Springer International Publishing, New York.

Abraham de Vazquez, E.M., Garleff, K., Liebricht, H., Regairaz, A.C., Schäbitz, F., Squeo, F.A., Stingl, H. Veit, H., Villagrán, C. 2000. Geomorphology and paleoecology of the Arid Diagonal in southern South America. Zeitschrift für Angewandte Geologie SH1: 55-61.

Allègre C. 1988. The behavior of the Earth. Harvard University Press, Cambridge. 272 pp.

Ardiles, V., Fariña, M. 2014. Flora no vascular de la región de Arica y Parinacota, Chile: Nuevos registros y consideraciones biogeográficas. Boletín Museo Nacional de Historia Natural, Chile 63: 213-223.

Arnell, S. 1956. Hepaticae collected by Dr. and Mrs. Carl Skottsberg on Cerro Talinay, Prov. Coquimbo, Chile, 1955. Svensk Botanisk Tidskrift 50(H 2): 308-312.

Arroyo, M.T.K., Cavieres, L.A, Peñaloza, A., Riveros, M., Faggi, A.M. 1996. Relaciones fitogeográficas y patrones regionales de riqueza de especies en la flora del bosque lluvioso templado de Sud América. En: Armesto, J.J., Villagrán, C., Arroyo, M.T.K. (Eds.), Ecología de los Bosques Nativos de Chile: 71-99. Editorial Universitaria, Santiago.

Bennett, K.D., Haberle, S.G., Lumley, S.H. 2000. The last Glacial-Holocene transition in southern Chile. Science 290: 325-328.

Brown, R.C., Lemmon, B.E., Shimamura, M., Villarreal, J.C., Renzaglia, K.S. 2015. Spores of relictual bryophytes: Diverse adaptations to life on land. Review of Palaeobotany and Palynology 216: 1-17.

Christenhusz, M. \& Byng, J.W. 2016. The number of known plant species in the world and its annual increase. Phytotaxa 261: 201-217.

Crandall-Stotler, B., Stotler, R.E, Long D.G. 2009. Phylogeny and Classification of the Marchantiophyta. Edinburgh Journal of Botany 66(1): 155-198.

Croizat, L. 1962. On the age of the floras of Fray Jorge and Talinay in Chile. Revista Universitaria 47: 57-61.

Cuvertino, J., Ardiles, V., Osorio, F., Romero, X. 2012. New records and additions to the Chilean bryophyte flora. Investigaciones Agronómicas 39(2): 245-254.

Denton, G.H., Heusser, C.J., Lowell, T.V., Moreno, P.I., Andersen, B.G., Heusser, L.E., Schlüchter, C., Marchant, D.R. 1999. Interhemispheric linkage of paleoclimate during the Last Glaciation. Geografiska Annaler 81(A, 2): 107-153.

Duff, R.J., Cargill, D.C., Villarreal, J.C., Renzaglia, K.S. 2004. Philogenetic relationship of the hornworts based on $\mathrm{rbcL}$ sequence data: novel relationship and new insights. Monographs in Systematic Botany from the Missouri Botanical Garden 98: 41-58.

Duff, R.J., Villarreal, J.C., Cargill, D.C., Renzaglia, K.S. 2009. Progress and challenges toward developing a phylogeny and classification of the hornworts. The Bryologist 110: 214-243.

Engel, J.J., Schuster, R.M. 1973. On some tidal zone Hepaticae from South Chile, with comments on marine dispersal. Bulletin of the Torrey Botanical Club 100(1): 29-35.

Flores, J.R., Catalanoa, S.A., Muñoz, J., Suárez, G.M. 2018. Combined phylogenetic analysis of the subclass Marchantiidae (Marchantiophyta): towards a robustly diagnosed classification. Cladistics 34(5): 517-541.

Forrest, L.L., Salazar, N., Gudiño, J.A., Korperlainen, H., Long, D.G. 2011. Molecular and morphological evidence for distinct species in Dumortiera (Dumortieraceae). The Bryologist 114(1): 102-115.

Frahm, J-P. 2001. Biologie der Moose. Spektrum Akademischer Verlag, Heidelberg. $367 \mathrm{pp}$.

Frey, W., Kürschner, H. 1998. Wüstenmoose: Anpassungen und Überlebensstrategien im täglichen Kampf mit der Sonne. Biologie in unserer Zeit 4: 231-240.

Frey, W., Stech, M., Meissner, K. 1999. Chloroplast DNArelationship in palaeoaustral Lopidium concinnum (Hook.) Wils. (Hypopterygiaceae, Musci). An example of stenorvolution in mosses. Studies in austral temperate rain forest bryophytes 2. Plant Systematics and Evolution 218: 67-75.

Frey, W., Stech, M. 2005a. A morpho-molecular classification of the liverworts (Hepaticophyta, Bryophyta). Nova Hedwigia 81: 55-78.

Frey, W., Stech, M. 2005b. A morpho-molecular classification of the Anthocerotophyta (hornworts). Nova Hedwigia 80: 541-545. 
Frey, W., Pfeiffer, T., Stech, M. 2010 Geomolecular divergence patterns of Gondwanan and Palaeoaustral bryophytes - An overview Studies in austral temperate rain forest bryophytes 34. Nova Hedwigia 91 (3-4): 317-348.

Garleff, K., Schäbitz, F., Stingl, H., Veit, H. 1991. Jungquartäre Landschaftsenwicklung und Klimageschichte beiderseits der Ariden Diagonale Südamerikas. Bamberger Geographische Schriften 11: 359-394.

Garreaud, R., Barichivich, J., Christie, D.A., Maldonado, A. 2008. Interannual variability of the coastal fog at Fray Jorge relict forests in semiarid Chile. Journal of Geophysical Research 113: 1-16.

Gómez, G. 2019. Historia del clima, la vegetación y los glaciares durante el período interestadial (Mis 3) de la glaciación Llanquihue en el norte de Chiloé. Tesis de Magister. Universidad Austral de Chile, Valdivia, Chile.

Gradstein, S.R., Wilson, R., Ilkiu-Borges, A.L., Heinrichs, J. 2006. Phylogenetic relationships and neotenic evolution of Metzgeriopsis (Lejeunaceae) based on chloroplast DNA sequences and morphology. Botanical Journal of the Linnean Society 151: 293-308.

Gradstein, S.R., Cuvertino, J. 2015. Observations on the liverwort flora of the surroundings of Santiago, Central Chile. Cryptogamie, Bryologie 36(2): 129-141.

Gradstein, S.R., Reeb, C., Osorio, F. 2016. Austrofossombronia peruviana (Gottsche, Hampe) R.M.Schust. ex Crand.Stotl., Stotler, A.V. Freire. Bryological Notes. New national and regional bryophyte records 48 . Journal of Bryology 38(3): 236.

Graham L.E., Wilcox L.W., Cook M.E., Gensel P.G. 2004. Resistant tissues of modern marchantioids liverworts resemble enigmatic Early Paleozoic microfossils. PNAS 101(30): 11025-11029.

Gregory-Wodzicki, K.M. 2000. Uplift history of the Central and northen Andes: A review. Geological Society American Bulletin 112: 1091-1105.

Groth-Malonek, M., Knoop, V. 2005. Bryophytes and other basal land plants: the mitochondrial perspective. Taxon 54(2): 293-297

Hässel de Menéndez, G. 1961. Las especies argentinas del género Symphyogyna. Boletín de la Sociedad Argentina de Botánica 9: 233-260.

Hässel de Menéndez, G. 1962. Las especies sudamericanas del género Pallavicinia. Boletín de la Sociedad Argentina de Botánica 9: 262-282.

Hässel de Menéndez, G. 1970. El género Haplomitrium (Hepaticae). Revista del Museo Argentino de Ciencias Naturales "Bernardino Rivadavia" 3: 235-238.

Hässel de Menéndez, G. 1983. Informaciones nomenclaturales sobre especies del género Plagiochila (Hepaticae) de Argentina y Chile. Boletín de la Sociedad Argentina de
Botánica 22: 87-129.

Hässel de Menéndez, G. 1986. Leiosporoceros Hässel n. gen. and Leiosporocerotaceae Hässsel n. fam. of Anthocerotopsida. Journal of Bryology 14: 255-259.

Hässel de Menéndez, G. 1987. Sobre dos especies de Riella (Hepaticae) recientemente halladas en Argentina. Boletín de la Sociedad Argentina de Botánica 25: 85-91.

Hässel de Menéndez, G. 1988. A proposal for a new classification of the genera within the Antocerotophyta. Journal of the Hattori Botanical Laboratory 64: 71-86.

Hässel de Menéndez, G. 1994. Patagonian Bryophytes 12. On Treubia scapanioides Schust. Journal of the Hattori Botanical Laboratory 75: 237-242.

Hässel de Menéndez, G. 2004a. Andino patagonian species of Plagiochila (Plagiochilaceae, Marchantiophyta) Sectio Obcunetae Carl. Revista del Museo Argentino de Ciencias Naturales 6: 197-208.

Hässel de Menéndez, G. 2004b. Andino patagonian species of Plagiochila (Plagiochilaceae, Marchantiophyta) I Sectio Robustae Carl emend. Hässel and II Sectio Equitantes Carl emend. Hässel. Journal of the Hattori Botanical Laboratory 96: 245-260.

Hässel de Menéndez, G. 2006. Paraphymatoceros Hässel., Gen. Nov. (Anthocerotophyta). Phytologia 88(2): 208-211.

Hässel de Menéndez G., Greene, S.W., Matteri, C.M. 1984. The occurrence and distribution of Bryophytes in Southern Patagonia between Latitude $51^{\circ}$ and $52^{\circ} \mathrm{S}$. Journal of the Hattori Botanical Laboratory 55: 45-64.

Hässel de Menéndez G., Solari, S. 1985. Catálogo de las Hepáticas. En: Boelcke, O., Moore, D.M., Roig, F.A. (Eds.) Transecta Botánica de la Patagonia Austral: 299-342. Conicet, Buenos Aires.

Hässel de Menendez, G., Marta Rubies, M.F. 2009. Catalogue of Marchantiophyta and Anthocerotophyta of southern South America. Chile, Argentina and Uruguay, including Easter Is. (Pascua I.), Malvinas Is. (Falkland Is.), South Georgia Is., and the subantarctic South Shetland Is., South Sandwich Is., and South Orkney Is. Nova Hedwigia, Beihefte, Beih. 134. 672 pp.

Hässel de Menéndez, G., Villagrán, C. 2007a. Hepáticas y antocerotes del área de la "Flora de Zapallar". En: Villagrán, C., Marticorena, C., Armesto, J.J. (Eds.) Flora de las Plantas Vasculares de Zapallar: 557-594. Ed. Puntangeles, Valparaíso.

Hässel de Menéndez, G., Villagrán, C. 2007b. New species of Fossombronia (Hepatophyta, Fossombrionopsida) from Chile. Nova Hedwigia 131: 13-20.

$\mathrm{He}, \mathrm{S} .1998$. A checklist of the mosses of Chile. Journal of the Hattori Botanical Laboratory 85: 103-189.

Heinrichs, J., Lindner, M., Gradstein, S.R., Groth, H., Buchbender, V. Solga, A., Fischer, E. 2005. Origin and subdivision of 
Plagiochila (Jungermanniidae: Plagiochilaceae) in tropical África based on evidence from nuclear and chloroplast DNA sequences and morphology. Taxon 54: 317-333.

Heinrichs, J., Lindner, M., Groth, H., Hentschel, J., Feldberg, K., Renker, C., Engel, J.J., von Konrat, M., Long, D.G., Schneider, H. 2006. Goodbye or welcome Gondwana? Insights into the phylogenetic biogeography of the leafy liverwort Plagiochila with a description of Proskauera, gen. nov. (Plagiochilaceae, Jungermanniales). Plant Systematics and Evolution 258: 227-250.

Heinrichs J., Hentschel J., Feldberg K., Bombosch, A., Schneider, H. 2009. Phylogenetic biogeography and taxonomy of disjunctly distributed bryophytes. Journal of Systematics and Evolution 47(5): 497-508.

Heusser, C.J. 1981. Palynology of the last interglacial-glacial cycle in midlatitudes of southern Chile. Quaternary Research 16: 293-321.

Heusser, C.J. 1982. Palinology of cushion bogs of the Cordillera Pelada, Province of Valdivia, Chile. Quaternary Research 17: 71-92.

Heusser, C.J. 1989. Late Quaternary vegetation and climate of southern Tierra del Fuego. Quaternary Research 31: 396-406.

Heusser, C.J. 1990. Chilotan piedmont glacier in the southern Andes during the last glacial maximum. Revista Geológica de Chile 17(1): 3-18.

Heusser, C.J., Heusser, L.E, Lowell, T.V. 1999. Paleoecology of the southern Chilean Lake District - Isla Grande de Chiloé during middle-late Llanquihue Glaciation and deglaciation. Geografiska Annaler 81(A, 2): 231-284.

Hinojosa, L.F. 2003. Fisionomía foliar y clima de las paleofloras mixtas del Terciario de Sudamérica. Tesis de Doctorado. Universidad de Chile, Santiago, Chile. 174 pp.

Hinojosa, L.F., Villagrán, C. 1997. Historia de los bosques del sur de Sudamérica: Antecedentes paleobotánicos, geológicos y climáticos del Cono sur de América. Revista Chilena de Historia Natural 70: 225-239.

Hinojosa, L.F., Villagrán, C. 2005. Did South American mixed paleofloras evolve under thermal equability or in the absence of an effective Andean barrier during the Cenozoic. Palaeogeography, Palaeoclimatology, Palaeoecology 217: 1-23.

Hollin, J.T., Schilling, D.H. 1981. Late Wisconsin-Wichselian mountain glaciers and small ice caps. En: Denton, J.H., Hughes, T.J. (Eds.) The Last Great Ice Sheets: 179-206. Wiley, New York.

Hueck, K. 1966. Die Wälder Südamerikas. Gustav Fischer Verlag, Stuttgart. 422 pp.

Hürlimann, H.1999. EpiphylleLebermooseausneukaledonischen Vegetationsaufnahmen. Haussnechtia Beiheft 9: 193199.
Jara-Arancio, P., Carmona, M.R., Correa, C., Squeo, F.A., Arancio, G. 2012. Leaf morphological and genetic divergence in populations of Drimys (Winteraceae) in Chile. Genetics and Molecular Research 11: 229-243. DOI: 10.4238/2012.February.3.3

Kenrick, P., Crane, P.R. 1997. The origin and early evolution of plants on land. Nature 389: 33-39.

Klohn, C. 1976. Beobachtungen über die Reste eins späteiszeitlichen Alercewaldes. Zeitschrift für Naturfreunde und Wanderer 1975-1976: 75-78.

Kummerow, J. 1966. Aporte al conocimiento de las condiciones climáticas del bosque de Fray-Jorge. Boletín Técnico de la Facultad de Agronomía de la Universidad de Chile 24: 21-28.

Landrum, L.R. 1981. The phylogeny and geography of Myrceugenia (Myrtaceae). Brittonia 33: 105-129.

Larraín, J. 2016. The mosses (Bryophyta) of Capitán Prat Province, Aisén Region, southern Chile. PhytoKeys 68: 91-116.

Latorre, C., Quade, J., McIntosh, W.C. 1996. The expansion of C4 grasses and global change in the Late Miocene: Stable isotope evidence from the Americas. Earth and Planetary Science Letters 146: 83-96.

Londoño, L., Villagrán, C., Rincón, I., Hinojosa, L.F., Astorga, G. 2020. Historia de la vegetación durante el Holoceno Medio a partir del análisis polínico y de macrofósiles vegetales del sitio Huapilacuy II, noroeste de la Isla Grande de Chiloé. Enviado a Andean Geology, Abril 2020.

Lumley, S.H., Switsur, R. 1993. Late Quaternary chronology of the Taitao Peninsula, Southern Chile. Journal of Quaternary Science 8: 1-5.

Mahu, M. 1981. Las Briófitas del Bosque Las Petras, Quintero, Provincia de Valparaíso, Chile. The Bryologist 84(4): 548-555.

Mahu, M. 1994. Corsinia coriandrina et Riccia ciliata subsp. canescens (Hepaticae) nouvelles pour le Chili. Journal of the Hattori Botanical Laboratory 75: 263-265.

McDaniel, S.F., Shaw, A.J. 2003. Phylogeographic structure and cryptic speciation in the trans-Antarctic moss Pyrrhobryum mnioides. Evolution 57(2): 205-215.

McGlone, M.S. 2005. Goodbye Gondwana. Journal of Biogeography 32: 739-740.

Meissner, K., Frahm, J-P., Stech, M., Frey, W. 1998. Molecular divergence patterns and infrageneric relationship of Monoclea (Monocleales, Hepaticae). Studies in austral temperate rain forest bryophytes 1 . Nova Hedwigia 67: 289-302.

Müller, 2009. An updated checklist of the mosses of Chile. Archiv for Bryology 58: 1-123.

Muñoz, J., Felicísimo, A.M., Cabezas, F., Burgaz, A.R., Martínez, 
I. 2004. Wind as a long-distance dispersal vehicle in the Southern Hemisphere. Science 304: 1144-1147.

Murillo, A. J., Ruiz, P. E., Landrum, L.R., Stuessy, T.F., Barfussc, M. 2012. Phylogenetic relationships in Myrceugenia (Myrtaceae) based on plastid and nuclear DNA sequences. Molecular Phylogenetic Evolution. 62(2): 764-776.

Nickrent, D.L., Parkinson, C.L., Palmer, J.D., Duff, R.J. 2000. Multigene phylogeny of land plants with special reference to bryophytes and the earliest land plants. Molecular Biology and Evolution 17(12): 1885-1895.

Nishiyama, T., Wolf, P.G., Kugita, M., Sinclair, R.B., Sugita, M., Sugiura, Ch., Wakasugi, T., Yamada, K., Yoshinaga, K., Yamaguchi, Ueda, K., Hasebe, M. 2004. Chloroplast phylogeny indicates that bryophytes are monophyletic. Molecular Biology and Evolution 21(10): 1813-1819.

Núñez-Ávila, M.C., Armesto, J.J. 2006. Relict islands of the temperate rainforest tree Aextoxicon punctatum (Aextoxicaceae) in semiarid Chile: Genetic diversity and biogeographic history. Australian Journal of Botany 54: 733-743.

Oberdorfer, E. 1960. Pflanzensoziologische Studien in Chile. Verlag von Cramer, Weinheim. 208 pp.

Pérez, F., Irarrázabal, C., Cossio, M., Peralta, G., Segovia, R., Bosshard, M., Hinojosa, L.F. 2014. Microsatellite markers for the endangered shrub Myrceugenia rufa (Myrtaceae) and three closely related species. Conservation of Genetic Resources 6: 773-775

Pérez, F., Hinojosa, L.F., Peralta, G., Montenegro, P., Irarrázabal, C., Cossio, M. 2017. Genetic patterns of Myrceugenia correifolia, a rare species of fog-dependent forests of Mediterranean Chile: Is it a climatic relict? Frontiers in Plant Science 8:1097. doi: 10.3389/fpls.2017.01097

Pfeiffer, T., Kruijer, H., Frey, W., Stech, M. 2000. Systematic of Hypopterygium tamarix complex (Hypopterygiaceae, Bryopsida): Implications of molecular and morphological data. Studies in austral temperate rain forest bryophytes 9. Journal of the Hattori Botanical Laboratory 89: 55-70.

Posadas, P. 1996. Distributional patterns of vascular plants in Tierra del Fuego: a study applying parsimony analysis of endemicity. Biogeographica 72(4): 161-177.

Proskauer, J. 1954. On Sphaerocarpos stipitatus and the genus Sphaerocarpos. The Journal of the Linnean Society of London. Vol. LV, 357: 143-157.

Puttick, M.N., Morris, J.L., Williams, T.A., Cox, C.J., Edwards, D., Kenrick, P., Pressel, S., Wellman, Schneider, H., Pisani, D., Donoghue, P.C.J. 2018. The interrelationships of land plants and the nature of the ancestral embryophyte. Current Biology 28: 1-13.

Quandt, D., Tangney, R.S., Frahm, J-P., Frey, W. 2000. A molecular contribution for understanding the Lembophyllaceae
(Bryopsida) based noncoding chloroplast regions (CPDNA) and ITS2 (NRDNA) sequence data. Journal of the Hattori Botanical Laboratory 89: 71-92.

Quandt, D., Frahm, J-P., Frey, W. 2001. Patterns of molecular divergence within the palaeoaustral genus Weymouthia Broth. (Lembophyllaceae, Bryopsida). Journal of Bryology 23: 305-311.

Quandt, D., Huttunen, S., Tangney, R., Stech. 2009. Back to the Future? Molecules Take Us Back to the 1925 Classification of the Lembophyllaceae (Bryopsida) Systematic Botany 34(3): 443-454.

Qiu, L., Wang, B., Chen, Z., Knoop, V., Groth-Malonek, M., Dombrovska, O., Lee, J., Kent, L., Rest, J., Estabrook, G.F., Hendry, T.A., Taylor, D.W., Testa, C.M., Ambros, M., Crandall-Stotler, B., Duff, R.J., Stech, M., Frey, W., Quandt, D., Davis, C.C. 2006. The deepest divergences in land plants inferred from phylogenomic evidence. Proceedings of the National Academy of Sciences of the United States of America 103(42): 15511-15516.

Renzaglia, K.S., Villarreal, J.A., Garbary, D.J. 2018. Morphology supports the setaphyte hypothesis: mosses plus liverworts form a natural group. Bryophyte Diversity \& Evolution 40(2): 011-017.

Rensing, S.A. 2018. Plant Evolution: Phylogenetic Relationships between the Earliest Land Plants. Current Biology 28: R208-R231.

Reynols, J.H, Jordan, T.E., Johnson, N.M., Damanti, J.F., Tabutt, K.D. 1990. Neogene deformation of the flatsubduction segment of the Argentine-Chilean Andes: Magnetostratigraphic contraints from Las Juntas, La Rioja province, Argentina. Geological Society American Bulletin 102: 1607-1622.

Rodríguez, R., Marticorena, C., Alarcón, D., Baeza, C., Cavieres, L., Finot, V.L., Fuentes, N., Kiessling A., Mihoc, M., Pauchard, A., Ruiz, E., Sanchez, P., Marticorena, A. 2018. Catálogo de las plantas vasculares de Chile. Gayana. Botánica 75(1): 1-430.

Roig, F.A., Le-Quesne, C., Boninsegna, J.A., Briffa, K.R., Lara, A., Grudd, H., Jones, P.D., Villagrán, C. 2001. Climate variability 50,000 years ago in mid-latitude Chile as reconstructed from tree rings. Nature 410: 567-570.

Roivainen, H. 1954. Studien über die Moore Feuerlands. Annales Botanici Societatis Zoologicae-Botanicae Fennicae "Vanamo" 28(2): 1-205.

Ruthsatzt, B., Villagrán, C. 1991. Vegetation pattern and soil nutrients of a Magellanic moorland on the Cordillera de Piuchué, Chiloé Island, Chile. Revista Chilena de Historia Natural 64: 461-478.

Schäffer-Verwimp, A., Wilson R., Yandun, S., Feldberg, K., Burghardt, M., Váña, J., Heinrichs, J. 2006. Additions to the bryophyte flora of Ecuador. Cryptogamie, Briologie 
27(3): 313-332.

Schäffer-Verwimp, A. 2014. Towards a more complete knowledge of the liverwort flora of Panama. Phytotaxa 172(3): 201-234.

Schaumann, F., Frey, W., Hässel de Menéndez, G., Pfeiffer, T. 2003. Geomolecular divergence in the Gondwana dendroid Symphyogyna complex (Pallaviciniaceae, Hepaticophytina, Bryophyta). Studies in austral temperate rain forest bryophytes 22. Flora 198: 404412.

Schaumann, F., Pfeiffer, T., Frey, W. 2004. Molecular divergence patterns within the Gondwanan Liverwort genus Jensenia (Pallaviciniaceae, Hepaticophytina, Bryophyta). Studies in austral temperate rain forest bryophytes 25 . Journal of the Hattori Botanical Laboratory 96: 231-244.

Schmithüsen, J. 1956. Die räumliche Ordnung der chilenischen Vegetation. Bonner Geographische Abhandlungengen 17: 1-86.

Schuster, R.M. 1979a. On the persistence and dispersal of transantarctic Hepaticae. Canadian Journal of Botany 57: 2179-2225.

Seki, T. 1974. A moos Flora of Provincia de Aisén, Chile. Journal of Science of the Hiroshima University 15: 9-101.

Shaw, J., Szövényi, P., Shaw, B. 2011. Bryophyte diversity and evolution: windows into the early evolution of land plants. Canadian Journal of Botany 98: 352-369.

Skottsberg, C. 1948. Apuntes sobre la flora y vegetación de Frai Jorge (Coquimbo, Chile). Acta Horti Gotoburgensis 18: 91-184.

Stech, M., Konstantinova, N.A., Frey, W. 2002 a. Molecular divergence between Treubia Goebel and Apotreubia S. Hatt., Mizut., the two genera of the archaic liverwort class Treubiopsida (Hepaticophytina). Studies in austral temperate rain forest bryophytes 19. Nova Hedwigia 75: 91-100.

Stech, M., Pfeiffer, T., Frey, W. 2002 b. Molecular generic classification of the Hypopterygiaceae (Bryopsida), with the description of a new genus, Arbusculohypopterygium gen. nov. Studies in austral temperate rain forest bryophytes 10. New Zealand Journal of Botany 40: 207221.

Stech, M., Pfeiffer, T., Frey, W. 2002 c. Chloroplast DNA relatioship in paleoaustral Polytrichadelphus magellanicus (Hedw.) Mitt. (Polytrichaceae, Bryopsida). Botanische Jahrbücher für Systematik 124: 217-226.

Stech, M., Quandt, D., Frey, W. 2003. Molecular circumscription of the hornworts (Anthocerotophyta) based on chloroplast DNA trnL-trnF region. Journal of Plant Research 116: 389-398.

Stech, M., Frey, W. 2004. Molecular circumscriptions and relationships of the selected gondwanan species of Haplomitrium (Calobryales, Haplomitriopsida, Hepaticophytina). Studies in austral temperate rain forest bryophytes 24. Nova Hedwigia 78(1-2): 57-70.

Troncoso, A.C., Villagrán, C., Muñoz, M. 1980. Una nueva hipótesis acerca del origen y edad del bosque de Fray Jorge (Coquimbo, Chile). Boletín del Museo Nacional de Historia Natural (Chile) 37: 117-152.

Veit, H., Garleff, K. 1996. Evolución del paisaje Cuaternario y los suelos en Chile central-sur. En: Armesto, J.J., Villagrán, C., Kalin Arroyo, M. (Eds.) Ecología de los bosques nativos de Chile: 51-69, Editorial Universitaria, Santiago, Chile.

Villagrán, C. 1980. Vegetationsgeschichtliche und pflanzensoziologische Untersuchungen im Vicente Pérez Rosales Nationalpark (Chile). Dissertationes Botanicae 54: 1-165.

Villagrán, C. 1988. Expansion of Magellanic Moorland during the Late Pleistocene: Palynologycal Evidence from Northern Isla Grande de Chiloé, Chile. Quaternary Research 30: 304-314.

Villagrán, C. 1990. Glacial, late glacial and post-glacial climate and vegetation of the Isla Grande de Chiloé, southern Chile. Quaternary of South America and Antarctic Peninsula 8: 1-15.

Villagrán, C. 1991. Desarrollo de tundras Magallánicas durante la transición glacial-postglacial en la Cordillera de la Costa de Chile, Chiloé: ¿Evidencias de un evento equivalente al "Jounger Dryas"?. Bamberger Geographische Schriften 11: 1-12.

Villagrán, C. 1995. Quaternary history of the Mediterranean Vegetation of Chile. En: M. Kalin, M., Zedler, P., Fox, M. (Eds.) Ecology and Biogeography of Mediterranean ecosystems in Chile, California and Australia: 3-20. Springer Verlag, New York.

Villagrán, C. 2001. Un modelo de la historia de la vegetación de la Cordillera de la Costa de Chile central-sur: la hipótesis glacial de Darwin. Revista Chilena de Historia Natural 74: 793-803.

Villagrán, C. 2018. Biogeografía de los bosques subtropicaltemplados del sur de Sudamérica. Hipótesis históricas. Magallania (Chile) 46(1): 27-48.

Villagrán, C., Armesto J.J. 1980. Relaciones florísticas entre las comunidades relictuales del Norte Chico y la zona central con el bosque del sur de Chile. Boletín del Museo Nacional de Historia Natural, Chile 37: 87-101.

Villagrán, C., Moreno, P., Villa-Martínez, R. 1995. Antecedentes palinológicos acerca de la historia cuaternaria de los bosques chilenos. En: Armesto, J.J., Villagrán, C., Kalin Arroyo, M. (Eds.) Ecología de los bosques chilenos. Editorial Universitaria, Santiago, Chile.

Villagrán, C., Hinojosa. L.F. 1997. Historia de los bosques del sur de Sudamérica, II: Análisis fitogeografico. Revista 
Chilena de Historia Natural 70: 241-267.

Villagrán, C., Le-Quesne, C., Aravena, J.C., Jiménez, H., Hinojosa, L.F. 1998. El rol de los cambios de clima del Cuaternario en la distribución actual de la vegetación de Chile central-sur. Bamberger Geographische Schriften 15: 227-242.

Villagrán, C., Barrera, E., Cuvertino, J., García, N. 2003. Musgos de la Isla Grande de Chiloé, X Región, Chile: Lista de especies y rasgos fitogeográficos. Boletín del Museo Nacional de Historia Natural, Chile 52: 17-44.

Villagrán, C., Armesto, J.J., Hinojosa, L.F., Cuvertino, J., Pérez, C., Medina, C. 2004a. El enigmático origen del bosque relicto de Fray Jorge. En: Squeo, F.A., Gutiérrez, J.R., Hernández, I.R. (Eds.), Historia Natural del Parque Nacional Bosque Fray Jorge: 1-42. Ediciones Universidad de La Serena, La Serena, Chile.

Villagrán, C., León, A., Roig, F.A. 2004b. Paleodistribución del alerce y ciprés de las Guaitecas durante períodos interestadiales de la Glaciación Llanquihue: provincias de Llanquihue y Chiloé, Región de Los Lagos, Chile. Revista Geológica de Chile 31: 133-151.

Villagrán, C., Hässel de Menéndez, G., Barrera, E. 2005. Hepáticas y Antocerotes del Archipiélago de Chiloé. Una Introducción a la flora briofítica de los ecosistemas templado-lluviosos del sur de Chile. Corporación de Amigos del Museo Nacional de Historia Natural, Santiago. 160 pp.

Villagrán, C., Armesto, J.J. 2005. Fitogeografía histórica de la Cordillera de la Costa de Chile. En: Smith-Ramírez, C., Armesto, J.J., Valdovinos, C. (Eds.), Historia, Biodiversidad y Ecología de los bosques de la Cordillera de la Costa de Chile, Editorial Universitaria, Santiago, Chile.

Villagrán, C., Hinojosa, L.F. 2005. Esquema Biogeográfico de Chile. En: Jorge Llorente Bousquets, J., Morrone, J. (Eds.),
Regionalización Biogeográfica en Iberoámeríca y tópicos afines: 551-577. Ediciones de la Universidad Nacional Autónoma de México, Jiménez Editores, México.

Villagrán, C., Abarzúa, A.M., Armesto, J.J. 2019. Nuevas evidencias paleobotánicas y filogeográficas de la historia Cuaternaria de los bosques subtropical-templados de la Cordillera de la Costa de Chile. En: Smith-Ramírez, C., Squeo, F.A. (Eds.), Biodiversidad y Ecología de los bosques costeros de Chile: 3-21. Editorial Universitaria de Los Lagos, Osorno, Chile.

Villarreal, J.C., Cusimano, N., Renner, S.S. 2015. Biogeography and diversification rates in hornworts: The limitations of diversification modeling. Taxon 64(2): 229-238.

Villarreal, J.C., Crandall-Stotler, B.J., Hart, M.L., Long, D.G., Forrest, L.L. 2016. Divergence times and the evolution of morphological complexity in an early land plant lineage (Marchantiopsida) with a slow molecular rate. New Phytologist 209: 1734-1746.

Wall, D.P., Herbeck, J.T. 2003. Evolutionary patterns of codon usage in the chloroplast gene rbcL. Journal of Molecular Evolution 56: 673-688.

Wheeler, J.A. 2000. Molecular philogenetic reconstructions of the Marchantioid liverwort radiation. The Bryologist 103(2): 314-333.

Wilson, R. 2007. Gradstein, S.R., Schneider, H., Jochen Heinrichs, J. 2007. Unravelling the phylogeny of Lejeuneaceae: Evidence of four lineages. Molecular Phylogenetics and Evolution 43: 270-282.

Woda C., Huber, A., Dohrenbusch, A. 2006. Vegetación epifita y captación de neblina en bosques siempreverdes en la Cordillera Pelada, sur de Chile. Bosque 27(3): 231-240.

Zachos, J., Pagani, M., Sloan, L., Thomas, E., Billups, K. 2001. Trends, rhythms, and aberrations in global climate $65 \mathrm{Ma}$ to present. Science 292: 686-693. 